FHWA/IN/JTRP-2007/22

Final Report

ACQUISITION AND ANALYSIS OF EARTHWORK PAY QUANTITY VERIFICATION DATA

Sharvil Shah

Makarand (Mark) Hastak

January 2008 


\section{TECHNICAL Summary}

INDOT Research

Technology Transfer and Project Implementation Information

TRB Subject Code: 33-2 Earthwork Construction

Publication No.: FHWA/IN/JTRP-2007/22, SPR-3082

January 2008

Final Report

\section{ACQUISITION AND ANALYSIS OF EARTHWORK PAY QUANITITY VERIFICATION DATA}

\section{Introduction}

The use of modern techniques and methods in earthwork data collection and earthwork quantity calculation would require less labor, cost and time on a project compared to currently used labor and time consuming methods by INDOT. These modern techniques and combination of different tools have a potential to offer more productivity and efficiency for INDOT in earthwork data collection and quantity calculation process. The objective of this research study was to investigate, compare and contrast different technologies and methods available in the surveying market for earthwork data collection and quantity calculation. The study comprised of mainly two parts: (i) data collection from different concerned parties through telephone interviews, questionnaire surveys, personal interviews and case studies (ii) data analysis and recommendations.

\section{Findings}

Surveying or Geomatics industry has grown rapidly in technology transformation in comparison to the Construction industry. One needs to take advantage of the technology transformation in the surveying industry to achieve desired efficiency and productivity in surveying work. In this research, an attempt is made to identify the technologies and methods which can be used by INDOT personnel in earthwork data collection and quantity calculation with less labor, overall cost and time consumption to complete this activity on large construction projects. In addition to a thorough literature review, different concerned parties (i.e. INDOT engineers, State DOTs, equipment and software vendors and manufacturers, professional companies and contractors) were contacted through questionnaires, personal interviews and case studies to collect the required data.

\section{Technology for Earthwork Data Collection}

The analysis of the data collected from all the different parties indicated that INDOT engineers were mainly using total station and
GPS in their process, while DOTs were mainly using total station, RTS, GPS/RTK GPS and aerial photogrammetry depending upon various conditions prevailing on the site as well as monetary and available expertise. However, professional companies were mainly using GPS/RTK GPS, RTS and total station in their earthwork data collection process. When asked to give recommendations on their personal choice, participants mainly recommended the combinations of RTK GPS, RTS and aerial photogrammetry depending on site conditions, timeline, accuracy required, environmental conditions, etc. Participants indicated that investing in a combination of various technologies would give the optimum solutions as opposed to one preferred technology.

The equipment companies and vendors of different equipment companies also suggested using combination of RTS and RTK GPS depending upon atmospheric, topographical, timeline, accuracy, etc. From all the data analysis and literature review, it can be recommended that using a combination of RTS, RTK GPS and aerial photogrammetry for earthwork data collection would offer more 
benefits for INDOT. GPS/RTK GPS and aerial photogrammetry options are some of the best options in large construction projects as they are fast and productive methods. The personnel requirement is also less in these methods and the accuracy levels are competitive.

However, RTK GPS, RTS and aerial photogrammetry are also some of the costliest options available today. In comparison to the selected technologies, total station and digital levels are very cheap with better accuracy. But the problem with these technologies relates to labor requirement and productivity levels. Total station and digital level require minimum 2 personnel on the field and require a lot of time to collect data on the field in comparison to the selected techniques. Some of the advantages like the electronic data transfer, software compatibility, etc., are also not available with these technologies. While, there is always a trade-off associated with selecting any technology for the problem faced by INDOT, a combination of RTS, RTK GPS and aerial photogrammetry seems to be the best available option.

\section{Equipment Company Selection}

Trimble was the most popular company among the INDOT participants, DOTs and professional companies, while Leica and Topcon were the second most popular companies. Trimble had the most costly equipment among all the companies however the main advantage of Trimble was its simplicity. One would not require lot of time to learn Trimble instruments before using them. On the other hand, Leica and Topcon were cheaper than Trimble but proper training is required before using those instruments. Leica instruments were powerful and complex, making them very suitable for the surveyors. After looking at all the companies, researchers found that Leica instruments were most efficient for surveying compared to other companies' instruments. A comparative analysis is provided in the report.

\section{Software Product Selection}

It was determined that INDOT districts are using several different software products including a DOS based software for earthwork quantity calculation as well as Bentley and Autodesk products. Bentley products were the most used products within different DOTs throughout the US. On the other hand, Autodesk products were the most used products among the private companies. The companies like Carlson, Microsurvey, etc., were having a small share of market but they were more popular among the small private players. One more advantage of these companies is their low cost. Because of their low cost, small players could afford them in comparison to the high cost of Autodesk and Bentley products. Autodesk and Bentley, both companies had competitive software products that were giving satisfactory performance to the DOT participants and private companies. However, it is important that all the offices of INDOT should use the same software product so that the data transfer is seamless and all are connected with each other.

\section{Training Needs}

After getting response from INDOT engineers, state DOTs, professional companies, vendors and case study participants regarding various training related statistics and issues, it was determined that training should be given to INDOT personnel either at regular interval of time or at the time when any new technology is introduced in the market or in the organization.

Some of the INDOT engineers did not get training for the new technologies that they were using and had to train themselves. The efficiency and productivity of those engineers decreased because they did not know the correct way to use those technologies. They said that it would be useful if INDOT would start giving them training for the new techniques and methods. They said that it would be a win-win situation for both INDOT and the personnel who are taking that training. The state DOT participants also mentioned the importance of training. They suggested giving training to the whole survey or design group when a technology or a software product is introduced in the organization. A number of participants have in-house training personnel who give training to the employees in keeping them up to date with the technology. Those DOTs did not have to pay for every individual training session as they had training personnel within the organization. The private companies also gave training to their personnel on a regular basis. They also mentioned that the cost of training is very less compared to the cost of a mistake made by an employee.

Therefore it is recommended that INDOT have training personnel inside the organization who could provide training to all the employees whenever training is required. It was observed in the INDOT that some districts were getting training at regular interval while the other districts were not getting training. 
Training sessions given by the dealers could be coordinated for a particular technology at the time of purchase. The cost of such training is around \$1,000/day as a flat fee for up to 10 people. INDOT can coordinate with the surveyors working for them and try to arrange training session for them whenever a new technology is being introduced in the organization.

\section{Other Findings}

The researchers received some suggestions from the vendors of different equipment for earthwork data collection and the participants of the case studies done in Indiana. Some of the recommendations are discussed below:

INDOT should work closely with their consultants while preparing the drawings for the project to eliminate mistakes and potential claims. In case of change orders, INDOT should give the revised copy of drawings to the contractor as soon as possible, so that it would be easy for the contractor to work according to the revised plans.

INDOT should purchase all the equipment and software products centrally for all their offices and try to use the same products all over the state. From the case studies and personal interviews, it appears that various districts do not communicate information about their equipment and software usage with other districts often resulting into duplication and ineffective use of resources. If the purchases are made centrally and all the offices are connected, then one can easily transfer the data from one office to other office and personnel can be transferred from one place to other depending upon the requirement. The coordination among all the offices would bring synergies and increase in productivity.

One of the contractor also mentioned that if INDOT could give them the drawings digitally before the bidding it would be easier for them. The contractor also mentioned that presently almost all the earthwork contractors have GPS on their earthmoving equipment. If INDOT were to provide digital files, they could be used by the contractor in the on board GPS via PCM card thus resulting into fewer chances of claims from the contractors as they would be directly using the owner's data. One of the vendors recommended including a clause in the bid documents requiring the use of a particular software product, so that data transfer between the owner and the contractor is more effective.

\section{Implementation}

This research provides significant benefits for INDOT and the construction/surveying industry as a whole. The research provides an overview of different techniques of earthwork data collection and quantity calculation. It also illustrates some of the new techniques like stakeless construction and Vangarde method which could be researched further by INDOT for future implementation. On the whole, this information would be useful to understand current earthwork data collection/quantity calculation techniques available in the market and their application by different parties concerned. This research also provides an insight into the different problems faced by the surveyors/engineers in using these instruments on site and software products in the offices. The information collected from all the parties can be used by INDOT in selecting technologies for earthwork data collection and quantity calculation.

Through personal interviews with vendors, this research provides an unbiased opinion on the advantages and disadvantages of different instruments and software products available in the market for earthwork data collection and quantity calculation. The researchers have provided a comparative analysis of various earthwork data collection equipment and related software products that are available for use by INDOT. Additionally this research has identified training needs and the associated costs. 


\section{Contacts}

For more information:

Prof. Makarand (Mark) Hastak

Principal Investigator

School of Civil Engineering

Purdue University

West Lafayette IN 47907

Phone: (765) 494-0641

Fax: (765) 494-0644

Email: hastak@ecn.purdue.edu
Indiana Department of Transportation

Division of Research

1205 Montgomery Street

P.O. Box 2279

West Lafayette, IN 47906

Phone: (765) 463-1521

Fax: (765) 497-1665

Purdue University

Joint Transportation Research Program

School of Civil Engineering

West Lafayette, IN 47907-1284

Phone: (765) 494-9310

Fax: (765) 496-7996

E:mail: jtrp@ecn.purdue.edu 
Final Report

FHWA/JTRP-2007/22

\title{
ACQUISITION AND ANALYSIS OF EARTHWORK PAY QUANTITY VERIFICATION DATA
}

\author{
by \\ Sharvil Shah \\ Graduate Research Assistant \\ and \\ Makarand (Mark) Hastak \\ Professor \\ School of Civil Engineering \\ Purdue University \\ Joint Transportation Research Project \\ Project No. C-36-73FF \\ File No. 3-4-32 \\ SPR-3082 \\ Conducted in Cooperation with the \\ Indiana Department of Transportation \\ and the U.S. Department of Transportation \\ Federal Highway Administration
}

The content of this report reflects the views of the authors who are responsible for the facts and accuracy of the data presented herein. The contents do not necessarily reflect the official views or policies of the Indiana Department of Transportation or the Federal Highway Administration at the time of publication. This report does not constitute a standard, specification, or regulation.

Purdue University

West Lafayette, IN 47907

January 2008 
TECHNICAL REPORT STANDARD TITLE PAGE

\begin{tabular}{|c|c|c|}
\hline $\begin{array}{l}\text { 1. } \text { Report No. } \\
\text { FHWA/IN/JTRP-2007/22 }\end{array}$ & 2. Government Accession No. & 3. Recipient's Catalog No. \\
\hline \multirow{2}{*}{\multicolumn{2}{|c|}{$\begin{array}{l}\text { 4. Title and Subtitle } \\
\text { Acquisition and Analysis of Earthwork Pay Quantity Verification Data }\end{array}$}} & $\begin{array}{l}\text { 5. } \quad \text { Report Date } \\
\text { January } 2008\end{array}$ \\
\hline & & 6. Performing Organization Code \\
\hline \multicolumn{2}{|l|}{$\begin{array}{l}\text { 7. Author(s) } \\
\text { Sharvil Shah and Makarand Hastak }\end{array}$} & $\begin{array}{l}\text { 8. Performing Organization Report No. } \\
\text { FHWA/IN/JTRP-2007/22 }\end{array}$ \\
\hline \multicolumn{2}{|l|}{$\begin{array}{l}\text { 9. Performing Organization Name and Address } \\
\text { Joint Transportation Research Program } \\
1284 \text { Civil Engineering Building } \\
\text { Purdue University } \\
\text { West Lafayette, IN 47907-1284 }\end{array}$} & 10. Work Unit No. \\
\hline \multicolumn{2}{|l|}{$\begin{array}{l}\text { 12. Sponsoring Agency Name and Address } \\
\text { Indiana Department of Transportation } \\
\text { State Office Building } \\
100 \text { North Senate Avenue } \\
\text { Indianapolis, IN } 46204\end{array}$} & 14. Sponsoring Agency Code \\
\hline \multicolumn{3}{|l|}{ 15. Supplementary Notes } \\
\hline
\end{tabular}

\section{Abstract}

This research identifies technologies and methods that can be used by INDOT in earthwork data collection and earthwork quantity calculation process on large construction projects that could result in timely completion of the projects with less labor and resultant cost. In order to achieve the above stated objective, several tasks were performed, i.e., literature review, data collection, data analysis, and recommendations. INDOT engineers were interviewed to determine their current state of practice. Also, all the state DOTs, professional companies in Indiana and vendors of earthwork data collection equipment and software products were contacted through questionnaire surveys and personal interviews. Two case studies were also performed with an owner and a contractor to understand the use, benefits and drawbacks of these equipment and software products. The analysis of data indicated that a combination of technologies was a better option to suit different scenario rather than one specific technology. For INDOT, use of robotic total station (RTS), RTK GPS and aerial photogrammetry are recommended, while a comparative analysis of the companies for earthwork data collection equipment and earthwork quantity calculations software products is provided. Recommendations on training costs and options are also made to INDOT. Also some other relevant issues that came up during interviews and case studies are also discussed in this report. All the recommendations were on the basis of the collected data and literature review performed by researchers during the course of this project.

\section{Key Words}

Earthwork data collection equipment, earthwork quantity calculation software products, earthwork data collection techniques, training.
18. Distribution Statement

No restrictions. This document is available to the public through the National Technical Information Service, Springfield, VA 22161

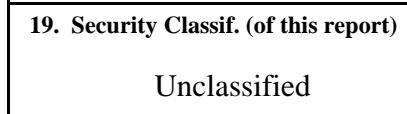

Form DOT F 1700.7 (8-69)
20. Security Classif. (of this page)

Unclassified

\begin{tabular}{|c|c|}
\hline 21. No. of Pages & 22. Price \\
200 & \\
\hline
\end{tabular}




\section{TABLE OF CONTENTS}

\section{Page}

LIST OF TABLES _ iii

LIST OF FIGURES iv

CHAPTER 1. INTRODUCTION 1

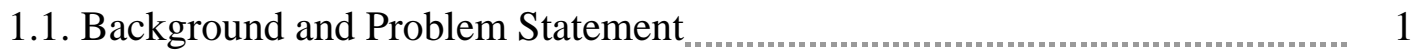

1.2. Objectives

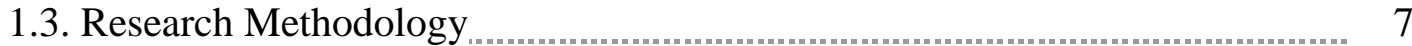

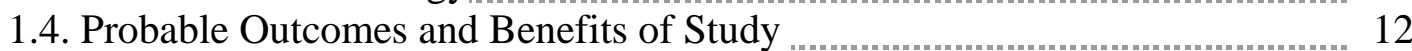

1.5. Conclusions 14

1.6. References $\quad 15$

CHAPTER 2. LITERATURE REVIEW 16

2.1. Introduction 16

2.2. Methods for Earthwork Data Collection 16

2.2.1. Level Instrument 17

2.2.2. Theodolite

2.2.3. Total Station 20

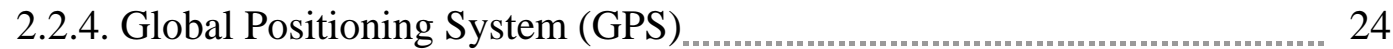

2.2.4.1. Static GPS 26

2.2.4.2. Rapid Static GPS

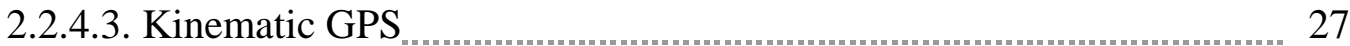

2.2.4.4. Real Time Kinematic (RTK) GPS 28

2.2.4.5. Online Positioning User Service (OPUS)

2.2.4.6. Errors Related to GPS Surveying ............ 31

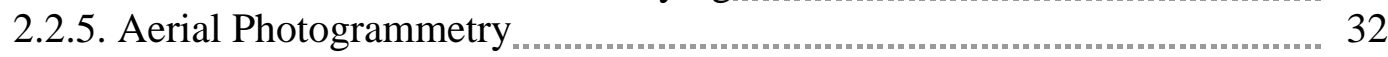

2.2.6. Light Detection and Ranging (LiDAR) Technology

2.2.7. Terrestrial Laser Scanning (Laser Scanner)

2.2.8. Vangarde System (VG) 43

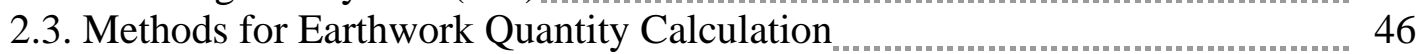

2.3.1. Manual Methods ........................................................................ 46

2.3.1.1. Average End Area Method .......................................... 47

2.3.1.2. Cross Section Method $\quad 47$

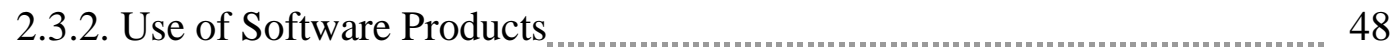

2.4. Stakeless Construction

2.5. Conclusion

2.6. References 56

CHAPTER 3. DATA COLLECTION

3.1. Introduction 57

3.2. Telephone Interviews with INDOT Surveyors/Engineers $\ldots \ldots \ldots$

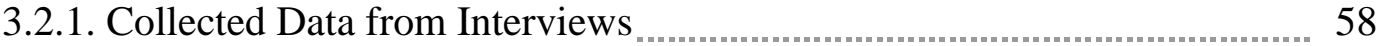

3.3. Questionnaire Survey for State DOTs 60

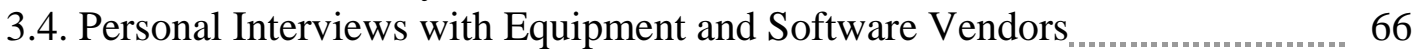




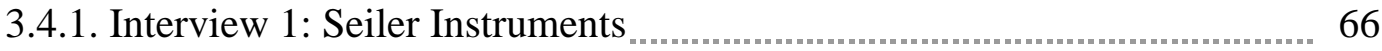

3.4.2. Interview 2: Advanced Lasers and Instruments _.................................... 73

3.5. Questionnaire Survey for Professional/Surveying Companies ....................... 77

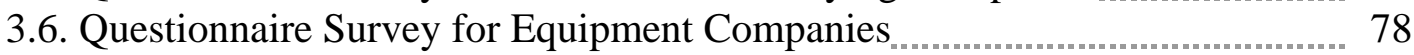

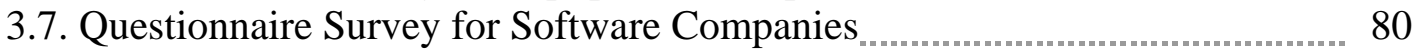

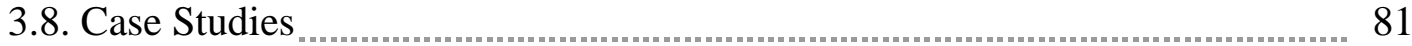

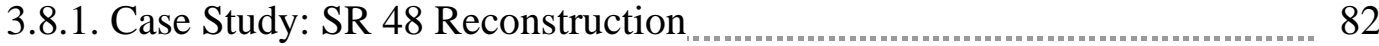

3.8.2 Case Study: SR 129 Reconstruction $\quad 90$

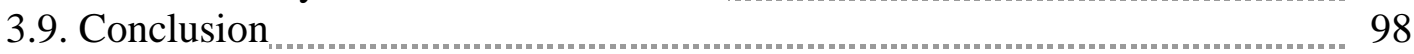

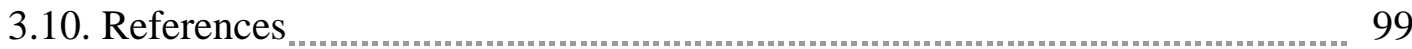

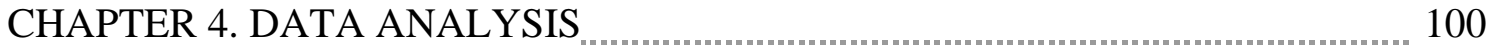

4.1. Introduction $\ldots$

4.2. Analysis of Telephone Interviews with INDOT Surveyors/Engineers _........... 100

4.3. Analysis of Questionnaire Survey of State DOTs _.................................... 105

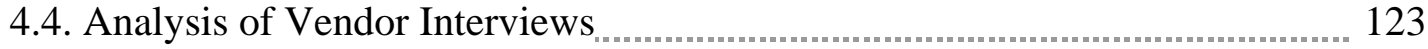

4.4.1. Analysis of Interview with Seiler Instruments _...................................... 124

4.4.2. Analysis of Interview with Advanced lasers and Instruments 126

4.5. Analysis of Questionnaire Survey of Professional/Surveying Companies ...... 128

4.6. Analysis of Questionnaire Survey of Software and Equipment Companies.... 136

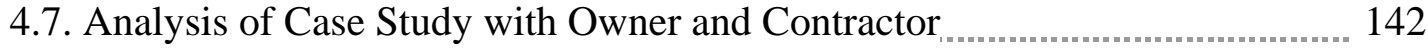

4.7.1. Analysis of SR 48 Reconstruction Project

4.7.2. Analysis of SR 129 Reconstruction Project _....................................... 143

4.8. Recommendations to INDOT Based on Data Analysis _................................. 145

4.8.1. Selection of a Technology for Earthwork Data Collection ....................... 146

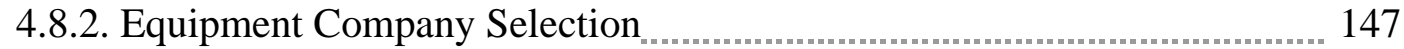

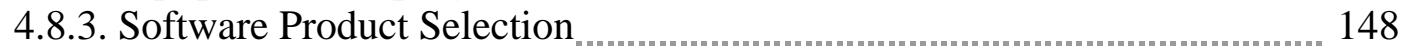

4.8.4. Training Needs

4.8.5. Other Recommendations

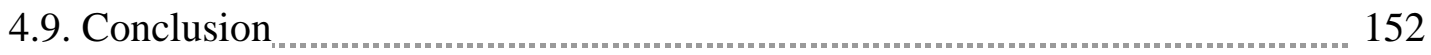

4.10. References

CHAPTER 5. SUMMARY AND CONCLUSION

5.1. Overall Summary and Conclusion …....................................................... 154

5.2. Limitations of This Research ................................................................... 157

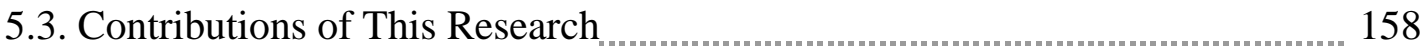

5.4. Recommended Future Research …........................................................... 160

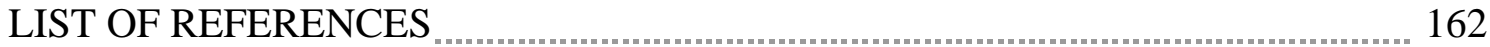

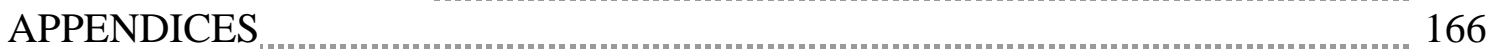

Appendix 1 Questions for INDOT Engineers/Surveyors ................................ 167

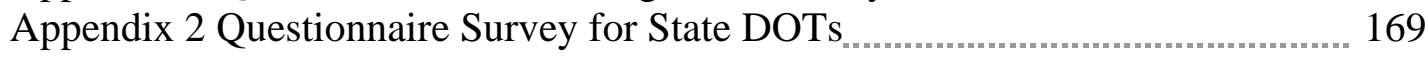

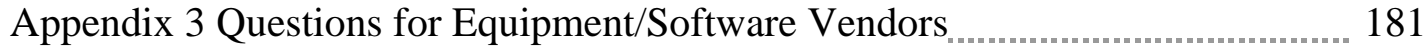

Appendix 4 Questionnaire Survey for Equipment Companies _.............................. 183

Appendix 5 Questionnaire Survey for Software Companies .................................... 191

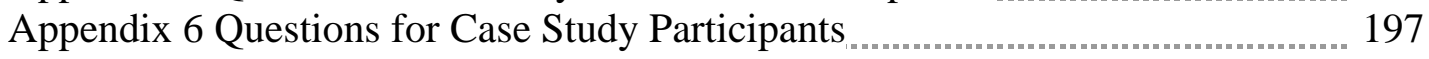




\section{LIST OF TABLES}

Table Page

Table 3.1 Data Collected from Interviewee 1 . 59

Table 3.2 Different GPS Techniques and Related Accuracies

Table 3.3 General Description on SR 48 Reconstruction Project

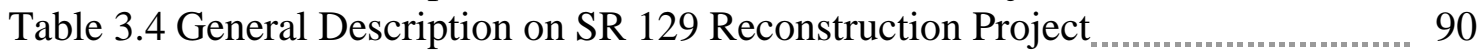

Table 4.1 Models of Different Technologies in Different Companies ................... 137

Table 4.2 Different Software Products Provided by Different Companies ............... 140 


\section{LIST OF FIGURES}

Figure Page

Figure 1.1 Questionnaire Survey Sent to Different Entities

Figure 2.1 Digital Level

Figure 2.2 Total Station

Figure 2.3(a) Robotic Total Station ....................................................... 23

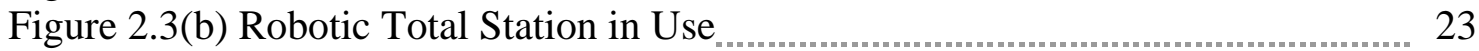

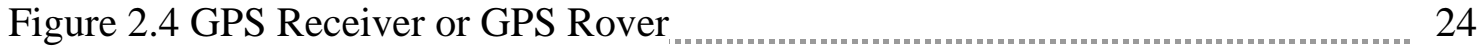

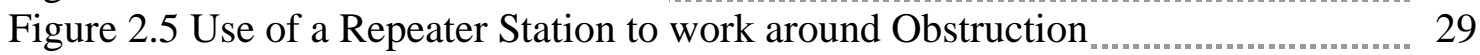

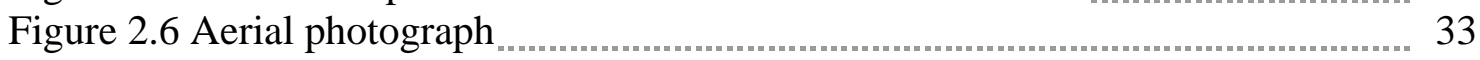

Figure 2.7 LiDAR System

Figure 2.8 Basic Components of LiDAR

Figure 2.9(a) Flying Technique

Figure 2.9(b) Flying Technique,

Figure 2.10 LiDAR Workflow 38

Figure 2.11 Laser Scanner

Figure 2.12 Scanner Positions with Predefined Targets

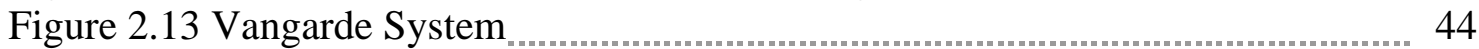

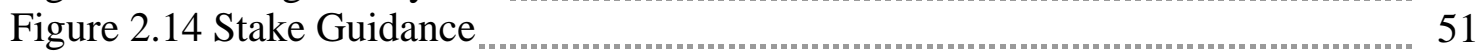

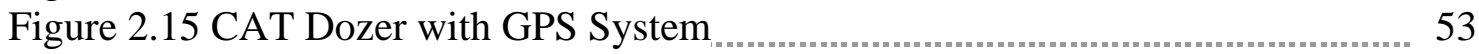

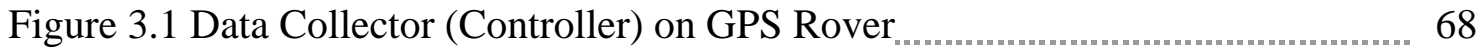

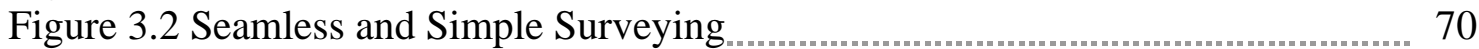

Figure 3.3 Trimble VX Spatial Station

Figure 4.1 Percentage of Participant's Current Method for Earthwork Data

Collection $_{1.1}$

Figure 4.2 Equipment Company Used by Participants

Figure 4.3 Use of Technology for a Project Less than 3 Miles

Figure 4.4 Use of Technology for a Project More than 3 Miles .............................. 107

Figure 4.5 Average Personnel Requirement on Field with Different Technologies ..... 107

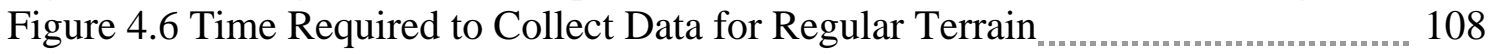

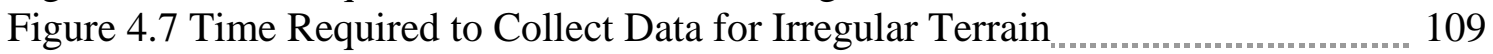

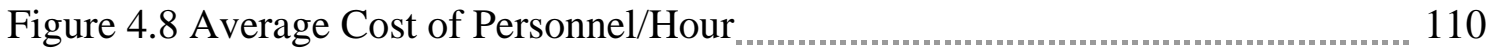

Figure 4.9 Use of Instruments of Different Companies

Figure 4.10 Horizontal Accuracy of Different Technologies

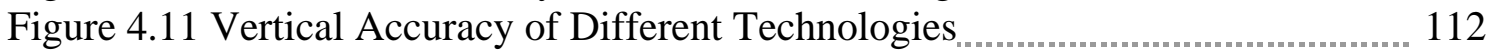

Figure 4.12 Manual Method vs. Software Method

Figure 4.13 Use of Different Software Products

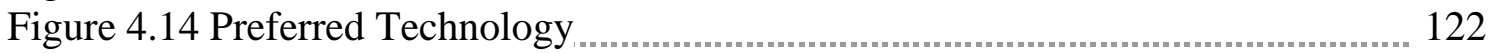

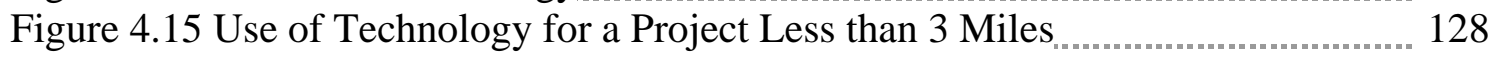

Figure 4.16 Use of Technology for a Project More than 3 Miles ............................. 129

Figure 4.17 Average personnel Requirement on Field for Different Technologies ..... 130

Figure 4.18 Time Required to Collect Data for Regular Terrain $\ldots . . . . . . . . . . . . . . . . . . . . . .130$ 
Figure 4.19 Time Required to Collect Data for Irregular Terrain $\ldots . . . . . . . . . . . . . . . . . . . . . .1131$

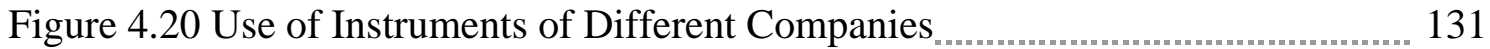

Figure 4.21 Average Cost of Different Instruments

Figure 4.22 Horizontal Accuracy of Different Technologies

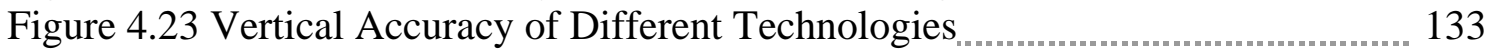




\section{CHAPTER 1. INTRODUCTION}

\subsection{Background and Problem Statement}

The definition of Earthwork given by Surveyor Reference Manual (2005), says that "Earthwork is the excavation, hauling, and placing of soil, gravel or other material found on the surface of earth. The definition also includes the measurement of such material in the field, the computation in the office of the volume of such material, and the determination of the most economical method of performing such work." In a way earthwork is the combination of data collection of the elevation of earth in the field, excavation, transportation and placement of such material on the surface of the earth and finding out quantities of material that is excavated and placed on the surface of the earth. Earthwork may not be a major activity in normal mid size and small construction projects (e.g. residential development, hospital construction, water treatment facility etc.) but it is one of the major activities in large construction and infrastructure projects (e.g. roads, dams, dikes, canals, big recreational complexes, township development, airport construction etc.).

Normally earthwork process comprises of mainly three components as mentioned earlier: 1) data collection or measurement of the topography of the field before and after construction 2) excavation, hauling and placing 3) quantity or volume calculation before and after construction. The first component i.e. data collection, is a responsibility of the surveyor. In the design stage of any project, surveyors go out in the field, collect the data of the existing ground profile with 
surveying equipment and give this data to the design team. The design team then uses that data to determine the estimated quantity of the earth which is to be removed and placed with the help of some manual and computerized methods. This whole procedure is done before construction and in most of the cases it is also done after construction to verify the quantities. The second component, i.e., excavation, transportation and placing is the responsibility of an earthwork contractor, and that is generally done in construction stage. Equipment like bulldozers, scrapers, graders, back hoes, dump trucks etc., are used for excavation, transportation and placing activities.

Generally it is said that the construction industry is one of the slowest growing industries in the world as far as technology transformation is concerned (HUD 2000). But if we take surveying, being a component of construction process and a major part of earthwork process, it has grown to its fullest and it is still growing at high speeds. As per Wolf at al. (2002), "surveying is defined as the science, art, and technology of determining the relative positions of points above, on, or beneath the earth's surface or of establishing such points." Surveying is also being called as Geomatics in the recent years. Surveying industry has changed significantly in recent years and the scope of work in this industry has also grown proportionally. This change occurred because of the modern technological developments that have given this industry with lot of new methods and tools for measuring earth surface and for computing quantities of the related material. In the past, surveyors were mostly using ground based, tedious and laborious methods like tape and transit to collect the data and some manual methods for calculating volumes. Today, surveying industry has several tools for measuring and calculating data including some electronic instruments which can measure distances and angles very quickly, 
satellite based systems which can give precise information about positioning and new aerial engineering technologies that provide surveying information very quickly. As a result of these new developments many stakeholders believe that the name surveying does not justify the expanded role of their profession, which resulted in the new name - Geomatics (Wolf at al. 2002). So in a way geomatics and surveying are synonyms but geomatics is more popular in United States, United Kingdom and Australia. In recent years, the rapid changes in the surveying business has made it difficult to keep up to date with the latest technologies. During the past 150 years, surveyors were using instruments from chain and compass, to a period of transit and tapes, into a period of theodolite, digital level, EDMs (electronic distance measurement) and finally using total station, robotic total stations, GPS (global positioning system), aerial photogrammetry, LiDAR (light detection and ranging) with the use of super fast computers. There has been an exceptional amount of participation from government, industry and private players in changing the face of the surveying and mapping sub industry (Kavanagh at al. 2001).

In the surveying sub industry, computers have totally transformed the way the data are collected and quantity calculation is done (Leick 2004). The most computer driven tools that are available to surveyors and engineers today are 1) total station and robotic total station 2) GPS 3) digital photogrammetry 4) LiDAR 5) GIS (geographic information system) 6) satellite remote sensing. These modern methods are providing surveyors and engineers with a good solution for collecting information at lower cost and in much less time than previously required. 
A larger number of DOTs (Department of Transportation) in the United States are predominantly using conventional methods (e.g. tape, theodolite, digital level, total station, manual methods of volume calculation, DOS based old software, etc.) for data collection and quantity calculation in earthwork process. However, these methods are time consuming and labor intensive as they take a lot of time and labor to get the data from the field and one has to go through a tedious method of quantity calculation (Yanalak 2005). As stated before, there is a lot more advancement in technologies for earthwork data collection and quantity calculation compared to the rest of the construction industry. Therefore, there is a wide availability of tools for replacing conventional methods with new modern methods and software products such as robotic total station, GPS, digital photogrammetry, LiDAR, GIS, remote sensing, visual survey software, AutoCAD etc. Some DOTs are currently using above stated methods and sometimes combination of those methods depending upon various situations and circumstances and they are getting a significant increase in productivity and efficiency in using those methods with the required amount of expertise. These methods allow faster data collection, highly accurate control, effortless import and export of data, automatic drawing creation and quantity calculation. These methods and software save a significant amount of time and personnel when used in large construction projects.

Current INDOT procedures for verification of existing ground surfaces, determination of final surfaces and calculation of earthwork quantities for payment are slow and labor intensive primarily due to the use of labor intensive methods stated above. Although a few computer programs exist, extensive field work to gather data is still required. Most data is still obtained by level circuits and cross-section with auto levels and level rods. The computer programs are also 
very old and outdated. There is no technology to transfer data from equipment to computer, so the data transfer is also done by hand which increases the time required for earthwork quantity calculation. The labor force required is often not available to INDOT, particularly for large, fast track type projects. These reasons affect the Department's ability to efficiently closeout contracts and can also result in disputes when multiple contractors are working on a multi-contract project. INDOT often employs consultants to perform field and office work to determine earthwork quantities on large projects, which makes them more expensive.

In order to increase the capability of INDOT personnel to gather data and calculate quantities for payment, it is essential to understand the data collection method and quantity calculation methods adopted by INDOT personnel, other state DOTs, and other professionals. It is necessary to find out what are the different properties of those methods (e.g. advantages, disadvantages, cost, time taken to collect data, efficiency, maintenance requirements etc). This information can be used to identify methods and tools most suitable for INDOT to use. Accordingly, this research provides assessment of the methods and tools employed by INDOT and other state DOTs, identify tools available in the market and recommend efficient techniques and training needs, which will shorten the time duration of earthwork data collection and quantity calculation process. 


\section{2. $\underline{\text { Objectives }}$}

The main objectives of this study are to determine modern tools and techniques that can be used for data collection or measurement of topography of the field and to calculate quantity or volume of the material which is to be cut and filled with less labor and optimum amount of time. The methods and techniques which will be found in this study would help improve the efficiency and productivity for INDOT.

The four objectives are as follows:

1. To identify and analyze methods and tools used by INDOT personnel for verification of earthwork quantities, determination of final surfaces \& calculation of earthwork quantities.

2. Survey of methods and tools employed by state DOTs and gather information of earthwork process, personnel training and problems faced by those DOTs.

3. To study methods and tools used by different companies professionally (available in the market) for earthwork data collection and quantity calculation.

4. Recommend methods, tools and training that would assist INDOT personnel in efficient data collection and quantity calculation in less duration. 


\subsection{Research Methodology}

In order to achieve the above stated objectives, the research methodology has been divided into five tasks, as described below:

Task 1: Literature Review and Personnel Interviews

This task covers exploring different tools and technologies available in the market for earthwork data collection and quantity calculation. An extensive literature review was conducted to identify and analyze the methods and tools used in earthwork process. For earthwork data collection, different surveying tools (e.g. total station, GPS, photogrammetry, digital level etc.) were identified and evaluated. For earthwork quantity calculation, different mainstream software products (e.g. AutoCAD, microstation etc.) and second line software products (e.g. terramodel, accugrade etc.) were identified and studied further. A literature review was done on the past practices of data collection and earthwork quantity calculation and a comparison is provided with respect to current modern technologies. Additionally, a review on general process of earthwork data collection and quantity calculation on large construction projects is included.

Second part of this task gathered information on current practices of INDOT surveyors and engineers in the field and in the office regarding earthwork data collection and quantity calculation. Telephone interviews were conducted with INDOT surveyors \& engineers to get the information. These interviews included information on current procedure of collecting data of 
existing ground surface, cost, advantages and disadvantages of those methods, efficiency and productivity of those methods, tools used for quantity calculations, cost, efficiency, advantages, disadvantages, problems faced by them in using these methods and tools etc. The same information was also collected through a questionnaire survey as discussed in Task-2.

Task 2: Survey of methods employed by state DOTs and case studies

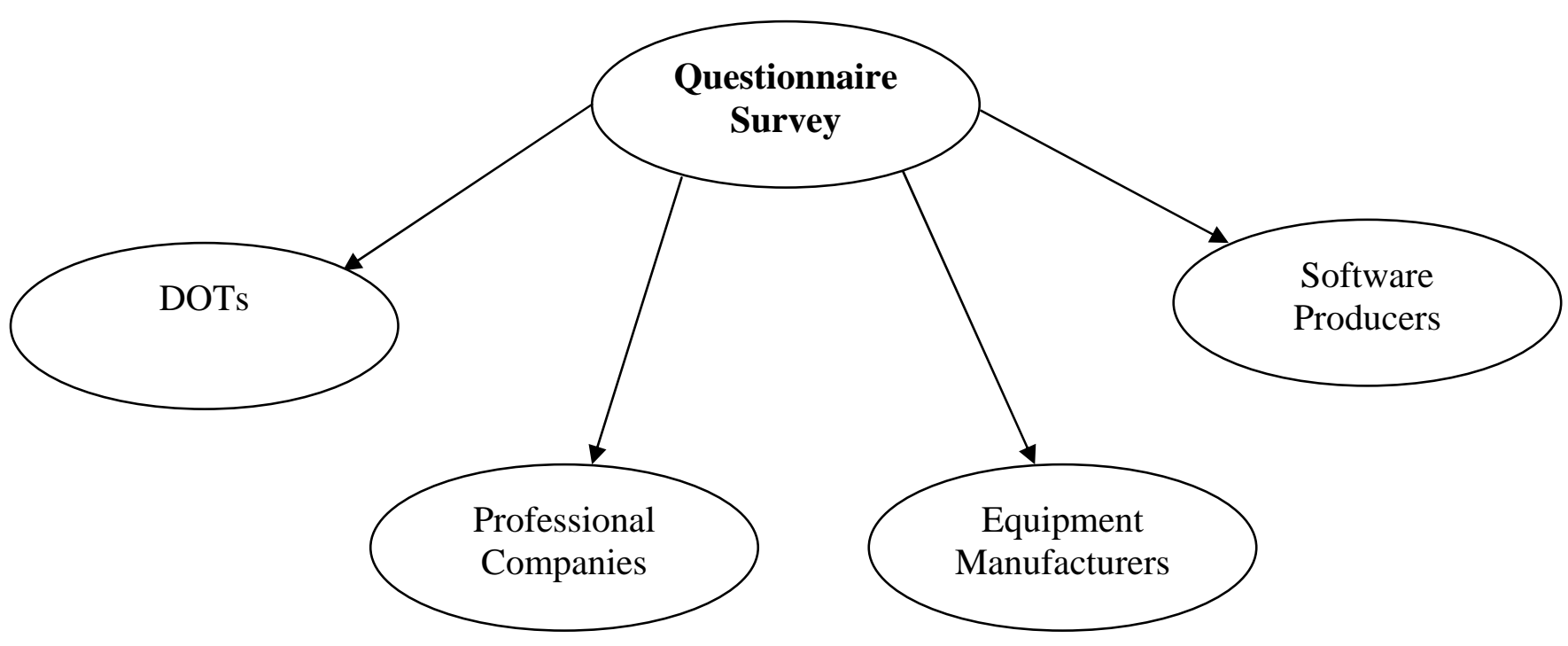

Figure 1.1 Questionnaire Survey sent to Different Entities

The objective of task-2 was to determine what other DOTs are doing to collect data in the field and finding quantities of material in the earthwork process. A questionnaire survey was sent to all the DOTs throughout the United States as a part of second task (Figure 1). The Survey included questions on: 
1. The various tools used by DOTs for earthwork data collection and quantity calculation.

2. Data on man-hour requirement, cost, duration, productivity, efficiency and advantages of those tools and techniques used in earthwork data collection and quantity calculation.

3. The problems faced by their personnel in using these methods and technologies.

4. Duration and cost of training given to their personnel to keep them up to date.

Case studies were conducted to gather the views of owners and contractors on different bottlenecks in earthwork process, various chances of improvements and their current state of practices. These case studies were performed on INDOT projects that have a large volume of earthwork and are currently undergoing.

Task 3: Survey of tools available in the market

After sending questionnaire surveys to all the DOTs in the country and performing case studies with owners and contractors, the next task was to know what tools and techniques were being produced by equipment companies and software product companies. It was important to know the current state of practice for professional companies or earthwork contractors and their view on the earthwork process. 
A questionnaire survey was sent to all major surveying equipment manufacturers and related software companies. The questionnaire survey included questions such as cost, advantages, disadvantages, efficiency, mutual compatibility of equipment and software products, maintenance requirement etc. Personal interviews were conducted with equipment and software product vendors in Indiana to gather their opinion on various equipment and software products and their suitability for INDOT.

A questionnaire survey was also sent to different professional companies working in Indiana in the design and survey field. The questions were very similar to questions asked in the DOTs (owner) questionnaire survey and allowed a comparative analysis of what was being used by the DOTs and what was being used by contractors.

Task 4: Evaluation and recommendation of different tools and training to INDOT personnel

After getting the data from questionnaire surveys, telephone interviews, personal interviews and case studies, it was analyzed and recommendations are provided according to the result of the data. As most of the collected data was subjective, a subjective and comparative analysis is provided. The comparative analysis was done with respect to different objectives and the information collected from all the above stated sources. After doing the analysis, most efficient and usable tools for earthwork data collection and quantity calculation are determined.

The research study team also tried to identify and evaluate alternate options that could include outsourcing of data collection and quantity calculation to consultants and/or formulate a 
survey crew in each of the district to perform these works resulting in economy with respect to purchase of limited equipment and software products. The second component of this task was to identify training needs that were required to use these modern tools and technologies. Questions regarding training needs were included in the questionnaire surveys, personal interviews and case studies.

Task 5: Development final report

After completing all the above mentioned tasks in a satisfying manner, a comprehensive report comprising all the tasks mentioned above in detail including data collection of all the tasks performed and data analysis was prepared. Regular meetings took place with INDOT SAC (study advisory committee) members and they were kept informed about the progress of the project and the type of data received while performing above mentioned tasks. Their inputs were taken care of while the project was going on.

The work performed in this study will be finally given in the format of a detailed report to SAC members for review and comments prior to the scheduled completion date of the project. The comments provided by INDOT will be incorporated and a final report will be delivered to INDOT by the completion date of the project. 


\subsection{Probable Outcomes and Benefits of Study}

The proposed research will have significant impact on current practices of INDOT personnel in data collection and quantity calculation in the earthwork process. This research will recommend tools and methods that will solve most of the problems being faced by INDOT surveyors and engineers in the field as well as in the office regarding earthwork data collection and quantity calculation. This research will identify some modern tools that take comparatively less time in the field to take data and verify the existing ground surface and also in determining the final surfaces. The research team will also find out some proven software products used by owners and contractors throughout the United States which will take very less time in transferring data from equipment to computer and volume calculation can be done precisely in given time constraints. These tools and technologies will help INDOT in completing their large and fast track construction projects in time.

Some of the probable outcomes of the study are listed below:

1. The study identifies various tools and methods used by state DOTs for earthwork data collection and quantity calculation and problems faced in utilizing these tools and methods.

2. The study identifies man-hour requirement, cost, duration, efficiency, advantages of those methods and problems faced by INDOT surveyors and engineers in using them in earthwork data collection and quantity calculation with respect to different methods and techniques available.

3. It also identifies the tools and software available in the market and used by professional companies and documents the efficiency of these tools and software. 
4. This research also recommends tools and options that are best suitable for acquisition and analysis of earthwork pay quantity verification data.

5. This study will also identify the training needs to utilize the identified techniques which should be given to INDOT personnel in order to perform these tasks in better manner. 


\section{5. $\underline{\text { Conclusions }}$}

The earthwork is one of the main components of large construction and infrastructure projects. Surveying, being a very major component and being used while collecting data in the earthwork process, has evolved as one of the fastest growing field in the construction business. Therefore one has to take advantage of this growing field and make earthwork process fast, less time consuming and more efficient. As a result, one has to think in the direction of upgrading the current practices of collecting data on the field, verifying the ground surface, determination of final surface and calculation of earthwork quantities. This research is aimed at upgrading / converting current slow and labor intensive methods of collecting data and find out quantities for earthwork to methods which require very less labor, which can be performed in very less time and which will give better productivity and efficiency. In the process of finding these types of methods and technologies, the research team will take into consideration efficiency / precision, cost, man hour requirements, user friendliness, maintenance requirements, training requirements as their main component platforms in comparing these technologies and give recommendations on the basis of comparative analysis.

The first step in this research as said before would be to do literature review, which will include the historic and current procedures of data collection and quantity calculation used by different parties in the construction industry. The next chapter will give you an extensive look at the various methods / technologies of earthwork data collection and volume calculation. 


\subsection{References}

Cole, George M., Harbin, Andrew L. (2006). Surveyor Reference Manual, Professional Publications, Inc., Belmont, CA.

“Industrializing the Residential Construction Site” (2000). Center for Housing Research (2000), Virginia Polytechnic Institute, Department of Housing and Urban Development (HUD) (2000).

Kavanagh, Barry F. (2001). Surveying: with construction applications, Prentice Hall, Upper Saddle River, NJ.

Leick, Alfred (2004). GPS satellite surveying, Wiley, New York, NY.

Wolf, Paul R., Ghilani, Charles D. (2002). Elementary Surveying: An Introduction to Geomatics, Prentice Hall, Inc., Upper Saddle River, N.J.

Wolf, Paul R. (2002). “Surveying and Mapping: History, Current Status and Future Projections”, American Society of Civil Engineers, $150^{\text {th }}$ Anniversary Paper.

Yanalak, M. (2005). “Computing Pit Excavation Volume”, Journal of Surveying Engineering, ASCE, February, Vol. 131, No. 1, pp. 15-19. 


\section{CHAPTER 2. LITERATURE REVIEW}

\subsection{Introduction}

This chapter represents the literature review with regards to various tools and methods which were being used and which are currently in use for earthwork data collection and earthwork quantity calculation. As said in the previous chapter, there has been a lot of advancement in this area of the industry, so there is a fair amount of literature available in this area. This chapter will provide an overview of the current technologies and software products available that are related to surveying (data collection) and quantity calculation of earthwork. The chapter will also discuss innovative methods for earthwork data collection and quantity calculation which could be used in construction stage to get maximum productivity in less time with less labor.

\subsection{Methods for Earthwork Data Collection}

As discussed in the previous chapter, the earthwork data collection deals with surveying technologies used before and after construction. The tools and technologies used to collect data before and after construction may or may not be the same. The following paragraphs illustrate available tools such as tape/chain and theodolite, level instrument, total station and robotic total station, static GPS (global positioning system), differential GPS, RTK GPS, aerial 
photogrammetry, LiDAR (light detection and ranging), laser scanning (terrestrial photogrammetry), vangarde system etc.

\subsubsection{Level Instrument (with Tape or Chain)}

The level is mainly used in surveying to determine the elevations of different points and difference in elevation between points. It is particularly useful for projects with small surveying requirements. Different types of level instruments and methods are available to determine the elevations.

The level instrument is made up of a telescope and a system to establish the line of sight of the level instrument in a horizontal plane. The horizontal distances are generally measured with either tape or chain. There are mainly four types of level instruments available in the market: i) Dumpy level ii) Engineer’s tilting level iii) Automatic level iv) Digital level. The main difference between these four instruments is that the dumpy level and tilting level employs level vials to adjust their line of sight while automatic level and digital level use automatic compensators. The dumpy level, tilting level and automatic level require a measuring rod for elevation measurement of any point while digital level has bar-coded rods for automated digital readings. There are three leveling screws in dumpy level and tilting level to make the instrument parallel to the horizontal plane. But in digital level and sometimes in automatic levels, automatic compensator levels the instrument by itself. 
Automatic levels are most frequently used in construction today because of their ease and rapid work capability. At the same time, digital level (Figure 2.1) is also gaining popularity because of its precision, less manual errors and ease of work. Tilting levels and dumpy levels, while still in use, are fairly outdated. The digital level's maximum range is approximately $100 \mathrm{~m}$, so it could be a limitation where the surveying region is several kilometers. It's accuracy in taking readings is around $+/-0.5 \mathrm{~mm}$ (Wolf at al., 2002) The cost of automatic level ranges anywhere between $\$ 300$ to $\$ 1500$ depending upon the brand and different properties of different instruments. While the cost of digital level lies anywhere between $\$ 1500$ to $\$ 2500$ depending upon company and characteristics (Wolf at al., 2002).

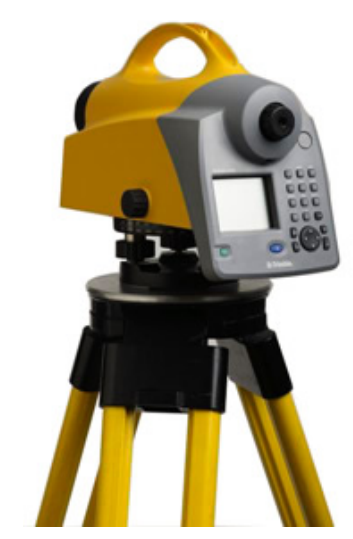

Figure 2.1 Digital Level (Source: http://www.trimble.com/graphics/dini.jpg, Last Visited - 10/08/07)

Normally digital level is around $60 \%$ faster than an automatic level which gives very high productivity in less time compared to other level instruments (Wolf at al., 2002). Digital level has an extra feature of storing the data into their internal memory and they also have a provision of external memory card, which gives a seamless transfer of data from instrument to PC. 
Moreover, digital level has a special feature of display on the instrument, which makes this instrument very user friendly and easy to perform. One of the main advantages of a level instrument is that it doesn't require a lot of training to use; it is one of the very simple instruments to use on the field.

Level instruments have good accuracy but they are not the solution for quick completion of project with less labor consumption especially in large construction projects. Use of level instruments require both labor and time and are suitable for construction projects where the size of the project is small with less surveying activities involved.

\subsubsection{Theodolite}

Theodolites are basically the predecessors of the total station instrument. The main function of a theodolite instrument is to measure horizontal and vertical angles of different points on or above the ground surface. One can also measure horizontal distances and thereby determine the elevation of different points by the use of stadia and a graduated rod. The telescope eyepiece on a theodolite has two stadia hairs. The difference in reading between the stadia hair when multiplied with a predetermined number provides the distance between two points. Some corrections are needed in order to get the precise result, but generally it gives result within an error of $1 \mathrm{ft}$. 
Theodolite includes a sighting telescope which has stadia hair on the lens and two circles for measuring angles, mounted perpendicular to each other. One of those two circles is for measuring horizontal angles and the other is for vertical angles. There are level vials and three leveling screws to make horizontal circle parallel to horizontal plane, which makes vertical circle automatically in a vertical plane.

Theodolites were very popular from 1960's to mid 1980's because of their good precision characteristics but after the advent of total station they slowly started becoming outdated. The number of people using theodolite in the surveying process are steadily decreasing since than. The main advantage of theodolite is its precision/accuracy. While some of the disadvantages are i) time consuming ii) range limitation iii) not good for big projects where time is one of the big constraints iv) labor intensive. Due to its reducing customer base, only a few companies make these instruments (i.e. Leica, Topcon, Sokkia, Nikon etc).

\subsubsection{Total Station}

Until mid 1980s transit and theodolites were the most popular instruments for surveying and they were used to measure angles and distance with the help of either tape or chain. But after the invention of total station, it has taken place of theodolites and transits in surveying activities almost every where. Total station can measure horizontal and vertical angles with much greater accuracy and it shows the angles on the display in real time. It can also measure the distance with great ease without the use of tape or chain with less time consumption. One can also store the 
data on the field during data collection and then transfer the data to the office computer after the field work is over. It has a seamless transfer from instrument to PC (Dagostino at al. 2003).

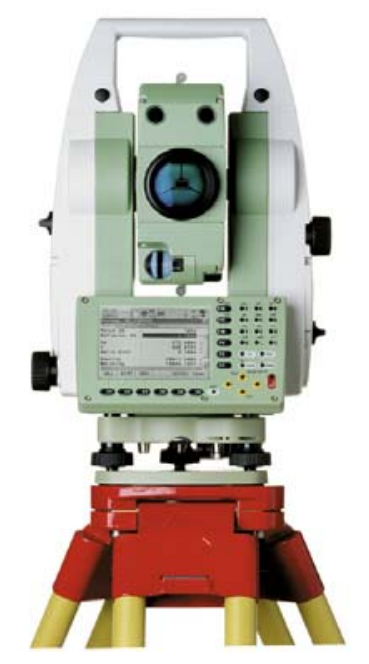

Figure 2.2 Total Station (Source: http://www.advancedlasers.com/images/tps1200.jpg, Last

$$
\text { Visited - 10/02/07) }
$$

A total station (Figure 2.2) has mainly three components in one unit: an electronic distance measuring (EDM) instrument, an electronic angle measuring component, and a microprocessor. These components together can measure horizontal and vertical angles as well as slope distances from a particular point. From this data the instrument would find the distance from that point, elevations and coordinates of the points sighted in no time and display it on a liquid crystal display (LCD). EDM instruments fixed in the total station equipment have range about $4 \mathrm{~km}$ with one prism and even far with a triple prism. The angle measurement resolution of a total station varies from 1" to 20" from precise and expensive instrument to some less expensive instruments. The compensator accuracy used in the instrument generally ranges from $1 ”$ to $3 ”$. 
Total station has many applications in surveying procedure. It can average out multiple angles and distance measurements. It can also make corrections, e.g. correcting measured distance for prism constant, atmospheric pressure and temperature. It has mechanism to make corrections for curvature and refractions to elevations determined by the instrument. It can also compute the elevations from the vertical distance components. Some total station can correct the human errors like incorrect leveling with the help of tilt-sensing mechanism. Lastly some total stations are able to make corrections on horizontal and vertical angles measurement with the help of microprocessor attached to the instrument.

Generally surveying with total station requires at least two people on the field to collect the data. A surveyor would stand at the total station and the other person would stand with a prism rod at the point where the elevation and distance to it is to be determined. If the size of the project is very large than it is not viable to use normal total station because it would take a lot of time to survey the whole project site and do calculation in the office afterwards. A robotic total station (Figure 2.3(a) and 2.3(b)) on the other hand gives a great amount of productivity and efficiency to the surveyor working on the site. It requires only one surveyor on the site to do the work. It works similar to the total station but there is a remote control system in the reflector instead of normal prism. This control system emits a laser beam which is detected by a detector in the robotic total station. Now robotic total station has the advantage of rotating about its axis on the tripod platform in the direction of the laser, automatically catching the laser beam. So all one needs to do is to position the robotic total station correctly and place the rod with remote control system where the elevation and distance are needed. 
With some instruments Bluetooth technology is available so one can transfer the data from the total station to the data collector in real time and store it safely in the data collector.

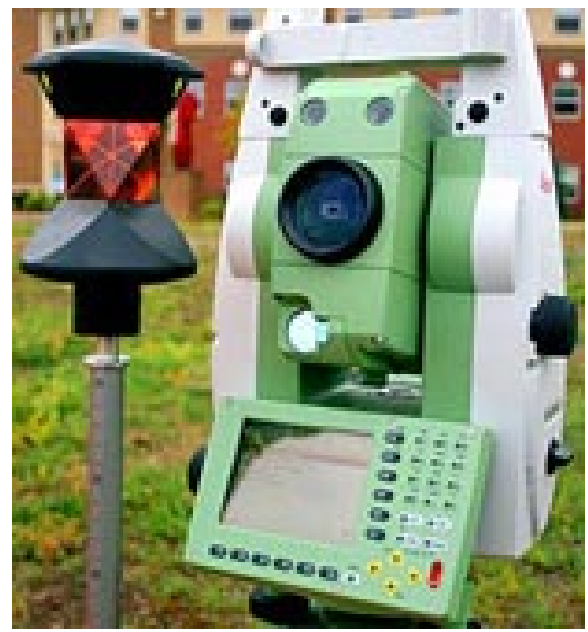

Figure 2.3(a) Robotic Total Station

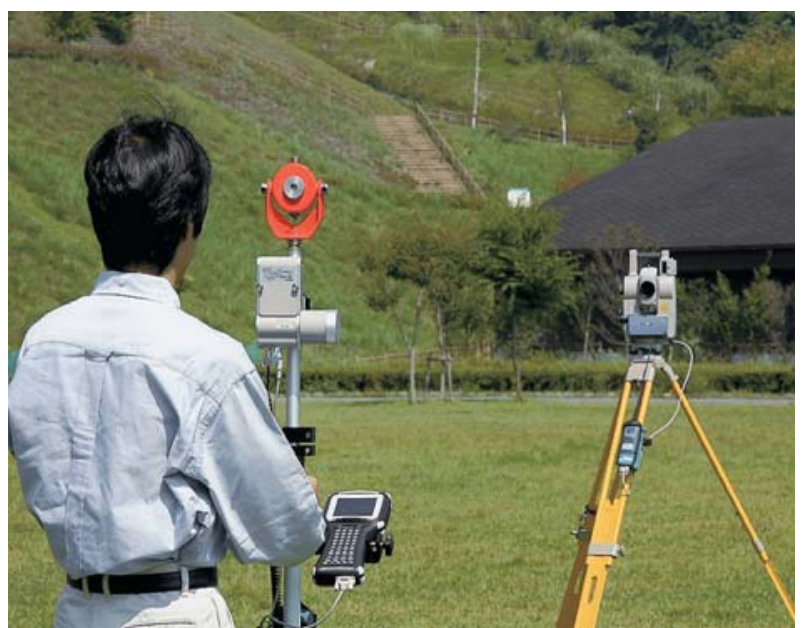

Figure 2.3(b) Robotic Total Station in use

(Source: http://www.teamelmers.com/surveying.htm, http://www.jobsitesurvey.com/23choosets.htm, Last Visited - 10/10/07)

Some of the disadvantages of a total station are as follows: 1) the use of total station requires a line of sight between the point to be measured and the instrument compared to no requirement of line of sight in GPS. 2) Some total stations are not water proof so they cannot work in the bad weather, rain and in snowy conditions. 3) As said before, it is not a feasible option for a large project because of its less speed compared to GPS.

A majority of the surveying market in the United States is using total station as one of the main instrument for surveying procedure. It has been used for past 15 years extensively and it has proved its capacity and efficiency to the customers. One of the major reasons for using this instrument could be the experience of using it and its user friendliness. 


\subsubsection{Global Positioning System (GPS)}

The US department of defense (DoD) Began developing global positioning system way back in 1970s. This system has basically evolved from the research and development of a global navigation and guidance system for military purposes. The DoD launched their first satellite to test this system in 1978. Since then, they have put 27 more satellites in the orbit. Among the 28 satellites, 24 satellites are in active mode and 4 are in spare mode. This system became fully operational on $27^{\text {th }}$ April, 1995. This development cost around $\$ 12$ billion to the United States (Wolf at al. 2002).

GPS is based on calculating distance and positions from the signals received by the GPS receivers from the satellites whose positions are precisely known. GPS system has mainly three components: 1) space component 2) controls 3) user component. Space component includes 24 satellites which are placed at $60^{\circ}$ interval around the equator in six orbits. These satellites are 20,200 km above the earth and they have orbital period of 12 sidereal hours (a sidereal day is 4 minutes shorter than a normal solar day). The control component includes five stations placed throughout the world to keep track on satellite signals and their orbital tracks. These controls make predictions on satellite positions and clock error corrections and they broadcast these corrections through satellites only.

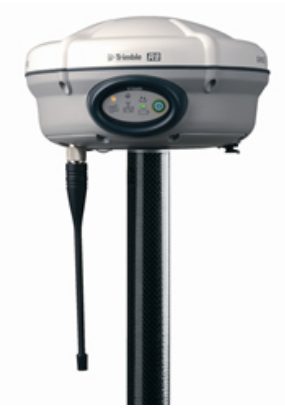

Figure 2.4 GPS Receiver or GPS Rover (Source: www.trimble.com, Last Visited - 10/06/07) 
The user segment contains two types of receivers (Figure 2.4) which are classified by standard position service (SPS) and precise position service (PPS). The SPS is available on L1 frequency which is available to receivers at no cost to the user and PPS is available on L1 and L2 frequency which is available to receiver having cryptographic keys (for DoD use) (Wolf at al. 2002).

GPS has lots of applications in engineering as well as non-engineering areas. Some of the applications of GPS are: 1) planning and environmental mapping of wetlands, historical/critical places, utilities etc. 2) mapping of topography in design stage, design surveys, control surveys, photogrammetry 3) control in photogrammetry and LiDAR applications 4) construction stake out 4) in machine guidance system during stakeless construction 5) incident/congestion management 6) navigation purposes in vehicles 7) inventory tracking etc. Different applications of GPS require different amount of accuracies and accordingly the instruments of GPS are made available to different type of customers. The accuracy of GPS depends on several factors. These factors are listed below:

- $\quad$ type of receiver ( dual frequency(L1 \& L2) and single frequency(L1) )

- $\quad$ accuracy of the reference stations

- number of satellites visible during the survey

- $\quad$ atmospheric conditions

- geometry of satellites during the observation time

- obstructions occurrence at the site of observation

- $\quad$ method of reduction used by software

- length of observation 
The above listed factors are not the complete list of accuracy measures but it includes most of the factors.

There are different field procedures associated with GPS surveying, these field procedures are classified according to the capability of the receiver used and type of survey to be performed. Some of the field procedures are static, rapid static, kinematic and real-time kinematic methods.

\subsubsection{1. $\underline{\text { Static GPS }}$}

This field procedure is the most precise and most time consuming procedure among all the GPS field procedures. This requires minimum two receivers to collect the data. In this process, one receiver is placed on an existing control location as a base station and all other receivers are placed at the unknown points whose coordinates are to be found out. The measurements are taken all at the unknown points with the minimum 4 satellites availability and then all the receivers are moved to other points except one point. That one point will now become the base station and the same procedure is repeated again. This procedure is done till all the unknown points are covered and their positions are known. Relative accuracy of this procedure is normally $+/-(5 \mathrm{~mm}+1 \mathrm{ppm})$ and typical duration length for single frequency is 30 $\min +3 \mathrm{~min} / \mathrm{km}$ and for double frequency $20 \mathrm{~min}+2 \mathrm{~min} / \mathrm{km}$. All the receivers have the internal memory into which the data is stored and then can be transferred for post processing to PC when all the work is done. 


\subsubsection{Rapid Static GPS}

The main difference between static and rapid static GPS is that in this method one receiver always remains at the control position compared to static GPS where the position of the receivers keeps changing. The other difference is the time period for which one observation is conducted; the duration of one observation is smaller than static GPS. For single frequency the duration of observation is $20 \mathrm{~min}+2 \mathrm{~min} / \mathrm{km}$ and for double frequency it is $10 \mathrm{~min}+1 \mathrm{~min} / \mathrm{km}$. The main limitation of rapid static GPS is its limited base line (up to 25km) in length. Relative accuracy of this procedure is normally $+/-(5 \mathrm{~mm}+1 \mathrm{ppm})$ similar to static GPS. To achieve these accuracies good ionospheric conditions and satellite configurations should be achieved. This method is very useful for small control surveys.

\subsubsection{Kinematic GPS}

This method also requires use of two or more receivers. One receiver will be placed at the base (known point) and it will work as the base station while the other receiver (i.e. rover) will move from one point to the other point along the line. The accuracy of this method is $+/-(5 \mathrm{~mm}$ to $10 \mathrm{~mm}+2 \mathrm{ppm})$. One care should be taken such that both the receiver and the rover must lock into four satellites throughout the data collection. If the lock is lost, the receivers must be reinitialized to get the precise positions. The data is temporarily stored in the rover or data collector attached to it till the session is over. The data is transferred to the PC in the office for 
post processing to get the positions of the unknown points. The data is also adjusted for the errors associated with GPS surveying.

Kinematic GPS can be used in any type of survey which requires many points to be located. It can be also helpful in situations like photogrammetry where one rover is placed inside the airplane to get the precise positions of airplane at each moment of time, and it is very useful in construction where the rover can be placed on the earthmoving equipment blade to get the position of the blade in real time (stakeless construction).

\subsubsection{Real-Time Kinematic (RTK) GPS}

The main difference between kinematic GPS and RTK GPS is that the kinematic GPS method requires post processing in the office to get the positions of the unknown points while RTK GPS gives you the positions of the unknown points in real time. Like kinematic GPS, this method also requires two or more GPS receivers (Wolf at al. 2002). The main advantage of this method is the radio attached to the base station which transmits the corrections to the rovers in real time. The rover at some unknown point gets these signals and the measurements are processed on the onboard computer in real time to get the position of that unknown point. So to get RTK GPS work, one has to get compatible hardware at each end of the radio link.

The use of radio signals can limit the distance between the receiver and the rover to about maximum $10 \mathrm{~km}$ but the use of powerful transmitter can increase the permissible distance or one 
can also use the repeater base station. But the use of more powerful transmitter requires permission from federal communication commission (FCC). One more point of concern is the requirement of line of site between base station and the rover if one is using radio transmitter to send the corrections. So as shown in figure 2.5, one can use the repeater base station to counteract this problem. The main advantage of this method is the reduced office work and one can check the field applied corrections in the office. This makes the work more productive and efficient.

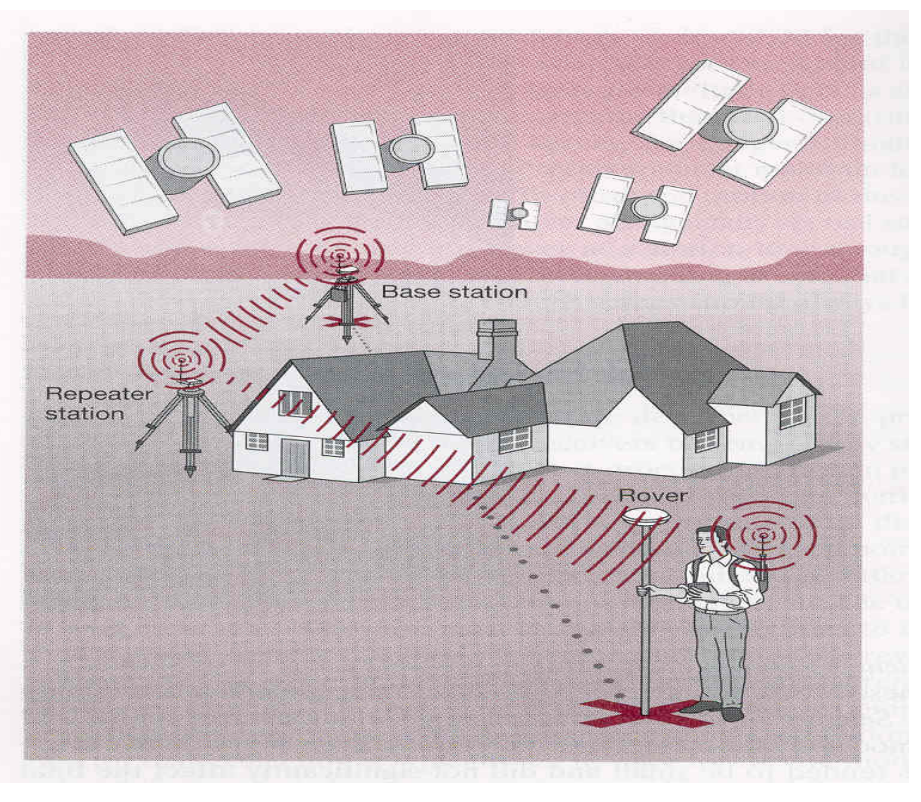

Figure 2.5 Use of a Repeater Station to Work around Obstruction (Source: Elementary Surveying: An Introduction to Geomatics, Tenth Edition)

A new technique in the RTK GPS system called virtual reference station (VRS) RTK GPS is a very interesting option which makes the GPS data more accurate and it makes RTK GPS positioning viable for wider areas. It uses continuously operated reference stations (CORS) to provide a complete solution with all the correction to user in real time. CORS is basically a base station which continuously operates and gives carrier phase and range based data 
throughout the US. A number of US states are having CORS network in their state which can be used by anyone to get the positions from the data received. A CORS network consists of several GPS reference stations throughout the state in such a manner that it covers most of the state. The VRS system enables to increase the distance between CORS stations which in turn enables to achieve economy by reducing the number of CORS. This system also reduces the PPM error related to GPS data thus giving more accurate results. With CORS and VRS technology, one doesn't need to set up base station at the site to use GPS but they can use CORS and get the best accuracy.

This VRS technology has made the RTK GPS system more efficient and productive and it has been implemented by lot of contractors because of efforts made by states to provide the statewide CORS.

\subsubsection{Online Positioning User Service (OPUS)}

OPUS is a service offered by the National Geodetic Survey (NGS) to facilitate GPS user and give them an easy access to National Spatial Reference System (NSRS). In this service, users of GPS are allowed to submit their GPS data online on the website of OPUS. The data will be automatically processed to find the positions using the software provided by the NGS. Each data file is processed with respect to 3 CORS station. Those three CORS station may or may not be the nearest ones to your site, the selection of CORS is done with respect to the distance, number of obstructions, site stability etc. To process the data, user has to provide the data file, 
antenna type used to collect the data, height of the antenna reference point above the point and 3 base stations (optional). After the data is processed, an email will be sent to the user containing the processed data in both International Terrestrial Reference System (ITRF) and North American Datum (NAD83) and Universal Transverse Mercator (UTM), United States National Grid (USNG) and state plane coordinates.

A number of public and private agencies are using OPUS as their main source of data processing and also for checking their post processing. It gives the solution within no time making the post processing fast as well and therefore improving productivity.

\subsubsection{Errors related to GPS surveying}

There are a number of errors associated with GPS surveying both on the field and in the office. One has to take care in applying corrections to the data taking into consideration all the possible errors associated with the data. There are some instrumental, natural and personal errors associated with this type of surveying.

Instrument errors include errors related to receivers and satellite clocks and errors related to set up of equipment. Natural errors include multipathing of satellite signals before coming to the receivers and refraction of the signals due to some atmospheric changes (e.g. lots of negative ions in the ionosphere). Personal errors include some manual error while post processing and tripod setting error by personnel. 


\subsubsection{Aerial Photogrammetry}

Manual of photogrammetry, ASPRS defines photogrammetry as “The art, science, and technology of obtaining reliable information about physical objects, and the environment, through processes of recording, measuring, and interpreting images and patterns of electromagnetic radiant energy and other phenomena” (Manual of Photogrammetry, $4^{\text {th }}$ Ed., ASPRS, 1980). There are basically two types of photogrammetry: 1) metrical 2) interpretative. The first type is about finding the information regarding distances, areas, elevations, cross sections, volumes etc. from the photographs, while the other type is about interpreting the significance of a photograph or an object from the photograph.

Aerial photogrammetry has a number of applications in surveying, engineering and non engineering departments. It is used to find co-ordinates of different points, to make large maps, for subdivision planning, to find out positions of points in a control survey, in hydraulic surveying in engineering departments. It is also useful in non engineering areas like forestry, agriculture, archeology, geology, traffic management and accident investigation. Photogrammetry becomes extremely helpful when one has to do survey in inaccessible areas where traditional methods cannot be applicable. Other advantages of aerial photogrammetry are its speed of data collection while flying and very less chances of forgetting any points while flying is taking place. It has low cost compared to LiDAR technology and its accuracy is also competitive. However there lays a big disadvantage with aerial photogrammetry compared to LiDAR. Aerial photogrammetry cannot be used in the nights and in bad weathers like storms, 
snow, rain etc. compared to LiDAR, which can be used in most of the situations. Therefore it is less versatile than LiDAR technology.

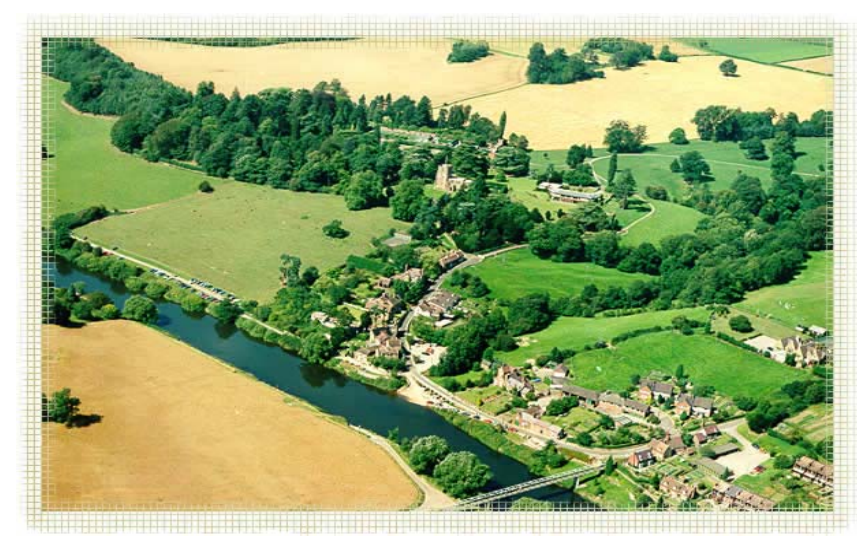

Figure 2.6 Aerial Photograph (Source: http://www.arley-arboretum.org.uk/araerial.php,

Last Visited - 10/15/07)

Aerial photogrammetry can be performed in different manner depending upon project characteristics, its requirement, type of resources available with project manager and amount of detail required in the project. Simple calculations and analysis can be done by measuring directly with engineering scale from the paper prints of photographs and assuming that the axis of camera was in plumb with the vertical plane while taking photos. This method will not be accurate but it will give you general idea about the existing or final ground surface (in case of construction surveying), which will be of good use. There are some other methods like analog, analytical and softcopy methods which give accurate results compared to earlier method. Analog method uses optical and mechanical machines to create the terrain or surface models which can be accurately measured and mapped. Analytical method relies greatly on mathematical formulas and precise measurement of photographs and objects in it. While softcopy method uses digital photos and uses computer software products to measure the positions and other required information. 
Ground control is also one of the main components responsible for greater accuracy. Literature suggests that there should be at least 3 horizontal and four vertical control points for aerial photogrammetry to have accurate results. Ground controls can be of simple traverse, GPS or it can be photo control natural points for which the positions can be found out from ground control survey. Currently most of the parties are using GPS as their means of ground control because of the advantages attached to this controlling system. For GPS to work as a ground control, a GPS receiver must be installed inside the airplane on the camera. This GPS receiver would have link to ground based GPS receiver and camera positions are continuously determined from this mechanism. From this information, the camera co ordinates can be calculated as per ground co-ordinates and that would make the job of an engineer in the office much easier and faster.

Aerial photographs taken from airplane are of two types: vertical and oblique. Vertical photographs are taken with vertical camera axis and oblique photographs are taken making camera axis at an angle to vertical plane. Vertical photographs are mainly used in metrical photogrammetry while oblique photos are used in interpretative photogrammetry. Vertical photographs are taken in the path like strips where adjacent strips have overlap of about $30 \%$ and end lap is about $60 \%$. An end lap of about $50 \%$ or more is necessary to ensure all point coverage.

In general, aerial photogrammetry and LiDAR are the competitors of each other. Untill the emergence of LiDAR, photogrammetry did not have a competition. However photogrammetry is still one of the main component of mapping industry and it can be very useful 
where the length of the project is in miles and as said earlier, it is very handy in the design stage where surveyors are trying to identify the existing ground profile.

\subsubsection{Light Detection and Ranging (LiDAR) Technology}

LiDAR technology is also called as airborne/aerial laser scanning. It is very similar to aerial photogrammetry but one of the main differences is the use of laser pulses in the LiDAR technique compared to light beams in Aerial Photogrammetry. LiDAR technology is mainly used for making Digital Terrain Models (DTM) and surface models of an existing ground. In this method of laser scanning, the airplane flies in the air around 1000 to 1500 feet above the ground compared to terrestrial laser scanning where the scanning is done with instrument lying on the ground.

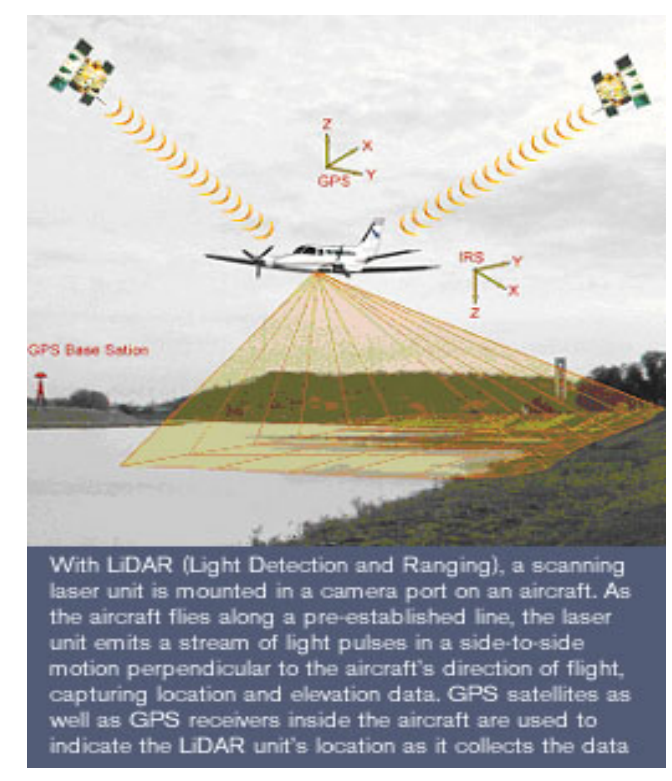

Figure 2.7 LiDAR System

(Source: http://www.woolpert.com/asp/articles/New_LiDAR_Technology.asp,

Last Visited - 10/12/07) 
As stated before, the LiDAR system is mounted on an airplane and airplane flies at certain height to scan the given amount of area as shown in figure 2.7. Figure 2.8 shows the components of a LiDAR system. Differential GPS (DGPS) component is useful to get information on precise position of the airplane platform. Inertial Measurement Unit (IMU)/Inertial Navigation System (INS) provide an accurate reference to an external coordinate system. There is a unit which emits laser, a unit for deflection of laser and a unit for measuring the range from that particular point on the ground to the platform of an airplane. A control and data recording unit is also set up for data storing on field. When the flight starts, the DGPS system is linked with the base station and will give the position of an airplane at every moment of time, while IMU/INS will give information regarding altitude, location and motion of the airplane. This information will help taking into account the angle of the platform with respect to horizontal plane and vertical plane.

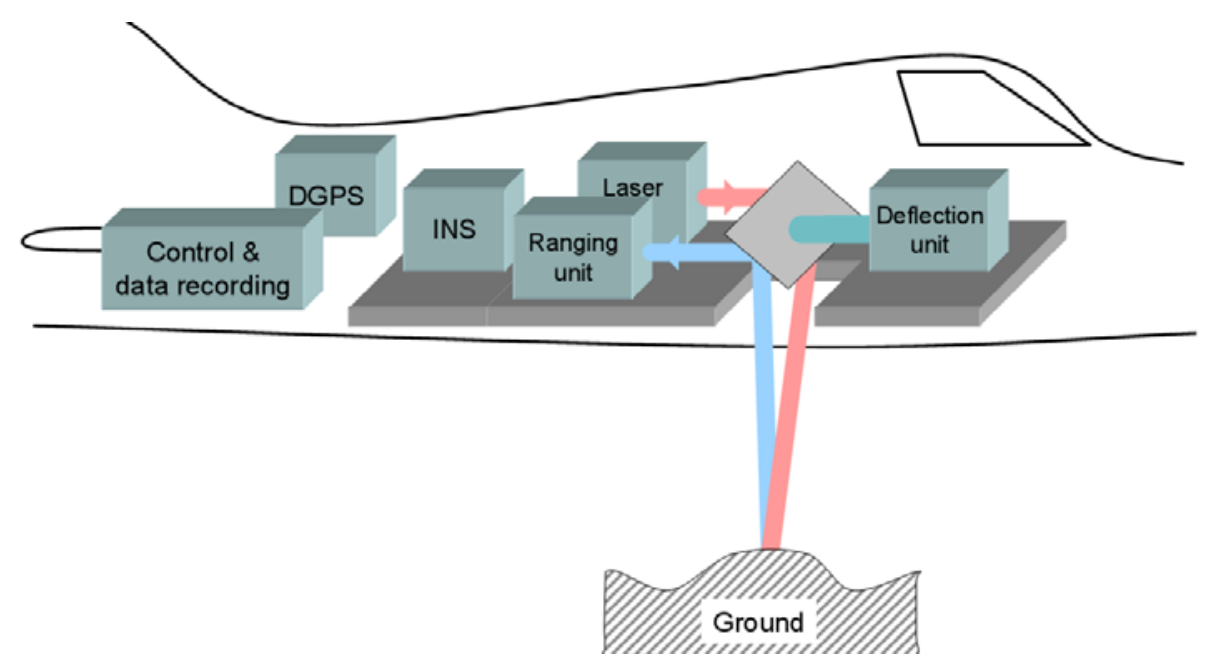

Figure 2.8 Basic Components of LiDAR (Source: Claus Brenner, International Summer School, “Digital Recording and 3D Modeling”, Greece, 24-29 April, 2006) 
Generally LiDAR is used in design stage of a construction project where the existing ground profile is measured with it. The sampling density on the ground range from 1 point per 20 $\mathrm{m}^{2}$ up to 20 points per $\mathrm{m}^{2}$. A lot of factors are considered before choosing density like the flying speed, scan angle, amount of detail needed, atmospheric conditions etc. As discussed in terrestrial scanning, the aerial laser scanning is also not capable of directing at any particular point or object; it will give you positions of footprint itself.

Two flying techniques are shown in figure 2.9(a) and 2.9(b). Figure 2.9 (a) suggests flying airplane on adjacent strips in opposite direction while figure 2.9(b) suggests flying airplane on adjacent strips in same direction. There could be other techniques of flying also, but the literature suggested these two among the most used flying methods.

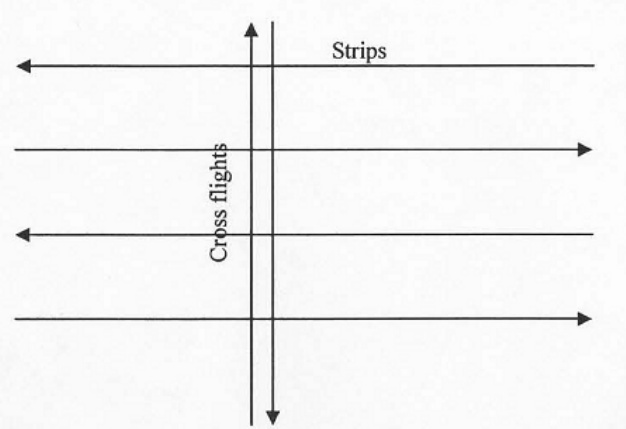

Figure 2.9(a) Flying Technique

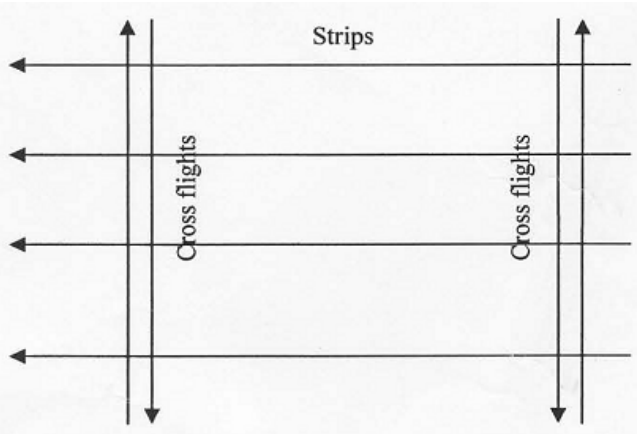

Figure 2.9(b) Flying Technique

(Source: Ohio Department of Transportation)

Figure 2.10 shows a typical LiDAR work flow given by Ohio Department of Transportation. It gives proper steps to be performed in order to get good accurate data from the field and generate a better DTM of an existing or final ground surface from it. The workflow has a lot of check points at which the data is checked for quality and accuracy. 


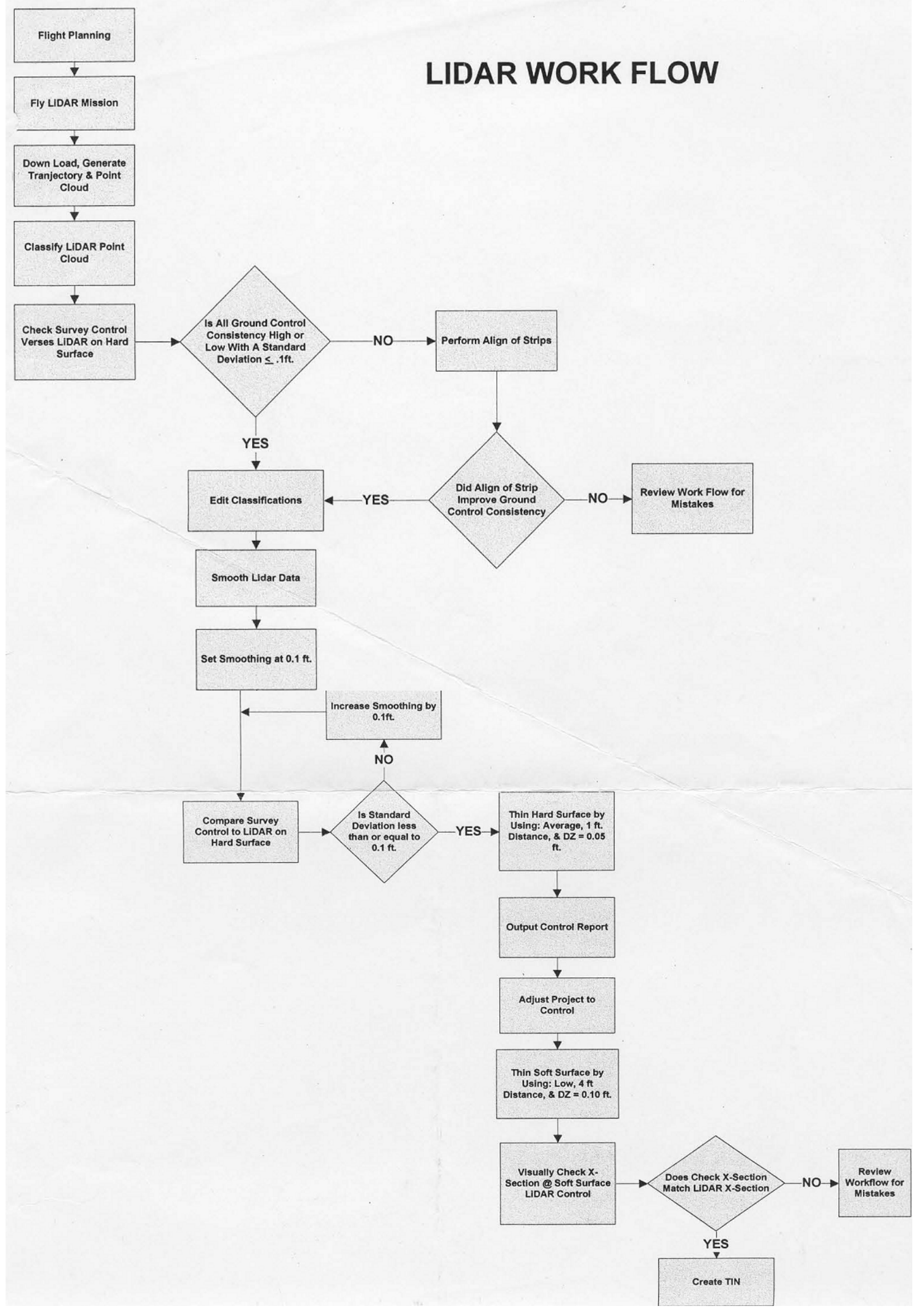

Figure 2.10 LiDAR Workflow (Source: Ohio Department of Transportation) 
Normally this technique takes very less time in the field but it takes a lot of time in the office because of tremendous amount of data generated from this method of surveying. Engineers have to work generally from 2 days to 2 weeks in office to generate a good DTM depending on size and needed detail of the project. One more requirement of using this method is skilled labor force. Compared to other simple techniques, this method requires skilled personnel.

LiDAR system accuracy is around $10^{\text {th }}$ of a foot but it depends on many factors such as accuracy of DGPS onboard, small angular misalignment between laser reference frame and IMU reference plane, accuracy of recording time of reflection of laser errors of GPS base stations etc. One of the main advantages of laser scanning is its active system. It can work at any time whether at day or night as compared to aerial photogrammetry, which cannot work at night. However, the laser scanning provides a high density of points but it does not capture features like buildings, trees, roofs etc. but aerial photogrammetry has all this information with it.

Overall, the LiDAR technology is a modern, versatile and to the most extent automatic method which gives results in very less time thus achieving greater productivity. It also consumes less labor but its initial cost is very high and it's a learning curve for the engineers and surveyors. Still there is a lot of ambiguity connected to the accuracy of a LiDAR system and stakeholders do not know about LiDAR accuracy issues in detail. This results in a very hazy atmosphere with respect to LiDAR and people are reluctant to use it because of accuracy issues and cost restraint for precise works. 


\subsubsection{Terrestrial Laser Scanning (Laser Scanner)}

Use of advanced laser measurement technology in 3D scanning results in a very powerful technology, with which we can measure the position of thousands of points per second. Laser scanning can be performed aerially as well as it can be performed on the ground. Aerial laser scanning is called as Light Detection and Ranging (LiDAR), while on ground laser scanning is called as terrestrial laser scanning.

This system uses time of flight measurement technique and it measures the time taken by a laser pulse as it travels from instrument to an object and reflects back to the instrument. This distance is also combined with the angle of that particular point and finally three dimensional position is obtained for that particular point. This technology is very similar to the technology used in robotic total station but the main difference is that, this technology can measure thousands of points per second while total station technology can measure only four to five points per second. The ability of laser scanner to measure thousands of points per second makes this method more productive, less time consuming on the field and more accurate.

Terrestrial scanning is very useful in surveying and geospatial industry. It has applications in crime scene diagnostics, accident diagnostics, historic restorations, as-built diagnostics etc (Brenner 2006). Generally laser scanner takes very less time on the field while taking data, but it takes a lot of time to analyze that data in the office. Every point cloud collected on the field contains millions of points and one has to clean that point cloud and get the position of points. Some of the instrument manufacturers give on-field software products 
integrated into the instrument, which makes the use of the instrument very user friendly. Companies like Trimble, Leica, Topcon etc. make laser scanners with different ranges and properties.

Leica scanner is shown in figure 2.11. It has a high speed pulsed laser which is used for fast scanning and long ranges. It has two dual axis compensators attached on the both sides of a pulsed laser. The high resolution camera is attached to the high pulsed laser on the center of the instrument for faster target selection. It also has an external bubble level and three screws for horizontal leveling of the instrument.

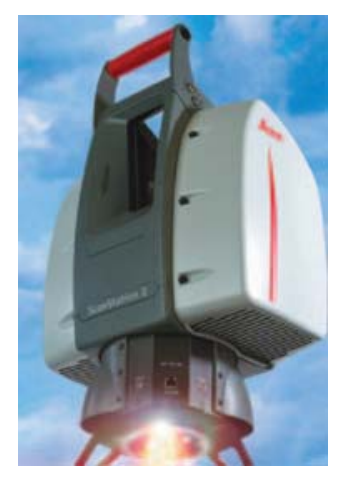

Figure 2.11 Laser Scanner (Source: www.leica.com, Last Visited - 10/13/07)

In the process of scanning, first of all the laser scanner is placed at any known or unknown point. As performed in total station, back sight is taken from that point to get the position of that location. The height of the instrument is also measured accurately. The scanner scans the object to be scanned and some predefined known targets. Then the scanner position is moved to some other point and same procedure is followed as discussed. Figure 2.12 provides a 
pictorial representation of the process, where dots are the predefined known targets, a building as an object and triangles are the positions of the scanners.

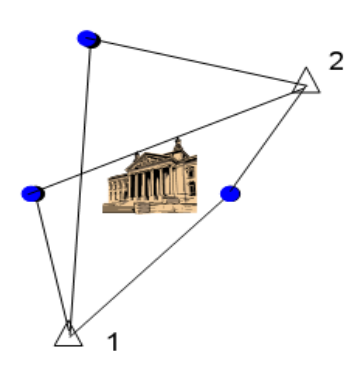

Figure 2.12 Scanner Positions with Predefined Targets (Source: white paper, www.trimble.com, Last Visited - 10/13/07)

The laser scanner's normal range is around 300 meters. Its scan rate is maximum 5000 points per second and its scanning density is around $1.2 \mathrm{~mm}$ maximum on horizontal and vertical plane. Data can be stored in the instrument's inbuilt memory and in external memory on the field and can be transferred to an office PC when the work is completed and the scanner is brought to the office. Laser scanning was not popular in surveying industry till end of $20^{\text {th }}$ century. But now it is getting popularity in the surveying area and people have started using this technology. Main constraints of not using this system are its initial cost (i.e. \$100,000 to $\$ 130,000$ ), lack of versatility and expertise needed to use this technology in appropriate environment at right situations. One other limitation of laser scanning is that it cannot point out to any particular point or object; it gives you the accurate positioning of an area. 


\subsubsection{Vangarde System (VG)}

Longdin \& Browning LTD, UK designed the system called Vangarde in the early 1990s to counteract the lack of safety for surveyors on the highways and to increase the reliability of data collected by the survey team.

To get the existing surface elevation data of any highway or an expressway, surveyors have to go to highways and expressways with high traffic to collect the digital data which an engineer would use to make digital terrain model (DTM) of an existing pavement. In the last two decades, lots of personnel including surveyors and data collectors have lost their lives because of lack of safety (e.g. California Department of Transportation (Caltrans) lost 54 people including 4 surveyors). To increase the safety, transportation departments have to close minimum one lane while necessary data is taken. Some studies also state that the accident ratio increases by $65 \%$ due to closure of one lane and it causes lot of traffic and delays to the motoring public. Due to these reasons; surveyors and personnel were reluctant to go to heavily traveled expressways and highways to collect the data. To counteract this problem, the Vangarde system came into existence. 


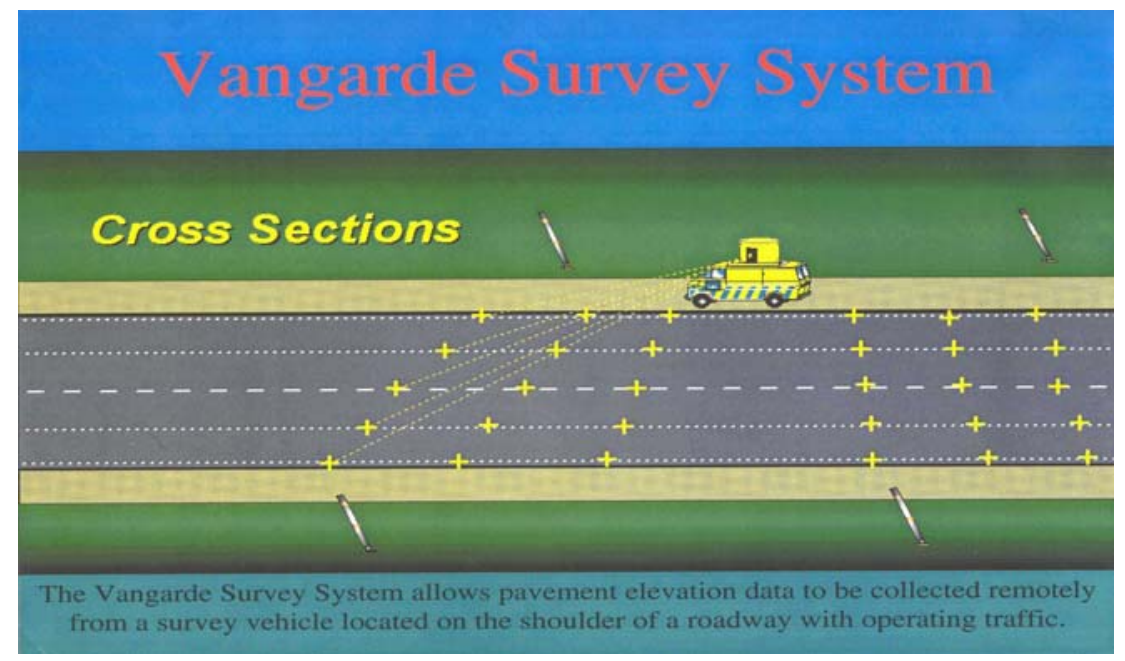

Figure 2.13 Vangarde System

(Source: CALTRANS, http://www.dot.ca.gov/hq/esc/geometronics/vangarde.html, Last Visited 10/12/07)

The Vangarde system is a very unique system. As shown in figure 1 , it has a 1 ton passenger van with fiberglass and a rotating tower attached to the top of the vehicle. Surveying instruments are kept inside that tower, so that a surveyor sits inside that tower and uses those instruments to take the readings on the roadway line.

To conduct a survey with this system, first of all primary survey control is set up using GPS control procedures. These control points are generally set up every two to three kilometers and they are connected to project's horizontal and vertical control bases. Now permanent ground monuments (PGM) set at every 100 meters in a staggered manner along both shoulders to act as a reference while data is being taken. Now the readings are taken at every 100 meters, taking PGM as a reference line and they are directly transferred to the onboard computer. The computer checks these measurements and if there is any error, the readings are taken again at that point and 
than the van moves to the next reference line. At the end of the day, DTM is generated in the software for the visual check.

One of the main advantages of this system is that the topographic data is collected in one pass only; there is no need to come back and forth to take data again. This advantage results into a quick procedure and almost 20\% savings can be generated from greater productivity. Moreover, all the data is collected by staying inside the vehicle, thus increasing the safety and reducing traffic delays. Caltrans and British ministry of transportation has tested this system for the accuracy and they found out an error of less than $2 \mathrm{~mm}$ for a test road of 50 meters.

Caltrans owns around 10 of these instruments and they are using it extensively in their survey activities. North Carolina, Florida, Delaware, Maryland, Georgia, Illinois, and Ohio also use this system through survey consultants who has this system. Some of the firms that have this system are URS, PBS\&J.

In a high Traffic expressway or highway, traffic management can cost as much as $\$ 3000$ for a six hours working day. Use of this system becomes much more economical in every aspects and this system gives good accuracy, quick completion, more safety, no traffic delays and less work. It is very useful where one has to do surveying in a highly traffic contained roads. 


\subsection{Methods for Earthwork Quantity Calculation}

In a construction project, after getting data from one of the methods of data collection discussed above, the surveyor returns to the office and gives the data to the design team. The design engineer using this data, makes different plans, and find out quantities of earthwork cut and fill. Earthwork quantity calculation is not a completely independent variable but it depends upon which method of data collection is chosen for the project. Different methods of quantity calculations are compatible with different methods of data collection.

In this sub chapter, some of the methods of quantity calculations will be discussed which were identified in the literature review. Basically there are two types of quantity calculation methods: 1) manual method 2) use of software product to find out the quantities. Uses of manual methods are mostly outdated in the current market and people are basically using different software products to make their work much easier and faster. But the basic fundamentals of manual methods are used to find the quantities of earthwork while using different software products.

\subsubsection{Manual Methods}

Manual methods of quantity calculation of earthwork consist of mainly two methods: 1) Average End Area Method 2) Cross Section Method. These two methods are widely known and easy to apply in the construction projects. 


\subsubsection{Average End Area Method}

This method of quantity calculation is generally used for narrow areas such as roads or highways. In this method, the site is divided into different stations; the stations are generally 100 feet apart. The lesser the distance between two stations, the more accurate the results are. At each station line, different measurements are taken (e.g. one on center line, one on each edge) and the

profile is made for each station. From the profile of that particular station, the volume of cut and fill is calculated. Finally, the cut or fill area of two adjacent profiles is averaged and multiplied by the distance between them to get the final volume of cut and fill.

\subsubsection{Cross Section Method}

The cross section method is useful for wide tracts such as building projects. In this method, the area to be surveyed is divided into a grid. The size of the grid is dependant upon the area of the site and the level of accuracy required. The lesser the size of the grid, the better the accuracy would be for that site. After dividing the site into a grid, elevation of each grid is measured. Now according to the existing elevation and planned elevation, the cut or fill requirement of each grid box can be measured. Summing up that cut or fill requirement for all the boxes will give the final cut or fill volume of the project.

Data collection instruments like digital level, theodolite, and total station would be compatible with these two methods of quantity calculation. Both methods are very easy to 
understand and apply into a construction project depending upon the situation. But the main disadvantage of these methods are i) Lot of time consumption ii) Personnel requirement to calculate the quantity. So the productivity of these methods is very less compared to software products. Moreover these methods are easy to apply in simple projects but they become very complex when there is a very big or complex project. So, these methods are slowly and slowly getting obsolete.

\subsubsection{Use of Software Products}

Use of software products in designing different plans and particularly in this case finding out the quantity of earthwork has made the work of engineers more smooth and easy. Some of the companies that make software products for quantity calculation are Autodesk, Bentley, Carlson (a sub section of Autodesk), Trimble, CAiCE, Microsurvey, Traverse PC etc. Some agencies have their own customized software product that they use for finding the quantities of the earthwork.

AutoCAD is the most simple and widely used software for the earthwork data collection throughout the United States. People are using AutoCAD for almost last 12 to 15 years. It is one of the base software where engineers prepare their design plan and then either transfer it to some other software product to calculate the quantities or use AutoCAD to calculate the quantities. AutoCAD is used for any type of construction or infrastructure project. It is one of the most versatile programs for designing plans. The AutoCAD is a product of Autodesk and to counteract 
this product, Bentley Systems introduced Microstation, which is also widely used software for the same purposes.

But these days the above mentioned companies are making software products specifically for different segments of construction (e.g. roadway design software, building design software, rail design software etc.). For each segment, they are providing different set of software products and each software product has some different characteristics for different issues. Bentley System apart from Microstation as a base, is providing GEOPAK, InRoads, Bentley powercivil, Bentley PowerSurvey to get solution from the collected field data. At the same time Autodesk apart from AutoCAD, is providing AutoCAD civil3D and AutoCAD land desktop as a solution for designing and quantity calculation. Carlson Company is providing Carlson Takeoff as estimating software which could be very useful for quantity calculation.

These listed software products are very much suitable for total station, robotic total station and GPS surveying where one can transfer the data from field to the computer. For Trimble’s GPS equipment it has different software products called Terra Model and PayDirt. Trimble’s GPS equipment are only compatible with these software products. There are different customized software products for LiDAR and Photogrammetry systems. Different companies like Optech, Geocue, Applanix, Opten, Terrasolid, Terralmaging etc. are making software products for LiDAR applications. These software products are used in combination with either Microstation or AutoCAD. The collected data is first transferred to LiDAR software product and then after processing, the final cross section is made in AutoCAD or Microstation. 
In General, there is a lot of variety in software product market and a software product is basically chosen with respect to the data collection technology. There are other factors like cost, efficiency, productivity, and user friendliness to be looked at while a software product is chosen.

\subsection{Stakeless Construction}

Stakeless construction is defined simply as a construction procedure performed with the construction equipment without the use of stakes as a visual indication/guidance means of designed elevation of any particular point or region. A machine guidance system will be installed in the construction equipment (e.g. excavator, bulldozer, back-hoe etc.) which will be fully automated. This guidance system will provide a visual indicator to the equipment operator of the position of the cutting edge (bucket, blade etc) relative to the design surface being constructed. The system is connected to controls and hydraulics of the equipment, thus machine operator just has to operate the equipment and manage to automation. Application of stakeless construction is mainly in earthwork procedure during construction. Earthwork may be cutting, filling or compacting, stakeless procedures can be used to get maximum productivity in less time with less labor.

Guidance systems used in construction are as following: 1) stakes 2) string lines 3) string lines with sensors 4) lasers 5) GPS 6) Total Station. While first three guidance systems are considered to be manual while the last three guidance systems are used in stakeless construction. In guidance systems like stakes or string lines, surveyors provide stakes to give visual reference 
and grade information to the grade checker. Grade checker reads the grade and guides the machine operator accordingly. Figure 2.14 is a pictorial representation of a stake being provided to guide the machine operator.

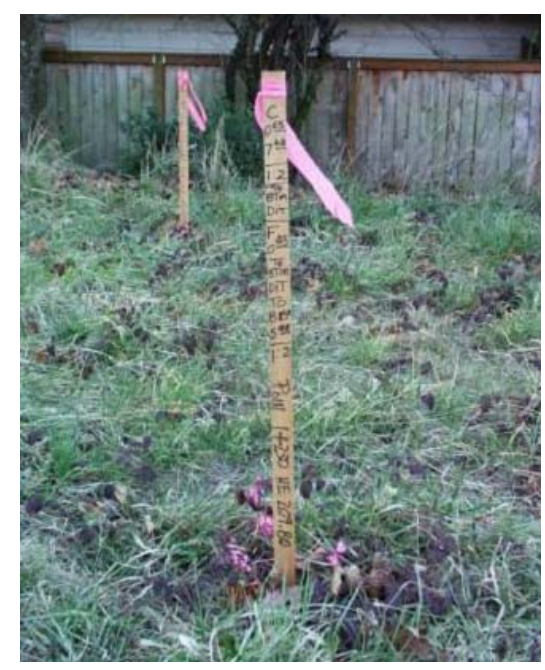

Figure 2.14 Stake Guidance

(Source: http://cms.transportation.org/sites/construction/docs/Gower\%20\%20Stakeless\%20Construction.pdf, Last Visited - 10/16/07)

Lasers were first introduced in 1970s just as an indicator on machine blade. It was attached to the cutting edge of the blade and controller used up and down indicators to control the positions of a blade. But then caterpillar (CAT) came out with the first GPS dozer controller in 1997. Trimble Inc. was the GPS equipment company who provided CAT GPT equipment for dozer control. This machine got popular in mining and military purposes but it didn't get much attention in the construction industry where it could be used to its maximum potential. Dwayne Mcaninch (owner of an earthmoving company in Southern Iowa) gathered with CAT and Trimble Inc. and pushed those companies to make these equipment more accurate to be able to use it in construction. He helped these two companies by giving them advice on what the 
customer really needed and asked them to redesign their machines according to these guidelines. He also gave his earthmoving machines and field to do experiments on these new equipment. Mcaninch invested millions of dollars in this joint venture to support his idea and these two companies with resources. After lot of experimentations, CAT released its first dozer in 1999 with GPS control which was called “Site Vision” with the help of Trimble, Inc.

The stakeless construction and machine guidance system works on the basis of 3-D plans. Till now the plans made by the owners were mostly in 2-D and they were distributed to the contractors and subcontractors as a paper copy and sometimes digital copy. But in this process of construction, the plans are converted to 3-D plans with the use of some software products and then they are given to different contractors and sub contractors in a soft copy as 3-D plans. The GPS system in machine guidance controls can take only 3-D files in it and it works according to the designed final elevations shown in that 3-D plans. The reason behind the need for 3-D modeling is that 3-D grade control systems measure the $\mathrm{X}, \mathrm{Y}$, and $\mathrm{Z}$ coordinates of the machine blade and compares that data with the preloaded digital terrain model. Then the design elevation and cross slope are calculated for the current position and the system moves the blade automatically with the use of machine hydraulics to the correct cut or fill elevation and slope.

The figure 2.15 shows a CAT dozer with machine guidance system attached to it. The GPS (1) receivers are attached to the masts on each side of the blade. They get GPS signals from satellites and give accurate horizontal and vertical positions of the point beneath the blade of a dozer. The accuracy of this position is of centimeter level. Masts (2) are mounted on the blade and they are mainly used to make GPS receiver available to get proper satellite signals. Radio (3) 
is mounted on the roof of the cabin. It is used to get information from GPS base stations which can be used to make position of the points more accurate.

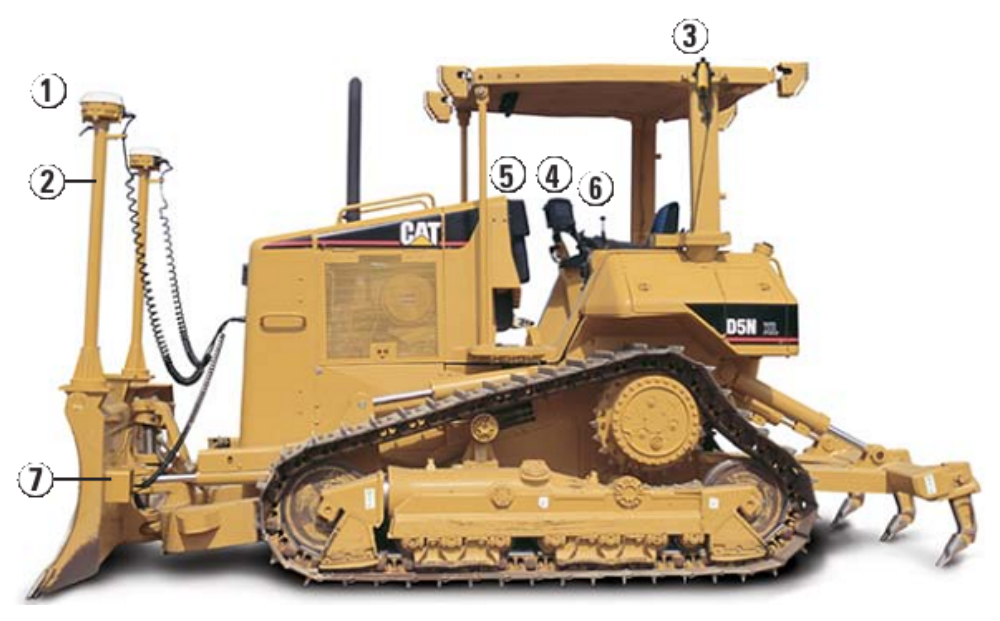

Figure 2.15 A CAT Dozer with GPS system (Source: www.cat.com, Last Visited - 9/30/07)

In-Cabin Display (4) will give an opportunity to operator to see the elevation of the points below the dozer blade relative to design plan. An operator can see different type of views like plan view, cross section view, text view of the information on points below the blade in real time with respect to the designed 3-D plans stored in the GPS flash card. Light bars (5) are placed in the machine cabin and they give indication on the position of the blade with respect to on grade, above grade or below grade. Remote switches (6) give freedom to the operator shifting from manual control to automatic control. In automatic control, the machine itself will govern the blade as per the designed elevation compared to manual control where an operator will control the blade of a machine. Tilt sensor (7) is attached to the back of the blade and it is used to find out the pitch of the blade and this information is useful in automatic control of the machine.

Apart from on board components GPS base stations and GPS satellites are off-board components that are very useful in getting correct position of points on the ground. Software 
products like terramodel, CADD software, Paydirt can be used in the office to make plans and get the quantities of the earthwork done on the field. Another approach of 3-D grade control systems is to use robotic total station instead of GPS. In this process advanced tracking sensors (ATS) are placed on the blade and they use robotic total station to find the elevation of a point beneath the blade at each instance of time. The ATS continuously measures the target's position and send this data to the in-cabin PC. GPS grade controls have precision up to 0.1 foot. However if the ATS is used in combination with total station, the precision gets increased to $+/-0.02 \mathrm{foot}$, which is a great amount of efficiency.

In today's world, lots of contractors are using stakeless construction activities to keep their project on time. The competition among equipment manufacturers is also getting tough these days because companies like Leica and Topcon have also come into this field. Literature also says that one can achieve $30 \%$ schedule savings because of this technology and safety of the project will also be increased. Some of the states like Minnesota, Iowa, New York, Rhode Island have already made specifications of stakeless construction and they also give digital plans to contractors in the bidding (often) and actual project life span. 


\subsection{Conclusion}

The various instruments and methods of data collection for earthwork like theodolite, digital level, total station, GPS, Aerial Photogrammetry, LiDAR, and Vangarde System were presented along with insight into how these instruments and systems work and how it could be helpful in getting earthwork data. Different technologies are best suitable for different conditions encountered. One has to look at different pros and cons of these systems and choose the best one according to the given conditions.

There are number of software products available in the market and one has to go with the software product which is compatible with the data collection method they choose and it should be efficient, productive and user friendly. It should also be compatible in the sense of cost and upgrade requirements with other market products.

In a way, this chapter gives you an overall idea of which technologies are available in the market which could be used to achieve more productivity and efficiency in less time with less labor for big construction projects. The next task is to find out the different properties of each technique and to choose the best suitable technique to solve the problem. The next chapter will consists of the data that had been collected in order to find the characteristics of these methods and to find out the best suitable technique. 


\subsection{References}

Aerial View of Upper Arley, < http://www.arley-arboretum.org.uk/araerial.php >, (Last Visited 8/30/2007)

Brenner, Claus (2006). “Digital Recording and 3D Modeling”, International Summer School, Greece, 24-29 April, 2006.

“CALTRANS”, <http://www.dot.ca.gov/hq/esc/geometronics/vangarde.html>, (Last visited 9/2/2007)

Dagostino, Frank R., Feigenbaum, Leslie. (2003). Estimating in Building Construction, Prentice Hall, Inc., Upper Saddle River, N.J.

$<$ http://cms.transportation.org/sites/construction/docs/Gower\%20\%20Stakeless\%20Construction. pdf >, (Last Visited - 9/3/2007)

<http://www.cenews.com/article.asp?id=618 >, (Last Visited - 8/2/2007)

Leica TPS 1200, <http://www.advancedlasers.com/images/tps1200.jpg>, (Last Visited 8/29/2007)

"New LiDAR Technology Helps U.S. Army Corps of Engineers Deal With Ages-Old Erosion Problem in Great Lakes Region”, $<$ http://www.woolpert.com/asp/articles/New_LiDAR_Technology.asp>, (Last Visited 8/29/2007)

“Ohio Department of Transportation”, <http://www.dot.state.oh.us/>, (Last visited - 9/1/2007)

Robotic Total Station, <http://www.teamelmers.com/surveying.htm>, (Last Visited - 8/22/2007)

Sokkia Robotic Total Station, <http://www.jobsitesurvey.com/23choosets.htm>, (Last Visited 8/19/2007)

“Surveying and Mapping: History, Current Status, and Future Projections”, $<$ http://scitation.aip.org/getabs/servlet/GetabsServlet?prog=normal\&id=JSUED20001280000 03000079000001\&idtype=cvips\&gifs=yes>, (Last Visited - 8/2/2007)

Trimble DiNi Digital level, <http:/www.trimble.com/graphics/dini.jpg>, (Last Visited 8/28/2007)

Wolf, Paul R., Ghilani, Charles D. (2002). Elementary Surveying: An Introduction to Geomatics, Prentice Hall, Inc., Upper Saddle River, N.J. 


\section{CHAPTER 3. DATA COLLECTION}

\subsection{Introduction}

This chapter illustrates the steps taken to collect data regarding various properties of the methods and techniques discussed in the previous chapters used in earthwork data collection (cut and fill), various techniques and software products used in quantity calculation of earthwork and modern methods of construction used by some of the contractors.

The main objective of this activity was to collect data regarding the current methods used by different DOTs throughout the US as well as different surveyors and contractors throughout Indiana. Data was also collected with respect to the advantages, disadvantages, labor requirement, accuracy, training requirement, training cost, equipment cost, maintenance requirement, etc., from DOTs, surveyors/contractors and manufacturers as well as dealers of surveying equipment and software products.

The following tasks were performed in order to achieve the above stated objectives: 1 ) Telephone interviews with INDOT surveyors 2) Questionnaire survey to all the state DOTs 3) Personal interviews with equipment and software vendors 4) Questionnaire surveys for professional companies in Indiana 5) Questionnaire surveys for equipment companies and software companies and 6) Case studies (with owner and contractor) of construction projects 
with large earthwork quantities. Following sections would give a detailed description about these tasks.

\subsection{Telephone Interviews with INDOT Surveyors/Engineers}

Telephone interviews with INDOT surveyors and engineers in different districts were conducted to determine the current INDOT state of practice in terms of methods used for earthwork data collection, techniques used for earthwork quantity calculation and related properties of those methods and techniques as well as problems (if any) faced by the surveyors and engineers using these methods. A total of five telephone interviews were performed

\subsubsection{Collected Data from Interviews}

In order to collect the data regarding the current technology used and related properties of that technology for earthwork process, several questions were asked to all the interviewees. A list of questions is given in Appendix 1. The questions were related to current technology used in earthwork data collection, personnel requirement to use that technology on field, labor cost/hr, equipment company, cost of equipment, average life of that equipment, horizontal and vertical accuracy of the equipment, advantages and disadvantages of those technologies, technology used 
before using this technology, software used to calculate the quantity, engineer requirement to perform quantity calculation in office, software products used before using this software product, training requirements for these technologies and software use, and their personal opinion about all the available technologies and software products.

Table 3.1 illustrates the data collected from interviewee- 1 and the type of questions asked and the replies received from interviewees. The data collected from all the interviewees is analyzed in the data analysis section (Chapter 4).

Table 3.1. Data collected from Interviewee 1

\begin{tabular}{|c|c|c|}
\hline No. & Questions & Interviewee 1 \\
\hline 1 & $\begin{array}{l}\text { Earthwork data collection } \\
\text { method }\end{array}$ & $\begin{array}{l}\text { Mostly Total Station, Use of RTK GPS for the first time in } \\
\text { the current project (after witnessing the productivity and } \\
\text { efficiency of GPS) }\end{array}$ \\
\hline 2 & $\begin{array}{l}\text { Personnel requirement for } \\
\text { above stated method }\end{array}$ & $\begin{array}{l}\text { Total Station: } 3 \\
\text { GPS: } 2\end{array}$ \\
\hline 3 & $\begin{array}{l}\text { Average cost of } \\
\text { personnel/hour }\end{array}$ & $\$ 70 /$ team \\
\hline 4 & Equipment company & $\begin{array}{l}\text { Total Station: Sokkia } \\
\text { GPS: Trimble }\end{array}$ \\
\hline 5 & Cost of Equipment & $\begin{array}{c}\text { Total Station: } \$ 15,000 \text { to } \$ 30,000 \\
\text { GPS: } \$ 30,000 \text { to } \$ 40,000 \text { (including rover, radio link, } \\
\text { tripod, software etc.) }\end{array}$ \\
\hline 6 & Average life of equipment & $\begin{array}{l}\text { Total Station: } 10 \text { to } 15 \text { years } \\
\text { GPS: } 10 \text { to } 15 \text { years }\end{array}$ \\
\hline 7 & Horizontal accuracy & $\begin{array}{l}\text { Total Station: } 0.03 \text { feet } \\
\text { GPS: } 0.04 \text { feet }\end{array}$ \\
\hline 8 & Vertical Accuracy & $\begin{array}{l}\text { Total Station: } 0.03 \text { feet } \\
\text { GPS: } 0.08 \text { feet }\end{array}$ \\
\hline
\end{tabular}




\begin{tabular}{|c|c|c|}
\hline 9 & $\begin{array}{l}\text { Pre and Post construction } \\
\text { method }\end{array}$ & Same \\
\hline 10 & $\begin{array}{l}\text { Method used before using this } \\
\text { method }\end{array}$ & Auto Level and Rod \\
\hline 11 & Advantages & $\begin{array}{l}\text { Total Station: No requirement of satellite availability, } \\
\text { good accuracy with both horizontal and vertical direction, } \\
\text { easy to use } \\
\text { GPS: Fast, direct readings from the instrument, } \\
\text { comparable accuracy, less personnel requirement }\end{array}$ \\
\hline 12 & Disadvantages & $\begin{array}{l}\text { Total Station: Time consuming, cannot use in all terrain } \\
\text { situations } \\
\text { GPS: Costly in comparison to total station, depend on } \\
\text { satellite availability, not applicable on all terrain }\end{array}$ \\
\hline 13 & $\begin{array}{l}\text { Software used for quantity } \\
\text { calculation }\end{array}$ & AutoCAD (Average end area method) \\
\hline 14 & $\begin{array}{l}\text { Software used before using the } \\
\text { current product }\end{array}$ & Quick Quantity (very old, cumbersome and outdated) \\
\hline 15 & Accuracy level & $\begin{array}{c}\text { Good accuracy, easy to apply, no cases happened so far } \\
\text { when contractor has claimed because of different } \\
\text { quantities }\end{array}$ \\
\hline 16 & Engineer requirement in office & 1 \\
\hline 17 & Training Requirement & $\begin{array}{l}\text { INDOT does not give training, it will be great if the } \\
\text { personnel are given training to use new equipment (to use } \\
\text { GPS, they trained themselves and applied it) }\end{array}$ \\
\hline 18 & Their own Take & $\begin{array}{l}\text { Given the opportunity to choose a method, the respondent } \\
\text { would apply RTK GPS, it is useful not only in earthwork } \\
\text { data collection but it would be useful in super elevation, } \\
\text { location findings etc. }\end{array}$ \\
\hline
\end{tabular}

\subsection{Questionnaire Survey for State DOTs}

A questionnaire survey was sent to all the state DOTs throughout the United States to get the data regarding their current state of practice as far as earthwork data collection and quantity calculation is concerned. 
Main objectives of the Questionnaire Survey were to get a general idea on:

- Current state of practice of different state DOTs in earthwork data collection methods

- Techniques used by different DOTs in earthwork quantity calculation

- Different properties of the currently used methods as far as earthwork process is concerned

- Training requirement, cost and duration

- Suggestions on different technologies based on the experience of the participant

According to the objectives of this task, a questionnaire survey was formed. A sample copy of the questionnaire survey is attached in the Appendix 2. Because of the time constraints, the researchers had only one opportunity to send questionnaire survey to all the DOTs. In order to make sure that all the appropriate questions were asked in order to gather the required information, several reviews were performed and the questionnaire survey was discussed with Study Advisory Committee (SAC) members before sending out to the different DOTs.

There were mainly two parts in the questionnaire survey prepared for DOTs. The first part contained questions regarding earthwork data collection and the second part included questions pertaining to quantity calculation of earthwork, training requirements and participant's personal choices regarding these methods and techniques depending on his/her experience in this field. It could happen that the organizations use one method to collect data on the field before construction and use another method after construction depending upon the efficiency and productivity requirements, precision constraints, monetary issues, atmospheric conditions, labor availability etc. So, the data collection part was divided into two segments: 1) As is earthwork 
quantity assessment stage (Earthwork data acquisition prior to construction to establish the approximate quantity of earthwork required) and 2) Earthwork pay quantity verification stage (Earthwork data acquisition post construction to establish the actual quantity of earthwork and pay quantity verification). Both segments had the same questions other than that both stages occur at different time period in any construction project. Two tables were made for these segments and each table had several options of techniques used in earthwork data collection. These techniques were found in the literature review stage. Participants had to choose the techniques they use in the preconstruction stage. They could choose more than one techniques depending upon the nature of the project (Kavanagh 2001). There was an option for “others”, which meant that if participant was not using any of the mentioned techniques in the preconstruction stage then he/she could write their technique in the "others" row. There were several other columns in those two tables, each column asked particular information about the technique used by the responder/participant. The body of the table was such that, participants would write information regarding their particular technique in the same row where they have check marked their technique. By this way, there was no ambiguity in the information that they provided and it became user friendly as well.

If some participants were using the same techniques for both pre and post construction, i.e., in both 'as is earthwork quantity assessment stage' and 'earthwork pay quantity verification stage', they just had to check mark a question which was asked in the beginning of the second segment, so they didn’t have to write the same information again in the later segment. 
The first two columns in that table asked for information on technology used for projects up to 3 miles in length and for more than 3 miles in length. The length of the project can be a major factor in choosing a technique for a project, and it was determined during literature review and personal interviews that INDOT and other agencies change the method for more than 3 miles long project. The next two columns asked for the personnel requirement for the particular methods chosen and approximate time required to collect data of 1 mile of regular and irregular terrain with chosen method. The "personnel requirement" gave an idea on how many surveyors and assistants were required for that particular technique, while the other column gave a ballpark figure on efficiency of that particular method by giving an estimation of time required to collect data for regular and irregular terrain. Some techniques work better in regular terrain and some work efficiently in irregular terrain. To differentiate techniques on this issue, a question was asked on the basis of regular and irregular terrain. The next two columns had questions requiring information about the average cost of personnel and instrument manufacturer for their particular technique. The cost as well as the instrument manufacturer information provides an approximate idea about the popularity of an instrument among all the DOTs. The next four columns asked about the cost of the instrument used in that particular technique, average life of that instrument and horizontal/vertical accuracy of the instrument used in that technique. Cost and average life of an instrument would be useful in finding the affordability of that instrument while horizontal/vertical accuracy would be useful in deciding which technique to go for if we require high accuracy or low accuracy. The last two columns had the questions regarding advantages and difficulties associated with the chosen technique. These two columns will give suggestion on choosing a technique depending upon their pros and cons. 
As mentioned earlier, both the segments (i.e. pre-construction and post-construction) had same questions, but the questionnaire had some more questions for the LiDAR and Photogrammetry techniques. As the equipment used in these techniques are very costly, the questions were mainly regarding owning or renting, cost of renting, fuel requirement, cost of sub contracting using these techniques, type of aircraft used etc. All this information would lead to a comparative analysis of all the techniques with respect to cost, personnel requirement, time constraints, accuracy, advantages and difficulties. Now apart from these tables in earthwork data collection stage, two more questions were asked regarding previously used method by the participant and the reason behind changing to the current method in order to identify limitations of some techniques.

The second part of the questionnaire survey was on earthwork quantity calculation, training requirements and some personal choices of the participant for earthwork procedures as mentioned before. It contained 10 questions on quantity calculation process, 3 questions on training issues and 2 questions on personal choices for the future earthwork processes. The first three questions under the quantity calculation part were regarding the method and software used by the participant providing information about the widely used software products among the state DOTs. The second set of questions under the quantity calculation part was regarding the accuracy level, advantages and disadvantages of software products used by different participants. The third set of questions was regarding the number of engineers required in the office and approximate time required to find out the quantities. These questions would be useful in finding the cost of personnel in the office for the given amount of work. Additionally questions were asked about the past software products used by the participants and if they had changed it to 
some other products. The participants were asked to describe the reason for change in order to identify the limitations and advantages of available software products.

The next set of questions were designed to identify the general cost of the training, duration of the training and the frequency of training given to engineers and surveyors by participating state DOTs. The last set of questions in this questionnaire survey was regarding personal choice of the participant with respect to the data collection technology and the reasons for that selection. Participants were also asked about their knowledge about the modern satellite systems like GLONASS and GALILEO and their use in the data collection process (Leick 2004).

The questionnaire survey went through number of reviews by the research team and finally the SAC committee reviewed it. All the comments made by SAC committee were included and then it was sent to all the 50 DOTs in the US. However since not all DOTs have a separate survey department but part of the design department, it was decided that if a DOT does not have a survey department then the questionnaire survey will be sent to the design department.

Twenty five (25) DOTs out of 50 DOTs responded to the questionnaire survey resulting in a response rate of $50 \%$. A detailed subjective analysis on the responses of the questionnaire survey is provided in the data analysis chapter. 


\subsection{Personal Interviews with Equipment and Software Vendors}

To collect data regarding current methods and technologies for earthwork data collection and quantity calculation, personal interviews with equipment and software dealers were conducted. The dealers generally sell equipment and software products of multiple companies as they have franchise of multiple equipment manufacturing companies and software making companies. The main idea behind interviewing the dealers was to get an unbiased opinion on different instruments and software products of different companies.

In order to collect data from dealers, two interviews were performed with dealers who held franchise for different companies. Both the dealers were located in Indianapolis area. A list of questions was prepared for equipment and software dealers to get the data regarding properties of different equipment and software products. A list of questions is given in Appendix 3.

\subsubsection{Interview 1: Seiler Instruments}

Seiler Instruments is situated in Indianapolis and they are dealers of Trimble and Sokkia products for earthwork data collection. They are also dealers of Autodesk and Trimble software products, which are useful in finding out the quantity of earthwork. They sell mainly Trimble products, however they have dealership of very few Sokkia products. 
The representative of the Seiler Instrument provided detailed information on different Trimble products, which can be used effectively on a project site and in office to get good productivity and efficiency in the project. The dealer explained the latest GPS and robotic total station instrument manufactured by Trimble. The latest GPS product is called Trimble R8 GNSS (global navigation satellite system) system. This GPS system is compatible with both GPS satellites and GNSS satellites (Russian satellite system with 18 satellites so far in space and aiming for 24 satellites by the end of 2010-2011). The main advantage behind this type of compatibility is to use the signals of both the satellite systems and try to get data from as many satellites as one can. In this way, the error rate gets decreased in the GPS data (because of better satellite visibility). For different scenarios, the surveyor gets the following accuracy with the use of Trimble R8 GNSS system.

Table 3.2. Different GPS techniques and related Accuracies (Source: Wolf at al. 2002, Leick 2004)

\begin{tabular}{|c|c|c|}
\hline Type of GPS positioning & Horizontal Accuracy & Vertical Accuracy \\
\hline Differential & $\pm 0.25 \mathrm{~m}+1 \mathrm{ppm}$ RMS & $\pm 0.50 \mathrm{~m}+1 \mathrm{ppm}$ RMS \\
\hline Static and Fast Static & $\pm 5 \mathrm{~mm}+0.5 \mathrm{ppm}$ RMS & $\pm 5 \mathrm{~mm}+1 \mathrm{ppm}$ RMS \\
\hline Kinematic & $\pm 10 \mathrm{~mm}+1 \mathrm{ppm}$ RMS & $\pm 20 \mathrm{~mm}+1 \mathrm{ppm}$ RMS \\
\hline
\end{tabular}

For all the above stated scenarios, the initialization time for the equipment is generally less than 10 seconds and its initialization reliability is greater than 99\%. Table 3.2 shows that one 
can achieve centimeter accuracy with the use of this equipment. To use this R8 GNSS system on any site, the rover (GPS receiver) is connected to the base station which is either on site or to a network of permanent base stations. Seiler Instruments has their private base station network in the south western part of Indiana where a lot of contractors and private surveyors use it for their work. The rover has either a cell phone connected to it which gets data from the base station or a radio link is connected to the rover, which in turn will get the data from the base station. The radio link is generally working in the radius of $10 \mathrm{~km}$ range but cell phone has a wider range. Some users use both radio and cell phone coverage. First they use cell phone coverage and wherever they don't find good signals, they set up their own base station and use radio signals to collect the data in data collector. Figure 3.1 shows a R8 GNSS rover with a data collector attached to it.

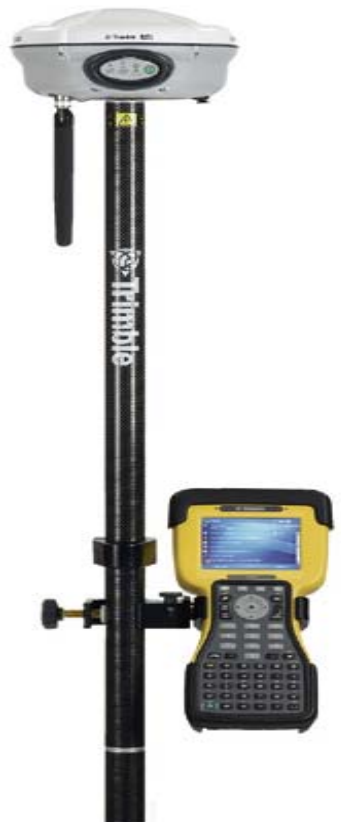

Figure 3.1: Data collector (controller) on GPS rover

(Source: www.trimble.com, Last Visited 11/11/07) 
The GPS rover, which contains a receiver and a battery, costs about $\$ 24,000$. This rover can also be used as a base station in case an onsite base station is required. The data collector comes for around $\$ 5,200$ and radio link costs generally around $\$ 3,400$. Radio link can be mounted on a tripod or it can be attached to the rover itself. Sometimes, on small construction site, GPS users don't have to buy the radio link, but they can use in-built radio link of GNSS system.

The dealer also provided an insight into Trimble's Virtual Reference Station (VRS) technology which is used in number of base station networks in different states. The VRS technology uses RTKNet software in its solution package, which utilizes a CORS network to provide a fully modeled RTK solution to rovers. The solution takes into consideration ionospheric and tropospheric factors as well as orbital reporting error to obtain centimeter-level positioning. With the use of VRS technology, the dealers claimed that ppm error would go away and an accurate result can be achieved. The main advantage of this technology is that, the user doesn't need to put any extra effort in reducing the errors, but the software itself does the work for the user. North Carolina, South Carolina, Ohio etc. have this type of statewide network in their state. Moreover, 8 to 9 countries in the world have this network countrywide for their use. In a way, this technology is very popular and has proved better productivity and accuracy worldwide.

The dealer also gave information on Trimble's latest robotic total station named 'Trimble S6 Total Station'. This equipment has similar features as Leica Smart Station (combination of robotic total station and GPS) and these two equipment are each other's main competitor in the 
surveying market. This equipment is a combination of GPS and robotic total station. Generally customers take the GPS rover and robotic total station to their site as shown in figure 3.2. The data collector for both of these equipment is the same (figure 3.2). Customers can start with any of the equipment and then transfer to the other one in no time if the situation asks to change the equipment. The data is stored in the single data collector for both GPS and robotic total station.

GPS Rover

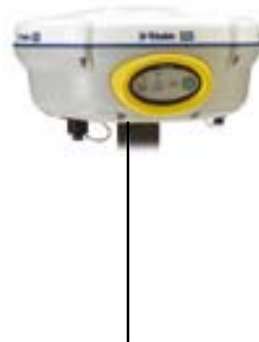

Robotic Total Station

Data Collector
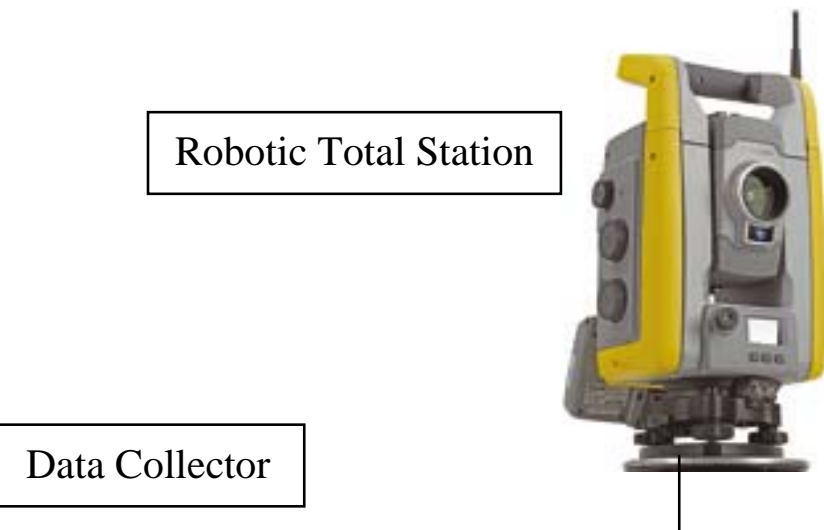

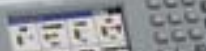

픈

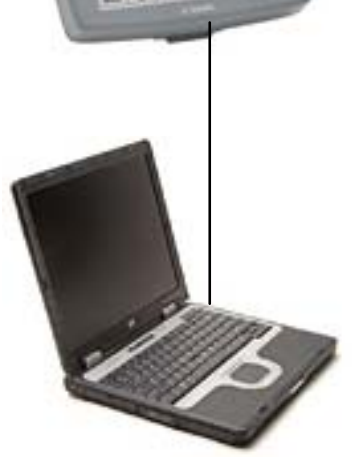

Figure 3.2: Seamless and Simple Surveying (source: www.trimble.com, Last Visited 11/10/07)

After the work is completed, the data is transferred to the computer and the software automatically differentiates between the GPS data and the robotic total station data. So in a way 
it's a seamless and simple transfer of data from different equipment to the computer with very less labor and less time consumption.

Technically, only 1 surveyor is required on the field when using any of these two equipment (i.e. R8 GNSS system or S6 Total Station) but most surveying crews have 2 men, one person handling all the surveying operations while the other performs miscellaneous works. There is no need of a person standing at the total station position in the robotic total station (RTS) equipment. But the only limitation with RTS is its requirement of line of sight. The cost of RTS is around $\$ 40,000$. Trimble Inc., has also manufactured the scan station, which is called “Trimble VX Spatial Station”. It is very useful in cases where the measurement has to be taken on the bridges, overhangs, and buildings. It has an advantage of reflector-less measurement,

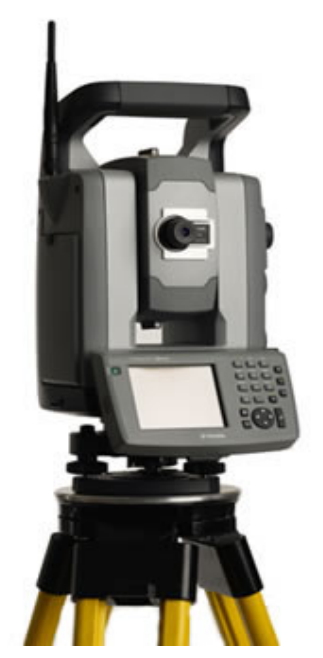

Figure 3.3: Trimble VX Spatial Station (source: www.trimble.com, Last Visited 11/2/07) 
so there is no need for a person standing at the object with a reflector such as a prism. Generally this scan station is used within the range of 300 meter, but the range is also dependant on the reflectivity of the object. The cost of this instrument is around $\$ 75,000$. As it is very expensive, it has a very small customer base.

Usually, Total Station needs yearly maintenance in the form of calibration. The charge of the yearly maintenance is around $\$ 300$. GPS doesn’t require any calibration and there is as such no requirement of maintenance in GPS. The dealer mentioned that there were lot of customers who have used their GPS equipment for last 6 to 7 years and they were still working properly. The main difference between the old and new instruments is the weight and speed at which they work.

Seiler Instruments give training in their office and also on site. They have a special training room in their office and charge a flat fee of $\$ 1,000 /$ day independent on the number of trainees. While on the job site, they charge the same $\$ 1,000 /$ day, but they allow maximum 10 to 12 trainees in one session. This training on instrument usage and software usage last for 2 days and they have technical support which can be reached via phone all day long. As discussed before, they have their private network of GPS base station in south western Indiana, Missouri and in Milwaukee. They take $\$ 400 /$ month as a charge from the customers who use that network. Seiler Instruments also give surveying instruments on rent. For GPS, which includes rover, base station, radio and data collector, the charge is around $\$ 500 /$ day, $\$ 2,000 /$ week and $\$ 4,500 /$ month. For total station, the charge is $\$ 300 /$ day, $\$ 1,000 /$ week and $\$ 3,500 /$ month. 
The dealer also gave some information on the compatibility of these instruments with different software products. The most compatible software product with robotic total station and R8 GNSS system is Trimble Geomatics Office (TGO). The cost of this software is around $\$ 5,000$. There are some other software products like AutoCAD 2008, Microstation, etc., which are also compatible with these instruments. Generally in road construction, the area is likely to be open from the sides, which will allow the use of GPS and thus fast data collection.

Seiler Instruments are also dealer for Sokkia, but they sell very few Sokkia products. They said that the product development of Sokkia lags behind all the other leading companies. Moreover their market share in United States is also very less. So from the cash flow perspective, they don't have that much cash to put into research and development of a product. Sokkia doesn't have the local dealers which help you or give you training. They can talk to you on the phone, but they cannot come to the site.

The interview gave an insight into Trimble's products which can be used on big construction project site and better productivity and efficiency can be achieved.

\subsubsection{Interview 2: Advanced Lasers and Instruments}

Advanced Lasers and Instruments Inc. is situated in Indianapolis, IN. They are the vendors for Trimble, Leica, Sokkia and Nikon. They sell Trimble construction instruments, Leica survey instruments, Sokkia construction and survey instruments and some Nikon instruments 
also. There are mainly three dealers for the above stated companies in Indiana for survey and construction instruments. Moreover, each and every dealer has the monopoly in kind of instruments they are selling. As a result, there is no competition for them in the state so far.

The first and foremost thing the dealer said that the owners (i.e. INDOT) should specify software requirement in the bid document so that both owner and contractor work on the same plane and there is no discrepancy as far as data collection and data transfer is concerned. They also stressed on the fact that the preconstruction data collected should be as accurate as possible so that the possibilities of disputes are minimized.

The dealer recommended some software packages that were most useful for earthwork quantity calculations such as the software products made by Carlson and Trimble including Carlson Survey 2008 and Carlson Road 2008. The 'Paydirt' software made by Trimble was specifically designed for quantity calculation in a construction project. However, the dealer also pointed out that Trimble had not made any changes to this software since last decade. The dealer suggested that the 'Terramodel' software made by Trimble, Inc. was a very powerful design software which can be used for the quantity calculation of the earthwork. However because of its complexity, if a user doesn't know how to use it properly he/she can have a lot of problems in using it. So proper training is required in order to use this software product. The dealer mentioned again and again that the flow of the data transfer should be seamless internally in the organization as well between the parties working on the project. This seamless transfer would increase the productivity of the work and it would result in less time consumption and better profitability. 
One of the dealer employees illustrated the impact of time-of-the-year when the data is collected. He said that if the data is collected in winter, the data could be different if it is collected in summer at the same place. There is no control on the variability of data due to natural changes. So weather conditions and environmental conditions do affect the data collection procedure in the field. The dealer was mainly selling auto/digital levels, total stations, robotic total stations, GPS and laser scanners. According to the dealer, every instrument would have the basic features; however, some might have better quality, some might have low cots, some may have extra features, some might give extra batteries and they could be more userfriendly. The dealer said that in total station category, 'Trimble S6' and 'Leica 1200' are really good instruments. They also said that they would recommend the customer which equipment to use, depending on their requirement. The dealer mentioned that if a customer was a contractor and if he didn't know much about surveying, then they would recommend Trimble instruments as they were easy to understand and simple. But for a professional surveyor, they would recommend Leica instruments as they were really powerful and more complex than the Trimble instruments.

The dealer provided training generally ran between 1 day and 2 days depending upon the knowledge of the customer on that particular issue. The dealers generally provided one day free training when a customer buys the instrument or software product from them. If additional training was needed then they would charge $\$ 1000 /$ day as a flat fee or $\$ 295 /$ person from the customer. They were also a full service/maintenance center for the survey instruments. The dealer mentioned that generally the service life of these instruments was very long, but instruments like total station and digital level required yearly maintenance. The dealer pointed 
out that the customers should check calibration of instruments every 6 months and total check up every 1 year. They had a system which would check around 168 points of the total station and would tell if there is any problem in the instrument. Their charge for this total check up for total station was $\$ 500$ and for robotic total station, it was $\$ 1200$. They also provided instruments on rent. Their normal charge for the rent was generally $10 \%$ to $12 \%$ of the price of the instrument per month.

The dealer also gave some insights into the cost of these software products and equipment. The Trimble software products were most expensive. The 'Terramodel' software cost about $\$ 9,000$ while the 'Paydirt' software cost about $\$ 7000$. The Carlson software products cost from $\$ 1500$ to $\$ 4,000$. While Bentley products ranged from $\$ 4000$ to $\$ 7000$. In terms of instruments, Trimble was the costliest one, and Sokkia was the cheapest one. According to the dealer, total station could range from $\$ 8,000$ to $\$ 15,000$ depending upon the features and manufacturing company. The Robotic Total Station could range from $\$ 30,000$ to $\$ 40,000$ and GPS equipment could range anywhere from $\$ 40,000$ to $\$ 50,000$ depending upon the company and feature requirement. (Refer to the list of references at the end of the chapter)

In the last segment, the dealer gave general summary on different companies' equipment. The dealer said that for machine control and in construction, Trimble instruments were better. They said that effective marketing had made Trimble very popular in comparison to other companies. For core surveying purpose, the dealer suggested to go for Leica instruments because of their powerful mechanism and extensive features. The dealer also said that Topcon equipment were better in GIS applications and in location activities. The Sokkia equipment had one major 
advantage of low cost, which made them sustainable in the market. In a way, the Advanced Lasers and Instruments Inc.'s employees gave some good insights into different instruments and software products.

\subsection{Questionnaire Survey for Professional/Surveying Companies}

A questionnaire survey was conducted in order to establish the current state of practice of private surveying/professional companies. The purpose of this questionnaire survey was to collect objective and subjective data with regard to various methods and tools used by different professional companies throughout the US for acquisition and analysis of earthwork pay quantity verification data for a construction project. Almost 35 Indiana based surveying and contracting companies were selected for this questionnaire survey, and a questionnaire was sent to them via email. These 35 companies were called personally after sending them emails to let them know about this project.

The questions asked in this questionnaire were almost similar to the questions asked in the DOT questionnaire survey. The main objectives behind those two surveys were identical but the parties were different in both the cases. One additional question was asked in this questionnaire. The question was on the approximate unit price contractors generally charge from the owner. 
The Professional/Surveying Companies were slow in responding to the questionnaire. After a lot of attempts with phone calls and emails, 10 companies replied to the questionnaire. Two of those participants didn't have time to fill the questionnaire, so they were asked questions on the telephone and the researcher wrote down the replies given by those participants. An in depth analysis of the responses (both through emails and telephone) is presented in the next chapter.

\subsection{Questionnaire Surveys for Equipment Companies}

Similar to the questionnaire surveys sent to state DOTs and Indiana based surveying/professional companies, a questionnaire survey was sent to equipment companies to cover all the parties involved in the earthwork process i.e. owners (state DOTs), contractors (i.e. surveyors), equipment manufacturers and software producers. The rationale behind this questionnaire was to collect objective and subjective data with regard to various equipment and software produced by different equipment companies throughout the US for acquisition and analysis of earthwork pay quantity verification data for any construction project. Five big companies were selected - Leica, Trimble, Topcon, Sokkia and TDS/Berger and a questionnaire survey was sent to all five companies through emails. A copy of the questionnaire survey is provided in Appendix 4. 
The questionnaire survey was divided into mainly three parts. The first part was regarding the equipment for data collection, second part was for the software products for quantity calculation and third part was regarding participant's own opinions on these different technologies and methods. The software products section in this questionnaire was only with respect to the compatible software with the specific instrument. There was a separate questionnaire only for software producers, which is described in the next sub chapter. Most of this questionnaire was in the form of a table which was also described earlier in the state DOT questionnaire (refer to Appendix 4). There were three tables in the first part, i.e., equipment for data collection. The first three columns contained questions on name and cost of models produced by that specific company for the technologies applicable to them. The research team assumed that each manufacturer would have some data regarding the speed of the equipment. So the next two questions were with respect to the time taken by that specific model to collect data for 1 mile in regular as well as rough terrain. The three subsequent questions asked about the accuracy and competitive advantages for each model specified by the respondent for data collection of earthwork.

The next set of questions were regarding some of the characteristics of the instruments namely in-built data collection memory, measuring range, service life, battery requirement, battery life, etc. These questions would be useful in getting all the major and minor details of the specific model. These properties also play an important role in selecting instrument/model for earthwork data calculations. The last set of questions associated with equipment was the requirement of personnel on field, training duration and training cost. All the equipment 
manufacturers provide training to their client for different equipment and software products. There is a fair bit of a cost associated with the training, which could be per day or per person.

Questions were asked regarding compatible software products produced by those equipment companies with respect to the instruments. The questions related to the compatible software (if any), any other specified software, licensing fee of that particular software, cost and duration of the training for software and accuracy of software. The last section of this

questionnaire was related to personal opinion of the participant on different techniques of earthwork data collection and quantity calculation. They were asked to give their recommendations on which technique and software should be used to get maximum productivity with optimum labor in earthwork data collection and quantity calculation.

The equipment companies seemed to be not interested in the questionnaire, but after a lot of emails and calls, two companies responded to the questionnaire survey. The analysis of those two questionnaire survey is given in the data analysis chapter.

\subsection{Questionnaire Survey for Software Companies}

Lastly, software producers for earthwork quantity calculation were surveyed to gather information about their products. A short questionnaire (Appendix 5) was developed for the software producers. The purpose of this survey was to collect objective and subjective data with 
regard to various software products used for analysis of earthwork pay quantity verification data for any construction project. Questions were mainly asked related to different software manufactured by that particular company, versions of that software, compatible computer operating system, licensing fees, maintenance requirements and fees, training duration and cost, accuracy, special features of that particular software and the personal opinion of the participant on using a software for earthwork quantity calculation.

Five software companies were contacted for this questionnaire survey - Autodesk, Bentley, Carlson, Microsurvey and Traverse PC. Questionnaire survey was sent to them via email. After a lot of effort, one company representative agreed to give information on the phone, so a telephone interview was conducted and data was collected. So, the success ratio here was one out of five. Other companies replied back by giving their website information and asked to

collect the relevant data from their website. The same incident happened in the case of equipment companies also. One of the equipment company also replied back with the same argument. The analysis of the software products is given in the data analysis part.

\subsection{Case Studies}

Two case studies were performed in this project in order to get an idea about the current technologies used for earthwork data collection and quantity calculation on big construction projects where earthwork volume is very large. Other objective of this activity was to determine the generic procedure adapted by different contractors and owners for earthwork data collection and quantity calculation in any construction project. Also the case studies helped find out the 
problems faced by different parties involved in the project during design and construction stage, type of training provided to INDOT personnel to use the modern technologies in earthwork data collection and quantity calculation.

One case study was performed on the contractor side and the other case study was performed on the owner side to get an insight from the main parties involved in the earthwork process. A list of questions was prepared for the case study for both contractor and owner. A partial list of the questions is included in Appendix 6.

\subsubsection{Case Study: SR 48 Reconstruction}

The SR 48 reconstruction case study was done with the prime contractor involved in that project. The information found out in this case study was related to the contractor side.

Table 3.3 General Description on SR 48 Reconstruction Project

\begin{tabular}{|l|l|}
\hline \multicolumn{2}{|c|}{ General Description } \\
\hline Project Name & SR 48 Reconstruction \\
Location & Lawrenceburg, INDIANA \\
Owner & Indiana Department of Transportation (INDOT) \\
Cost & \$12 million (approximately) \\
Contractor & Crider \& Crider (prime contractor) \\
Duration of the Project & 3 Years \\
Start Date & April/May 2004 \\
Completion Date & May 2007 \\
Volume of the Earthwork Quantity & 1.2 million cubic yard \\
Cost of Earthwork & \$4 million (approximately) \\
Type of Contract & Unit Price Contract \\
\hline
\end{tabular}


- Related description:

- $\quad$ SR 48 reconstruction project was started in April-May 2004. The original completion date was May 2006. At the beginning of the project, it was realized that there was a stream passing through the project site but the state highway department did not have permission to relocate that stream. As a result of which the Contractor had to slow down the production and the project got delayed with the delayed completion date as May 2007.

- Crider and Crider was the prime contractor on this project. They were directly in charge of earthwork, sewer-storm water pipelines. They were using sub contractors for paving, guard rail, traffic lights installations.

- $\quad$ The delay in the project brought many problems to the contractor. They had to slow down the production which didn't meet their cost considerations. They had to decrease their crew size and equipment which were sitting idle on the project site. As a result, they were making loss on this project. They filed claims for this problem, most of which were cleared by INDOT.

- General Procedure (bidding to completion):

- $\quad$ The bid documents for a project used by INDOT contained different plans and documents for containing special provisions. The provision documents included different pay items and their quantities, basic information about the project, labor rates for the job, completion date, penalty on the job if not completed on time, modifications to general specifications, claim specifications, etc. 
- One of the contractor said that if State starts to give these plans digitally, it would make their job a lot easier and faster.

- Each bidder was provided with a set of plans which contained existing and final sections at particular interval. Those plans had volume of fill and volume of cut in the plans itself.

- Crider \& Crider did not assume that those quantities were correct but they assumed that the survey and drawings were correct. In the initial period, they did not go out in the field and do the survey, they just re-digitized these plans and found out the quantities by themselves and made sure that those quantities were correct. They used instrument similar to planimeter and they found out the quantity of fill or cut from the physical drawing. This quantity would not be much accurate but at the initial stage it would be good to check with the state given quantities.

- They also used software called AGTEK and EDGE to find out the quantities at initial stage of the project when the bidding was going on.

- After bidding, when the contractor was awarded the job, they went out in the field, surveyed the whole area, found out the quantity of fill and cut by themselves.

- In SR 48 reconstruction job, the contractor found out that the existing ground surface was 6 inch higher than what was shown in the drawings. The cut material was 78,000 cubic meters more than it was in the bidding documents. So, the contractor filed a claim for this excess cut which had to be done on this project.

- After the earthwork process was done, the surveyors went out in the field and got the final surface data. From these data, the final cross section was made and actual quantity of cut and fill was determined.

- There are two ways a contractor gets paid for any typical earthwork job: 
- Estimated quantity pay

- Field measured quantity pay

- State road/highway projects are generally field measured quantity pay projects. Contractor gets paid two times a month. They normally agree on load count from the trucks. State has an inspector on the site, who keeps a count of all trucks filled with material and at the end of the day that inspector and contractor coordinates and come to a final number. There could be an error while counting the numbers of trucks and the quantity of material delivered. So at the end of the project from the final cross sections the actual material quantity is found out and if a contractor has been paid more than what is found out than he has to pay to the state highway department otherwise highway department has to pay the contractor.

- Surveying (data collection method) related information for SR 48 Reconstruction Project:

- Technology used before \& after construction: Total Station + RTK GPS

- Before starting out the surveying, the contractor cut all the shade trees which gave them better signal for GPS surveying.

- The contractor did initial survey with total station to make the original cross sections. They rarely used GPS in the initial period. They had 3 men crew for the total station surveying and 1 man crew for GPS surveying.

- $\quad$ For a 3 men crew, the hourly wages were $\$ 150-\$ 200$ per hour.

- After construction, the contractor used RTK GPS with 1 man crew to get the elevations of final surface, which helped them a lot. With the use of RTK GPS they could cope up with the speed of work, and they did not face any delays. 
- In this project, the contractor had 1 engineer in the office, survey crew in the field and a superintendent working on the site.

- $\quad$ Crider \& Crider has one professional surveyor on board, who does surveying for the project. Sometimes they subcontract it to other companies if they have multiple projects going on at the same time. They do not have that much manpower that can work on different projects at the same time.

- The contractor said that if one has to subcontract it to other company, then technology does not matter for them, sometimes use of total station may prove cheaper to them than the use of GPS.

- Instrument Company:

- Total Station: Topcon

- $\quad$ RTK GPS: Trimble

- Software Company:

- $\quad$ Autodesk - AutoCAD Land Development Desktop

- They have to use another software product (Terramodel, a software product made by Trimble, Inc.) to transfer data from Trimble GPS instrument to the computer. This software product is normally available with Trimble dealers and it is most user friendly with the same company instrument. 
- Unit Price Contract:

- As said before, this project was awarded as a unit price contract. Contractor was slightly reluctant to disclose the unit price for the earthwork in this project, but said that generally it is between $\$ 6$ and $\$ 12$ per yard. He also said that for this project it could be between $\$ 8$ and \$9 per yard.

- SR 48 reconstruction project has a lot of rock. Contractor had to blast the rock in order to cut the material, but because of the rock properties the material tends to swell in big amount. So contractor has to take into consideration the swell factor while bidding the job. Contractor gets paid on the surveyed material quantity only, so it may happen that contractor has to haul away more material than it was surveyed, which could be a major reason for discrepancy between the two parties.

- Level of accuracy:

- The level of accuracy needs to be maintained the same before and after construction. The reason is that contractor had to make original cross sections before the construction, and they had to make final cross sections after the construction. In both the processes, contractor needs equal amount of accuracy.

- The personnel employed in this work were experienced and same personnel were there before and after construction processes. So chances of human error were also decreased. 
- Training:

- Contractor had put a lot of emphasis on the training process. As said before, they had one professional surveyor on board who attended training sessions almost every couple of months.

- Contractor also said that as long as you buy instruments or software updates, dealers will continue to provide training with no charges. So he did not have any idea on training charges.

- These training sessions last for 1 or 2 days depending upon the type of training.

- Contractor was of the opinion that to be competitive, training and up to date knowledge was very important.

- Summary:

- Type of equipment and software

- Total Station (before construction, use of RTK GPS in very rare case)

o Company - Topcon

- $\quad$ RTK GPS (after construction)

o Company - Trimble

- Software used - Autodesk - AutoCAD land Development Software, Terramodel, AGTEK, EDGE. 
- Benefits and Drawbacks

- Project delay because state highway department did not have permission to relocate a stream passing through the project site. It resulted in more cost to the contractor. So at last, owner had to clear all the claims filed by the contractor.

- Use of total station before the construction to achieve the required accuracy

- Use of RTK GPS after construction to take the data of final surface helped them to cope up with the speed of work which resulted in no delays of the project.

- $\quad$ Use of user friendly software products which helped speed up the work.

- $\quad$ Provide training to their personnel to keep them updated and competitive.

- Lessons Learned

- $\quad$ The contractor said that the process of finding initial quantities before bidding from hard copy plans was really time consuming and tedious. The contractor suggested that if INDOT starts giving out digital plans, it would be easier for contractors to come up with the estimate in very less time

- $\quad$ The contractor suggested in innovative approach of make things easy for owner as well as contractor. They suggested using stakeless construction activity, by which the contractor uses the data given by the owner in their GPS-mounted earthmoving equipment, so that there is very less chance of any claims from contractor and the work is done according to the data given by the owner.

- $\quad$ Use of RTK GPS can speed up the work if it is used with greater efficiency and in the environment supported by the equipment. 
- Inaccurate plans can lead to delay of the project and thus more cost associated with the project.

\subsubsection{Case Study: SR 129 Reconstruction}

The SR 129 reconstruction case study was done with the owner (i.e. INDOT) of that project. The information found out in this case study was related to the owner side.

Table 3.4 General Description on SR 129 Reconstruction Project

\begin{tabular}{|l|l|}
\hline \multicolumn{2}{|c|}{ General Description } \\
\hline Project Name & SR 129 Reconstruction \\
Location & Switzerland County, INDIANA \\
Owner & Indiana Department of Transportation (INDOT) \\
Cost & \$20 million (approximately) \\
Contractor & Dave O’Mara (prime contractor) \\
Duration of the Project & 2.5 Years \\
Start Date & May 2005 \\
Completion Date & October 2007 (approximately) \\
Length of the Project & 12 miles \\
Cost of Earthwork & \$4.5 million (approximately) \\
Type of Contract & Unit Price Contract \\
\hline
\end{tabular}

- Related Description:

- $\quad$ SR 129 project was started in May 2005. Its original completion date was October 2007. But while the project was going on, there was a hill slide which created a delay in the project. 
Moreover, lots of change orders have been issued on the project project, which has further delayed the project. The project is now scheduled to finish in 2008.

- Dave O'Mara is the prime contractor for this project. They are in charge of earthwork, pavement construction, utilities construction, etc.

- USI Consultants are the structural engineers/consultants for the contactor. The owner gave the contract to the same company (i.e., USI consultants) to perform surveying and make the plans before the bidding.

- General Procedure (Bidding to Completion):

- INDOT (owner) hired USI consultants to perform survey work and to make plans according to the initial survey results for the 12 miles long SR 129 reconstruction project.

- After getting the initial plans from USI consultants, INDOT personnel checked the plans and floated out the request for bids for SR 129 reconstruction. Dave O’Mara was selected as the prime contractor for this project as stated before.

- The contractor also hired USI consultants as their consultant for this project, which gave them an extra edge because the consultant already knew the project and had worked on this project before as a consultant from owner's side.

- After getting the contract, the contractor started the work and performed the stake out procedure with mainly GPS equipment.

- The contractor was using GPS equipment for surveying as well as on the earthmoving equipment like dozer and scraper. In the beginning of the project, the owner did not have 
GPS equipment for the survey checks and elevation checks, so they were totally relying on the contractor's work. They appointed a person for survey checks on the site, who acted as a supervisor and checked all the procedures which were being performed on the site by the contractor.

- After staking out, contractor carried out cutting and filling wherever required and checked out the elevation of the surface again. The owner supervisor checked the elevation of surface by observing the procedure adopted by contractor and checked the actual surface elevations to the planned elevations.

- After observing the speed of work, efficiency and productivity of using GPS in surveying (before construction), in construction stage (checking out elevation of different layers of road at different points, GPS mounted earthmoving equipment etc.), the owner rented out a GPS equipment from the contractor itself.

- After checking out the elevation of the ground surface, the contractor started out the paving activity while the owner checked it with their GPS equipment whether the actual final elevation was in line with the planned final elevation of the pavement.

- The owner rented only the rovers from the contractor but used the contractor's base stations to collect the data while checking the contractor's work. The contractor was setting up base stations at different predefined points daily because of chances of theft, and would turn off the stations when they were not in use. The contractor also shared the files with owner because of lack of expertise from owner's side. By doing this, the contractor and owner were using the same drawing files to perform the activities and check the activities.

- The owner did not get the opportunity to collect the final ground surface elevation without paving on it because of the non availability of the GPS equipment. As a result it was decided 
to determine the final elevation with pavement on it, transfer the data to the computer and find out the amount of cut and fill carried out after deducting the thickness of the pavement. The final surface elevation was superimposed on the existing ground surface elevation to check out the quantity of fill and cut required after deducting the thickness of the actual pavement.

- Surveying related information:

- Technology used:

- Before Construction: total station and reliance on contractor

- After Construction: mainly GPS

- Instrument Company:

- $\quad$ RTK GPS: Trimble

- As said before, the owner had rented out the GPS rover from contractor and the rent for that equipment was $\$ 30,000 /$ project.

- Software Company:

- $\quad$ Autodesk - AutoCAD

- $\quad$ Trimble - Terramodel software product 
- Most of the related change orders were being incorporated into drawing at the job site using AutoCAD. The owners had two personnel working with available software on regular basis. One of the personnel working on this project had experience working with AutoCAD for last 15 years. Therefore the daily change orders were being corrected in the digital plans in AutoCAD on the site office.

- The owner was using the trial version of Terramodel software product to transfer data from equipment to computer. The owner personnel working on this project did not get training on how to use this software, so they were using it on a trial and error basis. The trial had very less functions thus increasing the need for the full version of Terramodel software. However, they came to know that Seymour district were using this software product, which might be available for their use.

- Unit Price:

- As said before, the contract applied on this project is a unit price contract. As discussed in the earlier case study, most of the highway projects or road reconstruction projects are based on unit price contract.

- During the project, the contractor submitted an invoice every month regarding the work they had performed and they were paid $80 \%$ to $90 \%$ of the work done depending upon the policies and contract agreement. This payment to contractor is according to the estimated quantity. At the end of the project, after finding out the actual cut and fill performed, the owner would pay the remaining amount to the contractor. However, if the 
owner has paid more than what should be paid, then contractor has to pay back the overpaid money to the owner.

- Training:

- As discussed before, the owner personnel had rented out GPS equipment from the contractor. They were given only one day training on how to use this equipment. A person from USI consultant came and taught them some functions of GPS instrument. They were not given any professional training from any GPS equipment company. They had to use the equipment and learning by trial and error.

- They also had to use Terramodel software product for transferring the data from the GPS instrument to the computer. They did not have expertise on this software and were not given any training on how to use this software.

- Summary:

- Type of equipment and software

- Total Station and reliance on the contractor (before construction)

- RTK GPS (after construction, on rent from contractor)

o Company - Trimble

- Software used - Autodesk - AutoCAD Terramodel. 
- Benefits and Drawbacks

- Lot of change orders have been issued on this project which is one of the reasons of project delay and thus increasing the cost of the project.

- The contractor hired the same consultant hired by the owner before, which helped contractor in this project.

- $\quad$ The owner did not have GPS equipment in the beginning of the project which made them rely on the contractor.

- Us of on-board GPS on the earthmoving equipment helped contractor do things faster in this project.

- After observing the productivity gained by contractor using GPS, owner has rented out the GPS for the remaining duration of the project.

- The owner did not have the full version of Terramodel software which is required to transfer the data from equipment and computer and analyze it.

- As the personnel working on this project had good experience with AutoCAD, it became beneficial for them to work on AutoCAD.

- The owner personnel did not get enough training for GPS equipment and they learned the equipment by trial and error.

- Lessons Learned

- The owner personnel informed that lot of change orders was one of the reasons of the delay of the project. Moreover, they did not have enough personnel from owner side to work on this long 12 mile project. 
- One of the big technological constraints was the absence of a good technology to take the data (GPS) in the beginning and lack of expertise to use this technology

- $\quad$ Lack of resources (i.e., full version of software product) from owner’s side.

- $\quad$ No training given to the personnel thus made them learned the equipment and software by trial and error.

- Use of on board GPS on earthmoving equipment can increase the productivity of the work. 


\subsection{Conclusions}

This chapter described the steps taken for data collection in this research. Telephone interviews with INDOT engineers/surveyors were discussed in order to understand the current state of practice in Indiana. Questionnaire surveys for state DOTs, professional companies and equipment/software companies were discussed with the results obtained. This chapter also illustrated two case studies conducted with a contractor and the owner along with the vendor interviews conducted in Indianapolis region.

The analysis of the data collected through interviews, questionnaire surveys and case studies is discussed in the next chapter (i.e., Data Analysis). 


\subsection{References}

Autodesk Inc., <www.autodesk.com> (Last Visited - 9/23/07)

Bentley Systems, Inc., <www.bentley.com> (Last Visited - 9/12/07)

Carlson Software, <www.carlsonsw.com> (Last Visited - 9/27/07)

Kavanagh, Barry F. (2001). Surveying: with construction applications, Prentice Hall, Upper Saddle River, NJ.

Leica Geosystems, <www.leicaus.com> (Last Visited - 9/20/07)

Leick, Alfred (2004). GPS satellite surveying, Wiley, New York, NY.

Microsurvey, <www.microsurvey.com> (Last Visited - 9/27/07)

Sokkia Co., <www.sokkia.com> (Last Visited - 9/23/07)

Topcon Positioning Systems, Inc., <www.topconpositioning.com> (Last Visited - 9/18/07)

Total Station Data Sheet, <www.trimble.com> (Last Visited -11/10/07)

Wolf, Paul R., Ghilani, Charles D. (2002). Elementary Surveying: An Introduction to Geomatics, Prentice Hall, Inc., Upper Saddle River, N.J. 


\section{CHAPTER 4. DATA ANALYSIS}

\subsection{Introduction}

The collected data was analyzed to determine the most efficient methods for earthwork data collection and quantity calculation. The analysis also determined the training needs for INDOT. In the last, the recommendation would be given on the basis of the analysis. As discussed in the Introduction chapter, the main objectives of this research study were to find out current state of practice of all the DOTs including INDOT as far as earthwork data collection and quantity calculation is concerned, current state of practice of professional/surveying companies, different equipment and software available for earthwork data collection and quantity calculation, and lastly to recommend tools and methods to INDOT based on the literature review and data collected. The data collection and analysis is performed according to the objectives. The following sub chapters provide a detailed subjective and comparative analysis with respect to the collected data.

\subsection{Analysis of Telephone Interviews with INDOT Surveyors/Engineers}

The data collected through telephone interviews with INDOT surveyors and engineers provided the current state of practice within INDOT design and surveying divisions. As discussed in the data collection chapter, five interviews were performed in different parts of 
Indiana to get an overall picture of current practice for earthwork data collection and quantity calculation methods.

When participants were asked about their current method for earthwork data collection, four of the five participants (Figure 4.1) were using total station as their main technique for earthwork data collection.

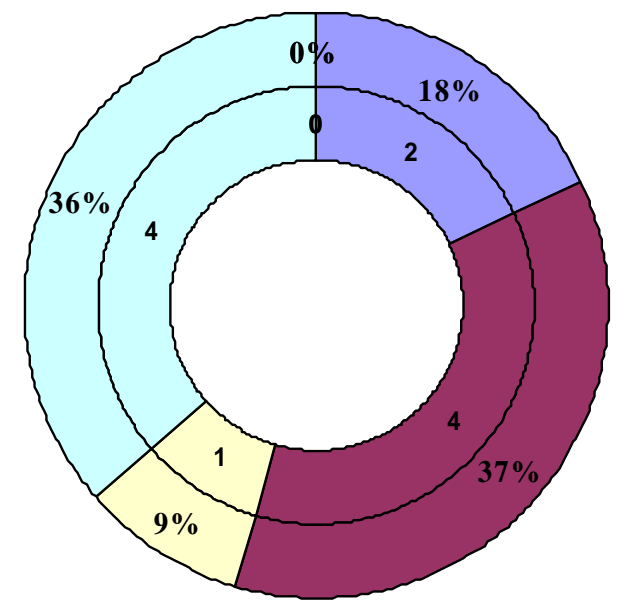

$\square$ Digital Level

$\square$ Total Station

$\square$ Robotic Total Station

$\square$ GPS/RTK GPS

$\square$ LiDAR

$\square$ Aerial Photogrammetry

Figure 4.1 Percentage of Participant’s Current Method for Earthwork Data Collection

As shown in Figure 4.1, 4 participants were also using GPS for their earthwork data collection, but one of the participants said that they used GPS on $10 \%$ of their projects. One participant said that they used GPS for the first time after observing the productivity achieved by the contractor working on that project, while one of the other participants used GPS just for laying out the baselines. So it was confirmed that use of GPS was minimal in earthwork data collection. Two of the participants also confirmed that they still use digital level for some of their small construction projects. While one participant said that they used combination of GPS, total station and robotic 
total station depending upon the conditions and equipment available. None of the participants used aerial photogrammetry or LiDAR which could speed up their work on large construction projects. The interviews suggest that participants were still using total station on most of the construction projects. Consequently while using total station, average of three personnel were required in the field. While using GPS, their personnel requirement reduced to two.

Figure 4.2 shows different companies' instruments used by different personnel in Indiana. The numbers shown in the pie chart includes total station, GPS and RTS. Mostly Trimble GPS instruments are used by INDOT, while Topcon total station as the second choice. But some districts also use Leica and Sokkia instruments. In general, there is no uniformity as far as the choice of instrument companies. It also seems that the purchase is not being done centrally through one office, but different districts and project offices do it individually.

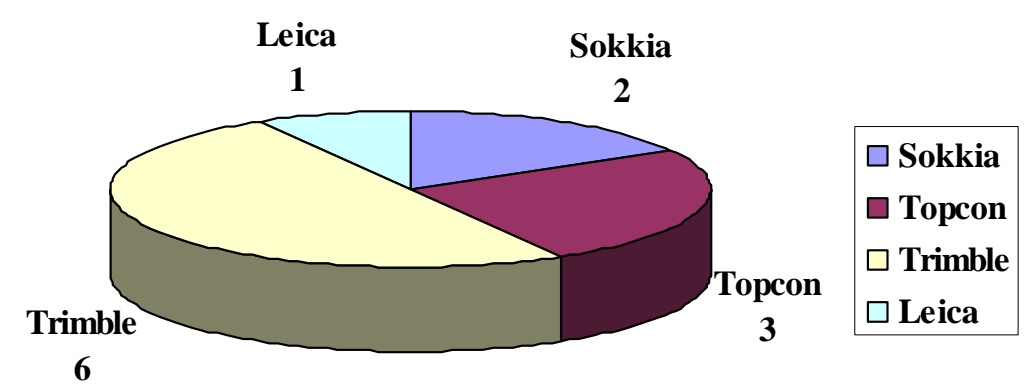

Figure 4.2 Equipment Company Used by Participants

The participants said that the average life of a normal total station and GPS was almost same i.e. 12 to 15 years. In the response to the question asked for horizontal and vertical accuracy of these instruments, participants' replies were similar. Total station's horizontal 
accuracy was on an average $0.03 \mathrm{ft}$ and vertical accuracy was around $0.04 \mathrm{ft}$. While, GPS instrument's horizontal accuracy was around $0.05 \mathrm{ft}$ and vertical accuracy was approximately $0.08 \mathrm{ft}$ to $0.1 \mathrm{ft}$. From initial cost, service life and accuracy point of view, total station proves to be better than GPS.

Questions were asked about advantages and disadvantages of the techniques used. The main advantages of total station were following:

- Better accuracy in both horizontal and vertical direction

- Easy to use

- Personnel are using this instrument from long time thus more productivity

- No requirement of satellite availability

- Best in region where there is lot of vegetation, trees, canopy, hills etc.

- Less capital cost

While the main disadvantages of total station are stated below:

- Time consuming

- Labor intensive

- Limited distance coverage

- Cannot use in all terrain conditions

- Not as quick as GPS, need more time in large construction projects 
Whereas the main advantages of GPS according to participants were as follows:

- Faster in comparison to total station and robotic total station

- Easy transfer of data from instrument to computer

- Less personnel requirement

- 3 to 5 linear miles of data can be surveyed from one single base station

- Comparable accuracy

While the main disadvantages of GPS instrument are stated below:

- Costly in comparison to total station

- Totally dependent on satellite availability

- Not applicable to all the terrain (trees, vegetation, canopy etc)

- More complicated than total station, so require trained personnel

Three of the five participants were using Bentley MX as their main software in coordination with Microstation for their earthwork quantity calculation purpose, while other two participants were using AutoCAD as their main software for quantity calculation. One of the participant said that they were using a software called 'Quick Quantities' before, which was a DOS based software, time consuming and tedious. He said that some of the offices in Indiana were still using that software for earthwork quantity calculation. As said earlier about the instrument purchasing, there was no coordination among the different districts in Indiana for the software use and they were using different software products for quantity calculation. The 
disadvantage behind different products was that the data transfer would become more complicated and time consuming between different INDOT offices.

Almost all the participants said that they require two engineers in the office to do earthwork quantity calculation. One engineer would calculate the quantities and the other one would check the work done by the other engineer. However, INDOT surveyors and engineers facing problems as far as training for new methods and software products is concerned. Three of the five engineers said that INDOT does not provide training to their engineers and surveyors. They had to self train themselves in order to use new technology or method. This had resulted in long learning curve and in turn less productivity. They said that if they were given training, it would have been beneficial to them and INDOT as well. But on the other hand, two participants told us that INDOT and vendors of those particular new instrument and software products gave them training. This indicates that there is a need for better co-ordination of training which should be made available to all INDOT engineers and surveyors working with the earthwork data collection instruments and quantity calculation techniques.

\subsection{Analysis of Questionnaire Survey of State DOTs}

This sub chapter would give a detailed analysis of the current state of practice of different DOTs throughout the US. As discussed in the questionnaire survey the response rate for this questionnaire survey was $50 \%$. Following is the data analysis of the data collected from the questionnaire survey. 
The participants were asked about the technology used by them for projects less than 3 miles long and projects more than 3 miles long in earthwork data collection. Figure 4.3 shows the technologies which are being used for projects less than 3 miles long. Total station and GPS/RTK GPS almost have the 50\% share of the donut establishing them as the predominant technologies used by DOTs in the US. Aerial photogrammetry, RTS and GPS with CORS takes 16\%, 15\% and 10\% share respectively. However, digital level/theodolite and LiDAR techniques are least used in earthwork data collection process.
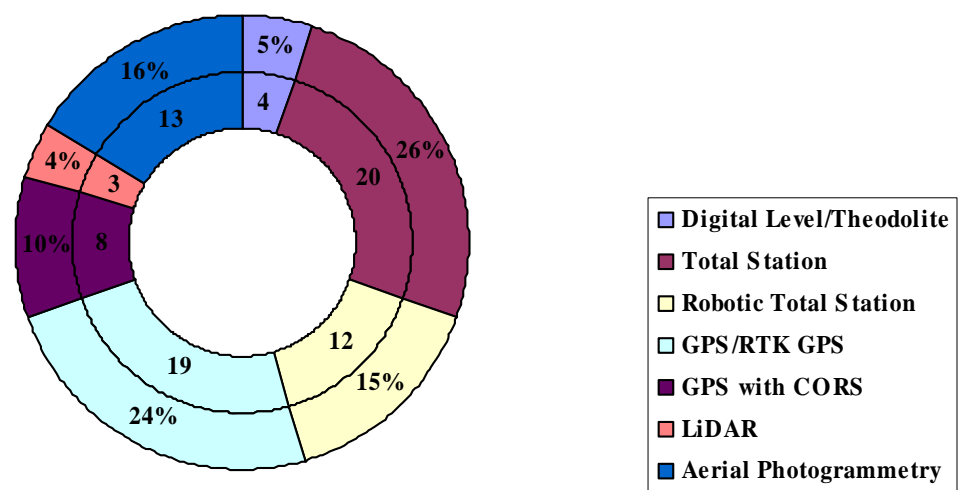

Figure 4.3 Use of Technology for a Project Less Than 3 Miles

On the other hand, for projects more than 3 miles, the most popular technology is GPS/RTK GPS which is having 25\% share of the donut. (Figure 4.4) The aerial photogrammetry and total station carries around 23\% and 21\% respectively (Figure 4.4). These numbers show that the aerial photogrammetry share has increased with the length of the project, while the share of total station has decreased. The GPS with CORS, LiDAR and digital level/theodolite carried almost same \% share as they were carrying in the projects less than 3 miles (Figure 4.4). 


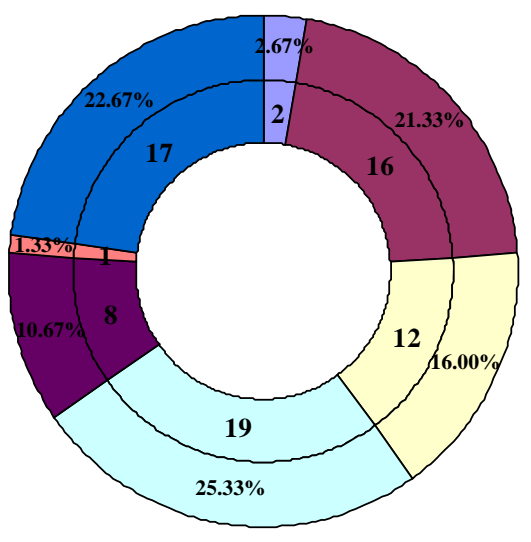

\begin{tabular}{|l|}
$\square$ Digital Level/Theodolite \\
$\square$ Total Station \\
$\square$ Robotic Total Station \\
$\square$ GPS/RTK GPS \\
$\square$ GPS with CORS \\
$\square$ LiDAR \\
$\square$ Aerial Photogrammetry \\
\hline
\end{tabular}

Figure 4.4 Use of Technology for a Project More Than 3 Miles

The participants were asked about the personnel requirement on the field for the technology that they use for earthwork data collection. Various responses were obtained from different participants for the technology that they use in their large construction projects. After getting all the responses, weighted average for the personnel requirement was found out for each technology. Figure 4.5 shows the average requirement of personnel on the field for different technologies.

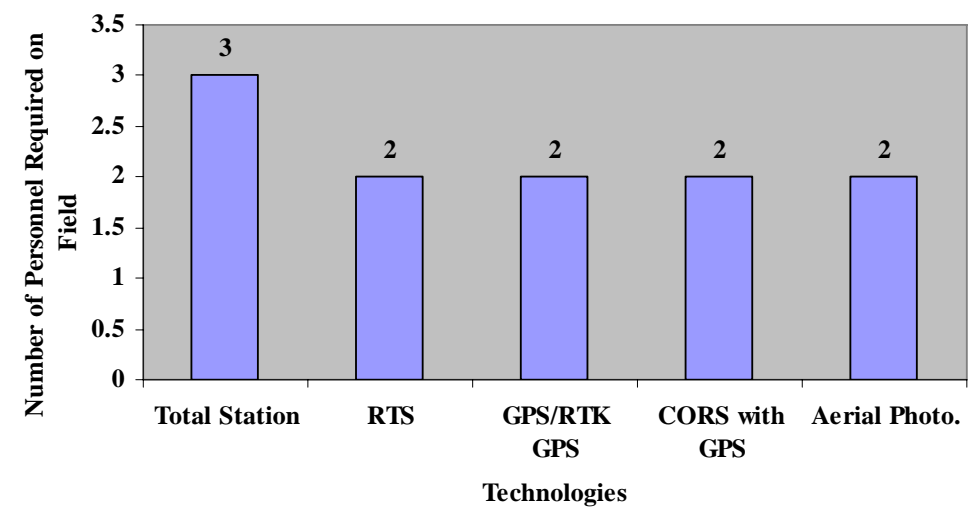

Figure 4.5 Average Personnel Requirement on Field with Different Technologies 
Responses were also obtained for the 'time required to collect 1 mile of data for regular terrain' with different technologies. The participants mentioned that the answer would be approximate in this case as lot of factors affects the time taken to collect data in the regular terrain. Figure 4.6 shows that the aerial photogrammetry technique takes the least amount of time to collect the data on the field while theodolite/digital level is the most time consuming technique. The GPS/RTK GPS consumes less time than CORS with GPS, which is slightly contradictory as generally one need less time in collecting data when he is using CORS in comparison to establishing their own base station on site.

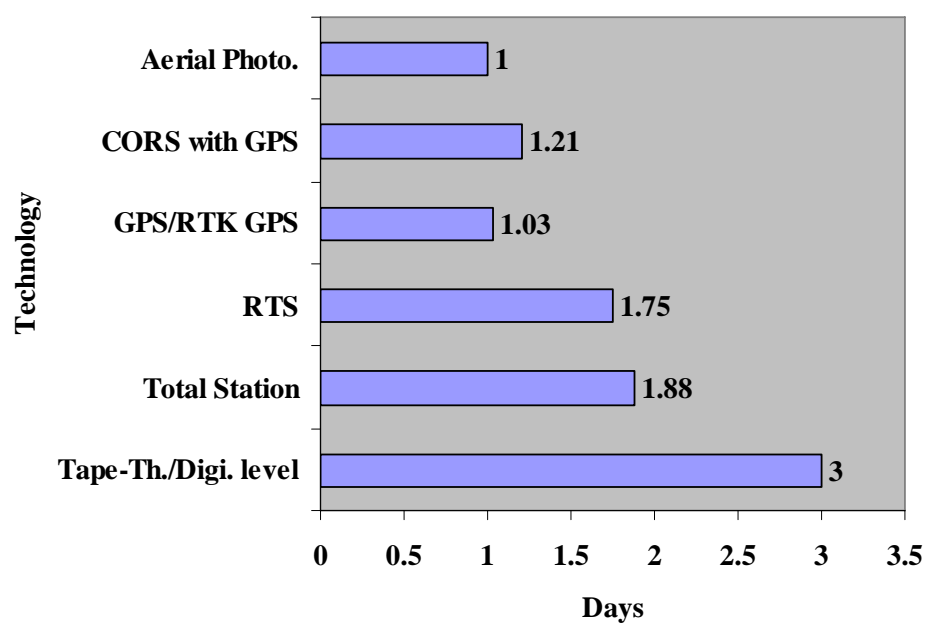

Figure 4.6 Time Required to Collect Data for Regular Terrain

For the irregular terrain, the trend was similar as it was in the regular terrain. The aerial photogrammetry needed the least amount of time to collect the data while digital level/theodolite needed the most amount of time to collect the data. However, the contradiction in the regular terrain was not seen in the irregular terrain as participants agreed that one require less time in 
collecting data with CORS as compared to normal GPS/RT GPS technique. Figure 4.7 shows the time required for different technologies for the irregular terrain.

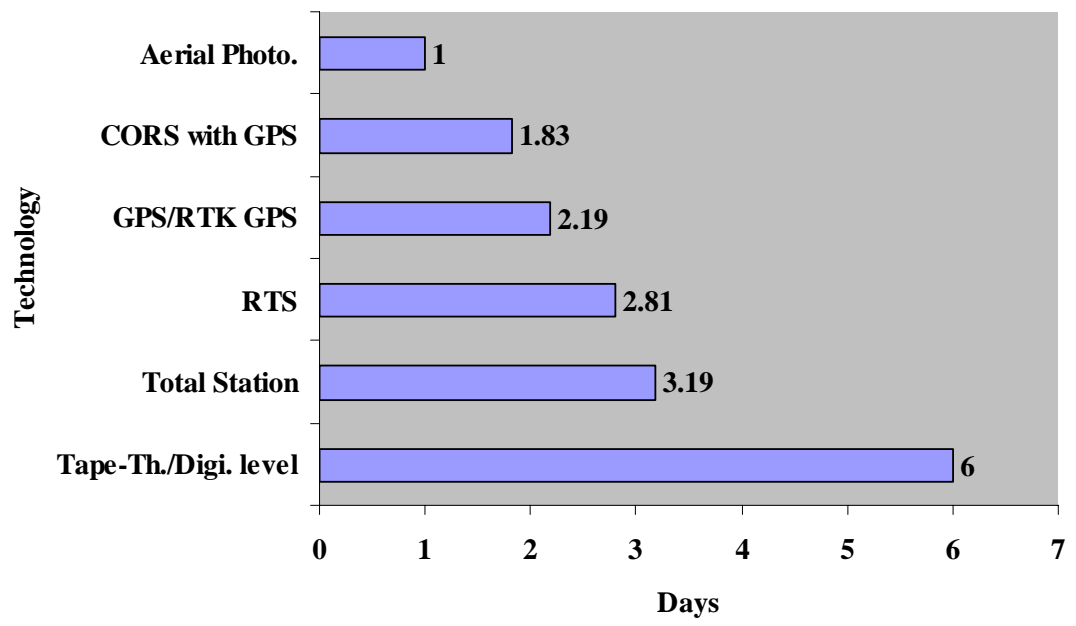

Figure 4.7 Time Required to Collect Data for Irregular Terrain

A question was asked about the cost of personnel/hour for earthwork data collection. It was seen that the cost did not change if the technique was changed from one to another. The average cost of personnel/hour was around \$25 for all the technologies. However, this cost was directly related to the personnel requirement on the field for different techniques. Figure 4.8 shows the average cost of personnel/hour for different technologies. 


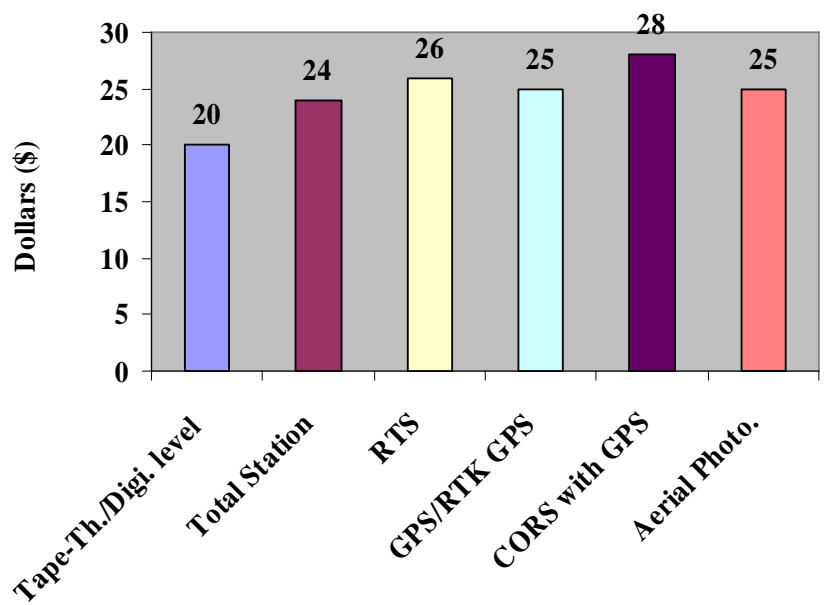

Figure 4.8 Average Cost of Personnel/Hour

Different DOTs were using different companies' instrument in the earthwork data collection process. A question was asked to give information on which company's equipment they use. Figure 4.9 explains that Trimble Inc. was the most popular company among the DOTs. The second most popular company was Leica. These two companies were by far the most popular among the participants. Figure 4.9 also shows that Topcon had a little bit of share in the market.

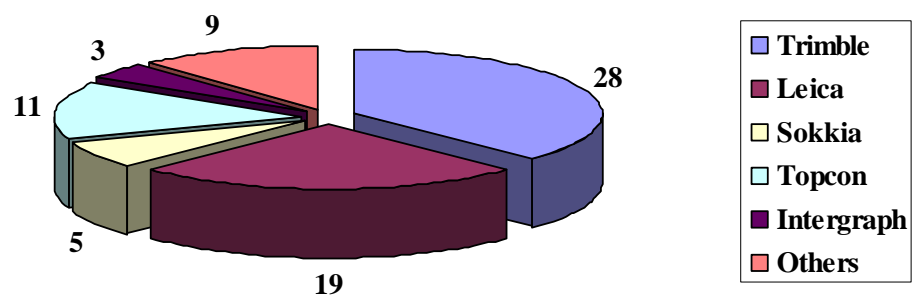

Figure 4.9 Use of Instruments of Different Companies 
Participants were asked to give an approximation on the average service life of these different instruments. Participants said that these instruments had long service lives. Generally they are in good shape for at least 12 to 15 years unless they are broken due to some accident. Participants said that the average life of all these different instruments was more or less the same. But these instruments differ from each other in the accuracy section. Horizontal and vertical accuracy of different instruments were asked from all the DOTs and the collected accuracies were averaged out for each technology. Figure 4.10 illustrates the horizontal accuracy of different technologies achieved by different participants throughout the US.

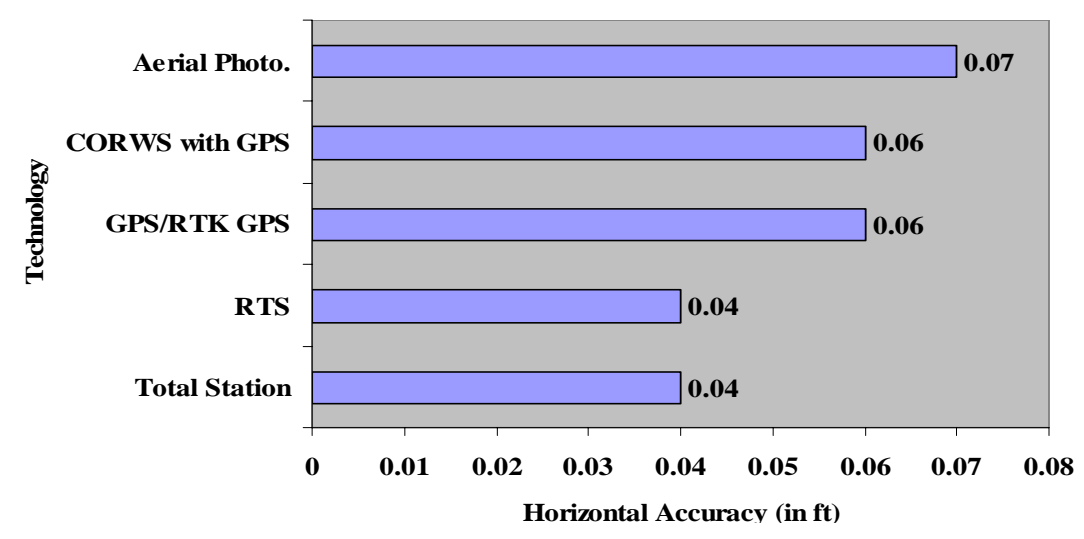

Figure 4.10 Horizontal Accuracy of Different Technologies

Figure 4.10 explains that the total station and RTS provide the most accurate readings while aerial photogrammetry has the lowest accuracy among all the different technologies. GPS/RTK GPS stays between those two technologies as far as horizontal accuracy is concerned. The same trend is seen in the vertical accuracy also. Figure 4.11 shows that the vertical accuracy reading for total station and RTS is the most precise while it is lowest for aerial photogrammetry. 
Therefore as far as the accuracies are concerned, total station and RTS top the charts while aerial photogrammetry is at the bottom.

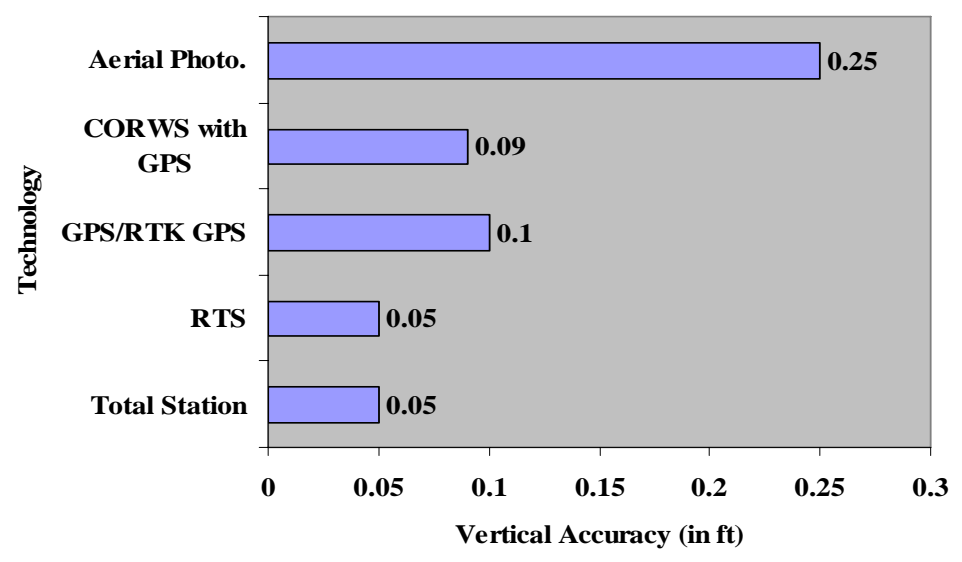

Figure 4.11 Vertical Accuracy of Different Technologies

Participants were asked to illustrate the advantages and disadvantages of these technologies according to their experience in using these instruments. The advantages of all the technologies are listed below.

Total Station:

- Low cost instrument

- $\quad$ Can be used under canopy

- Better horizontal and vertical accuracy

- Electronic data collection and data transfer

- Easier to train personnel to use this instrument

- It doesn’t require satellite access to work

- $\quad$ Minimal terrain restrictions 
- Users in the DOTs are very familiar with it, so no learning curve is required

Robotic Total Station:

- Comparative cost

- Useful to work with under canopy

- Less labor intensive

- Identically one person operation

- Can collect data on a data collector from any traverse

- Reflector less capabilities

- Doesn’t need satellite availability

\section{GPS/RTK GPS:}

- Less time consuming

- Faster data collection

- Doesn't require line of sight to work

- Less personnel requirement thus less personnel cost,

- Real time data availability

- Identically (theoretically) one person operation

- More consistency in data accuracy

- Faster completion times

CORS with GPS (Besides all the advantages of GPS):

- Permanent base station, thus no need to set up a base station before work 
- $\quad$ Large coverage areas

- $\quad$ Only need GPS receiver and some sort of communication means

- Error reduction techniques available

- Better accuracy

Aerial Photogrammetry:

- Faster data collection

- $\quad$ Photo images can be used for other project functions

- Can cover very large area

- No interference with private land or land closure

- Greater data density

- Cost efficient,

- Data can be stored for longer period of time

\section{LiDAR:}

- Safer method in some conditions (e.g. edge of a cliff, hills etc)

- $\quad$ Faster data collection

- $\quad$ Does not depend on the atmosphere

- Data can be stored for longer period

- Data can be collected at night also 
The disadvantages of all the technologies are listed below:

Total Station:

- Line of sight required

- Instrument has to be set up numerous time,

- More personnel requirement thus more personnel cost

- On sight control required

- Time consuming

Robotic Total Station:

- Line of sight required

- Battery life could be a constraint

- Obstructions due to reflectivity of other objects

- Unmanned instrument subject to theft and damage (security concerns)

- On sight control required

- Traffic and other obstacles can block the tracking device

- Training required to use this instrument

GPS/RTK GPS/CORS GPS:

- Lower accuracy in comparison to total station and RTS

- Require satellite availability to use it

- Cannot use where lot of vegetation, canopy or high rise buildings are there

- Initial cost is high 
- Training required to use this instrument efficiently

- Difficult to use in urban settings and around tall structures

- Base station require some person for security

- Cell phone coverage may be an issue

Aerial Photogrammetry:

- Low accuracy in both horizontal and vertical direction

- Depend on season or atmosphere

- Cannot get data for obscure areas, so a field survey required

- Very high initial cost

- Processing time can be very long

- Cannot work in thick vegetation

- Training required to use this technology

- Spot discrepancies may arise as an issue

- Cannot work properly in lot of vegetation, canopy, shadows

\section{LiDAR:}

- Low accuracy in both horizontal and vertical direction

- Large data cloud is generated - management of this data is really difficult

- Very high initial cost

- Training required to use this technology 
Nineteen (19) of the 25 DOTs that responded, were using the same techniques for earthwork data collection before and after the construction stage (i.e. as is earthwork quantity assessment stage and earthwork pay quantity verification stage), while the remaining 6 DOTs were using mainly total station in earthwork pay quantity verification stage. The earthwork data collection techniques were chosen depending upon several factors like the accuracy required, situation, availability of resources, availability of instruments, time in which the survey is to be done etc. One of the respondents said that they normally pay for the original estimated quantities unless there was compelling evidence that such values were off by $20 \%$ or more. One of the DOTs subcontracted the pay quantity verification job, while the other DOT measured only the plan quantity and made the contractor measure the final quantity if the contractor felt it was inaccurate. They would sometimes have to verify the quantities provided by the contractor but the method used was not in detail as exact dimensions were not required.

Only 2 of the 25 participants used LiDAR for the earthwork data collection process. Both of the DOTs had subcontracted it to a private company. The subcontract charge was $\$ 2,000 / \mathrm{hr}$. However, 12 of the 25 DOTs were using aerial photogrammetry for their work. Five of those DOTs owned the equipment, while rest of the seven subcontracted it to a private company. If the job was rented or subcontracted, the charge was around $\$ 1000$ mobilization $+\$ 500 / \mathrm{hr}$. Some companies charge $\$ 25 /$ mile, while some companies charged $\$ 1,000$ to $\$ 2,000 /$ hour. The selection of a technique also depends on the specifications for that project. One DOT mentioned that their specifications didn't allow them to use LiDAR or aerial photogrammetry, so they used total station for their project. 
Twelve (12) of the 25 DOTs were using digital level/theodolite/tape before using their current technology. The main reasons behind changing their technique were mentioned as availability of the new and improved technology, need for more efficiency and productivity, required accuracy, less time consumption, better cost and less resource requirement. Lot of DOTs were using total station before adopting their current technology.

For the earthwork quantity calculation, mainly two kinds of methods are available, manual method and the software method. The participants were asked about their current method for quantity calculation. Figure 4.12 shows the distribution among the 25 DOTs that responded to this question.

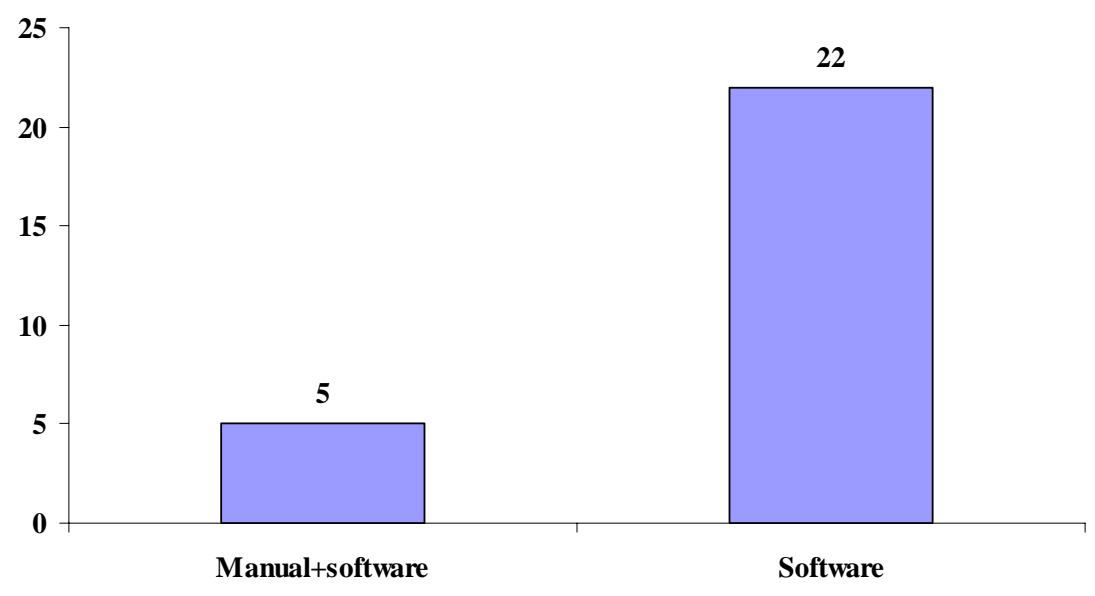

Figure 4.12 Manual Method Vs Software Method

Figure 4.12 illustrates that 5 DOTs were using both manual and software based methods for their quantity calculation, while 22 DOTs were using only software based method to come up with the preliminary as well as final quantity of earthwork. 
Figure 4.13 illustrates the different software products used by different DOTs for quantity calculation.

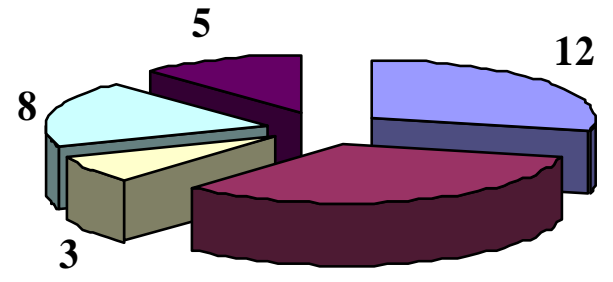

14

$\square$ Geopak
$\square$ Microstation
$\square$ AutoCAD
$\square$ InRoads
$\square$ Others

Figure 4.13 Use of Different Software Products

The responses by the participants indicate that the use of Microstation was among the highest in the DOTs throughout the US. Almost all the DOTs were using Geopak in combination with Microstation for their quantity calculation. Some DOTs were also using InRoads with Microstation. All three products are from Bentley Systems. There were some DOTs who were using AutoCAD, but the usage of AutoCAD was much less in comparison to the Bentley products. Moreover, there were two DOTs who were using CAiCE for their quantity calculation purposes, while the other DOTs were either using their own customized software products or some other less known software products.

Almost all the participants indicated that they were satisfied with the performance of their selected software product. The accuracy of all the software products varied depending upon the standards set by the individual DOTs. Some DOTs round up the numbers to the nearest whole, while some use the lowest measurement as $1 \mathrm{CY}$ and some others would require the limits of +/$10 \%$ of the predicted quantity. Participants cited some problems and advantages that they came across while using these software methods to find out the quantities of the earthwork. 
Some of the participants complained that the use of Microstation was sometimes time consuming. Some of the customized software products were also time consuming (e.g. quick quantities in INDOT). Sometimes the data collected from LiDAR or Aerial Photogrammetry is so dense that it takes a lot of time to analyze the data in the office. The participants said that the personnel who use these software products must know these techniques very well. The training becomes very important to use these software products.

The advantages of some of the software products as described by different participants are as follows:

Geopak:

- It saves time, resources and reduces reliance on more labor intensive methods

- It contributes to the completion of project on estimated time with the estimated cost

- It is reliable and accurate enough

- It is efficient to re-run this software if any change has been made (changes to original design are easy)

- Easy to train personnel for this software product as it is commonly used

\section{Microstation:}

- Lot of DOTs have personnel who are trained and experienced in using this software

- It is uniform and a very simple software product to use

- Data can be adjusted quickly if any change is made

- Fairly fast and cheap 
InRoads:

- $\quad$ Speed and accuracy are its main advantages

- It gives you the graphic verification of quantity results

- $\quad$ Fairly easy to train personnel for this software product

A question was also asked on how many engineers are required in the office to do the quantity calculation of earthwork quantity. Almost all the participants said that they required 2 engineers to do the work in the office for any project. One engineer would find out the quantity of the earthwork and the other engineer would check the work done by the first engineer and verify it. Some participants said that the requirement of engineers in the office depends on the size and complexity of the project. The requirement varied from 1 to 5 depending upon the characteristics of the project.

In reference to the previous method before using the current method, almost all the participants replied that they were using Average end area method either manually or with a spreadsheet. Some DOTs used in-house software products to find quantities but a lot of data had to be entered into the software and it was time consuming and tedious for the engineers. Some of the reasons behind changing the methods were reduced time requirement with new technology, less manpower needed, desire to keep up with modern technology, more accurate and efficient results, ability to directly transfer data from equipment to computer, use of digital terrain model (DTM) instead of some hand made drawings, speed and quality of work, less human error with new technologies, flexibility and overall integration of interactive roadway design. Figure 4.14 shows the distribution of technologies preferred by the participants. 


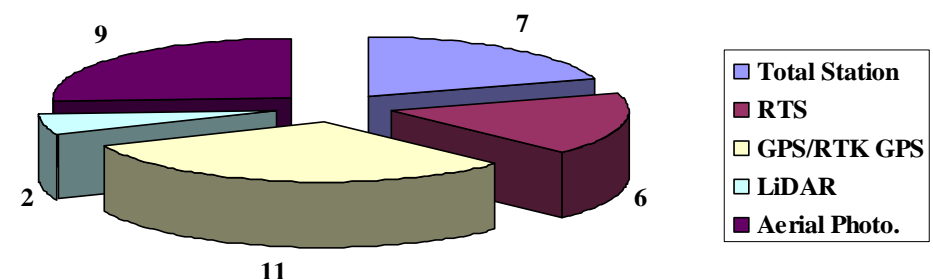

Figure 4.14 Preferred Technology

Lot of participants selected multiple technologies as their choices. But the highest preference was for the RTK GPS technology. The reason behind choosing this technology was to get faster data collection, easy transfer, good accuracy and more productivity. This method required fewer personnel, which was also one of the benefits participants mentioned. Participants also said that for small to medium size projects, this technology proved to be the cheapest one. Some participants said that they had used this technique before and they were satisfied using this technique. The second most preferred technique was aerial photogrammetry as it provided the safest and fastest data collection. It also saved on resources and was described as the least time consuming method. Participants said that for large projects, aerial photogrammetry was the cheapest option. The participants said that one cannot work with only one technology, a combination of two three technologies is required. Some techniques might work in some conditions while some might now work in other conditions, e.g. GPS cannot work where there are lots of trees, vegetation or canopy. So in such situations one has to use total station or robotic total station, while if there is a problem of line of sight then one cannot use RTS or total station, one has to use GPS, aerial photogrammetry or LiDAR. The selection of a technique also depends on the accuracy needed. So there are lots of factors which might come into play while choosing a technology to use in any particular project. 
Participants were also asked about the new technologies like GLONASS and GALILEO that can be used to get good accuracy in GPS survey. A number of DOTs had the GLONASS capable equipment and they had started using this technique in their projects. While some DOTs were still waiting for some reports to come out about their efficiencies before they would think of applying this to their projects. But on an average, almost $66 \%$ of the participants knew about this advancement, which was a good sign of being updated with the working field.

Lastly participants were asked questions about the training issues. Twenty (20) of the 25 DOTs provided training to their personnel, while 5 responses indicated that they were not given training from their respective DOTs. The average duration of training was 1 to 2 days depending upon the knowledge of the person who was taking that training and the topic on which the training was given. Most of the DOTs had their in-house personnel provide training to other employees. So they didn’t have any extra cost on giving training. Normal charge for the training was around $\$ 1,000 /$ day or $\$ 150$ to $\$ 300 /$ person.

\subsection{Analysis of Vendor Interviews}

As discussed in the data collection part, two interviews were performed with the vendors of instruments and software companies for earthwork data collection and quantity calculation. Both the vendors gave some useful information and suggestions that could be used by INDOT for more productive and efficient work. 


\subsubsection{Analysis of Interview with Seiler Instruments}

As discussed in the data collection part, Seiler Instruments were mainly selling equipment by Trimble Inc. This dealer specified two instruments (i.e. GPS and total station), which could be used in earthwork data collection and quantity calculation to improve productivity and efficiency. The specified GPS instrument was their latest product called R8 GNSS system. This system brings out some advantages as follows:

- This system can use signals from both GPS and GNSS system, thus it can get data from both the systems simultaneously. As the satellite availability would not be an issue here, the error rate will be decreased greatly.

- Initialization for this instrument is less than 10 seconds and initialization reliability is greater than $90 \%$. This instrument gives centimeter accuracy in both horizontal as well as vertical direction.

- The rover used in this method has either radio or cell phone connected to it, which gives the data from the base station. The customer generally brings both radio and cell phone to the site. Firstly they try the cell phone coverage and get the correction in real time, but if they don't get the coverage then they would set up their base station in near by area and use radio link to get the GPS corrections. The coverage of radio link is generally $10 \mathrm{~km}$; however cell phone has better coverage. The GPS receiver costs around \$24,000. While the data collector costs around $\$ 5,000$, while radio link comes for around $\$ 3,400$.

- Trimble's VRS technology is used in number of states in the US and in almost 8 to 9 countries worldwide. The main advantage of this technology is its error free data collection. 
The dealer claimed that ppm error would go away by using this technology in GPS and in removing this error, the user doesn't have to do anything but everything is taken care by the software. This technology needs RTKNet software and a CORS network to work in any condition and give an error free solution

- Trimble's S6 total station is a combination of robotic total station and GPS. Customers can start with either of the technologies and if the situation asks for a change, the technology can be changed in no time from GPS to total station. The data is collected in only one data collector, which in the end will distinguish the data collected from the two different technologies.

- Trimble's VX spatial station is a scan station which can be useful when the data is to be taken at overhangs, bridges, building tops etc. However its range is around 300 meters and it costs $\$ 75,000$. Its cost and range are its main limitations.

- There is a requirement of only 1 surveyor in the field while using any of these technologies. The dealer takes a flat $\$ 1,000 /$ day for the training of any instrument or a software product. They give training in the office or on the job site. The duration of training is generally between 1 to 2 days. They also give instruments on rent. The charge of rent for GPS is around $\$ 500 /$ day, $\$ 2,000 /$ week and $\$ 4,500 /$ month. For total station, the charge is $\$ 300 /$ day, $\$ 1,000 /$ week and $\$ 3,500 /$ month.

- Trimble Geomatics Office (TGO) is the most compatible software used with the above mentioned instruments. Software like Microstation, AutoCAD, etc., are also compatible with these instruments and can be used with them.

- The last point Seiler instruments' employee mentioned is that the product development of Sokkia lags behind that of Trimble and they have not put much money into R\&D. Moreover, 
they don't have local dealers to take care of the customers. So it might not be a good idea to go with this company.

\subsubsection{Analysis of Interview with Advanced Lasers and Instruments}

Advanced lasers and instruments mainly sell instruments for Trimble, Leica, Sokkia and Nikon. They also sell software products for Trimble and Carlson. The following description gives an analysis of the information and suggestions made by the dealers for INDOT to work more productively in the field and in office as far as earthwork data collection and quantity calculation are concerned.

- The dealer suggested that the owner can put a clause in the bid adding a requirement of particular software to be used on that particular project. By this way, the owner and contractor will not have any problem in transferring the data electronically and they both will be working on the same plane.

- The dealer also said that the owner or the consulting company should be accurate in collecting data in pre bidding stage so that the drawings made from those data and given to the contractor would be correct. The correct data collection would reduce the number of claims made by the contractor during the construction stage.

- They offer software developed by Carlson and Trimble for the software for earthwork quantity calculation. The 'Terramodel' by Trimble and 'Carlson Survey 2008' made by Carlson were their recommended choice. They also said that proper training is required to 
use these software products efficiently. The dealer said again and again that the flow of data transfer should be seamless internally within the organization as well as the parties working on the project.

- There are some trade offs that the customers make when they buy instruments or software products. One company might be having better quality, one might have some extra features on the instrument or one might have low cost. But all the instruments would be having the basic features on it and the service life of all these instruments is more or less similar. But they also recommended 'Trimble S6' and 'Leica 1200' for the total station category. The dealer added that if a customer is a contractor then they would recommend them a Trimble product because of its simplicity and easy to use characteristics, but if a customer is a surveyor, then they would recommend Leica product which is more advanced and powerful.

- They give generally 1 to 2 days of training to their customers. Their charge is also $\$ 1000 /$ day as a flat fee or $\$ 295 /$ person, but there is a limitation on the number of students in one batch (i.e., up to 10 to 12 students).

- The dealer recommended that customers should get a yearly check up for their earthwork data collection instruments like total station and digital level. There is no need for service in GPS. They also give instruments on rent and their normal charge is around $10 \%$ to $12 \%$ of the cost of the instrument per month.

- Lastly the dealer gave some good comparison for different instrument manufacturers. The dealer noted that for machine control and construction, Trimble instruments were better. For core surveying purpose, Leica instruments would be more powerful and more recommended. Topcon instruments were better in GIS applications and Sokkia instruments had an advantage of low cost. 


\subsection{Analysis of Questionnaire Survey of Professional/Surveying Companies}

This subchapter provides a detailed analysis on the current techniques and methods used by different professional/surveying companies in Indiana. As discussed in the questionnaire survey, 10 companies responded to the questionnaire survey out of 30 companies, thus a response rate of $33 \%$ was achieved. Following is the analysis of the data collected from the questionnaire survey.

The questions asked in this questionnaire were almost same as they were asked in the state DOT questionnaire survey. Figure 4.15 shows the distribution of the technologies used by different participants for their projects less than 3 miles. One important point which came out from this information was that the participants used only three of six technologies. Their most used technology was GPS/RTK GPS. The second most used technique was total station and last was RTS.
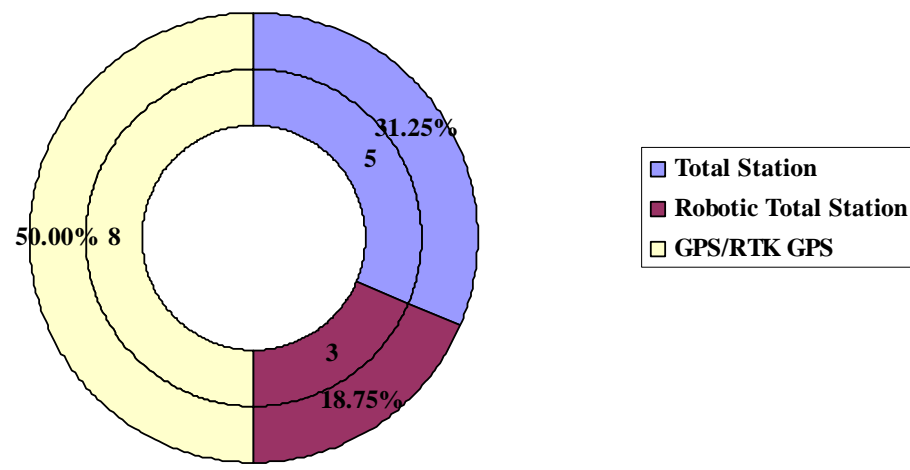

Figure 4.15 Use of Technology for a Project Less than 3 Miles 
The reason behind not using LiDAR, aerial photogrammetry or RTK GPS with CORS was the high initial investment needed to use those technologies. The GPS RTK GPS was the most popular technology for projects less than 3 miles.

For projects more than 3 miles, same trend was observed. Participants were mainly using GPS/RTK GPS on their projects (Figure 4.16). But the second most popular technology was RTS instead of total station in this case. The reason for choosing RTS instead of total station was its capacity for faster data collection, its accuracy and less labor requirements. The total station was the last choice for projects more than 3 miles.

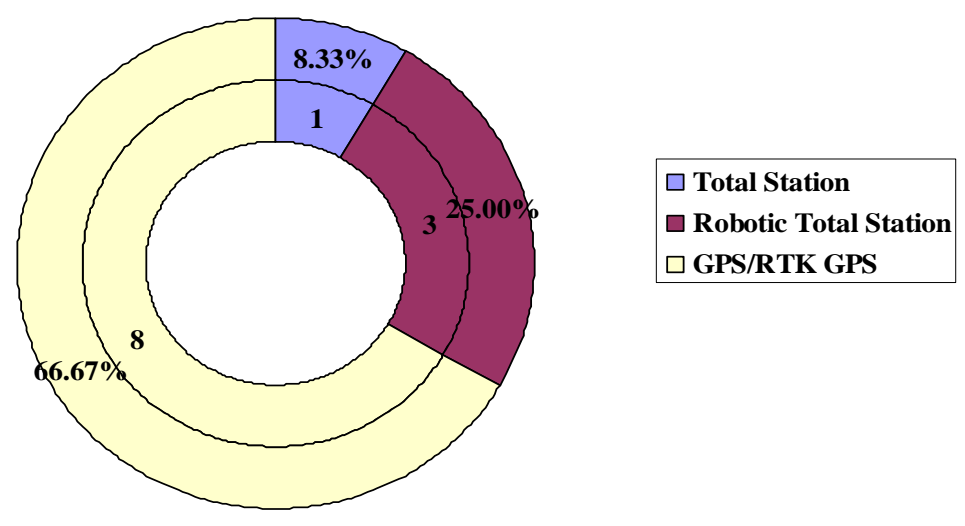

Figure 4.16 Use of Technology for a Project More than 3 Miles

Personnel requirement for different technologies varied from 3 for total station to 2 people for RTS and GPS technology (Figure 4.17). As a result, the cost of personnel is more for total station in comparison to the RTS and GPS/RTK GPS. 


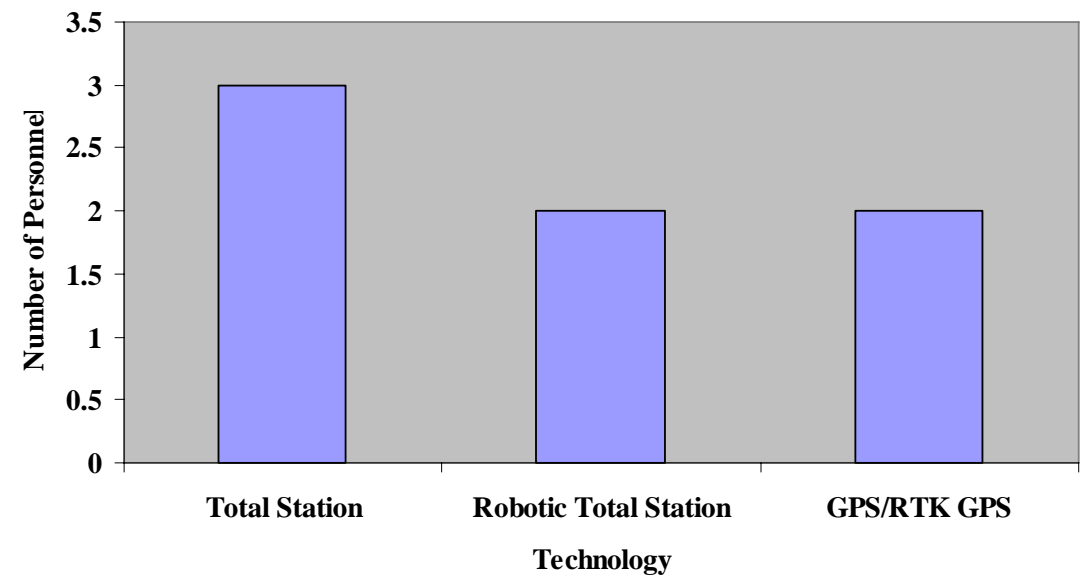

Figure 4.17 Average Personnel Requirement on Field for Different Technology

The next question was regarding the time required to collect the data for 1 mile in regular and irregular terrain. Figure 4.18 shows that the GPS/RTK GPS required the least amount of time in comparison to the RTS and total station. Total station needed the most amount of time among all three technologies.

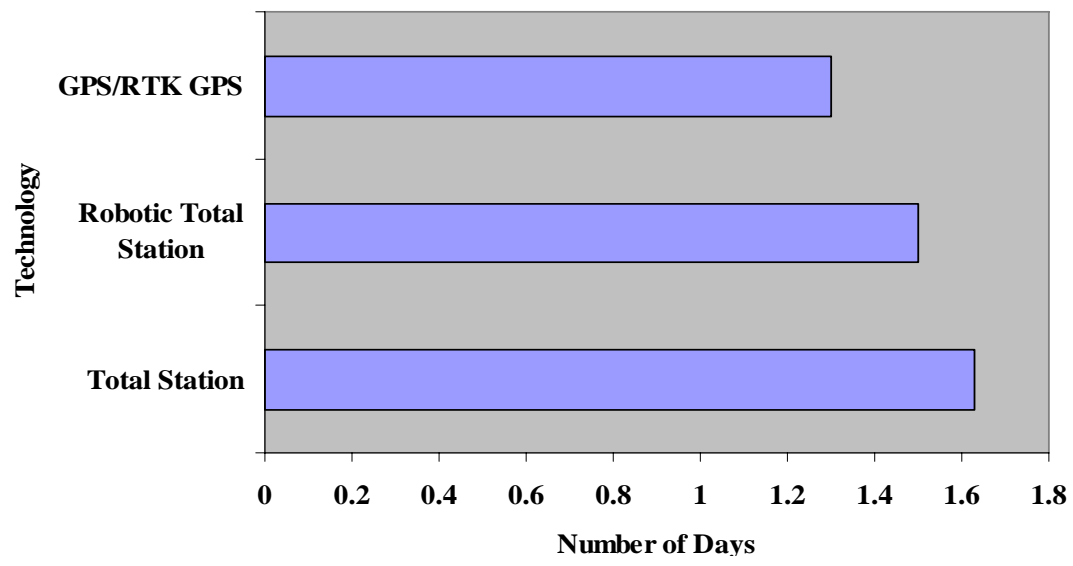

Figure 4.18 Time Required to Collect Data for Regular Terrain

For the irregular terrain, the result was the same. GPS/RTK GPS was the method which required the least amount of time to collect the data for irregular terrain while total station took 
the highest amount of time (figure 4.19). This analysis also shows that total station was the most time consuming method.

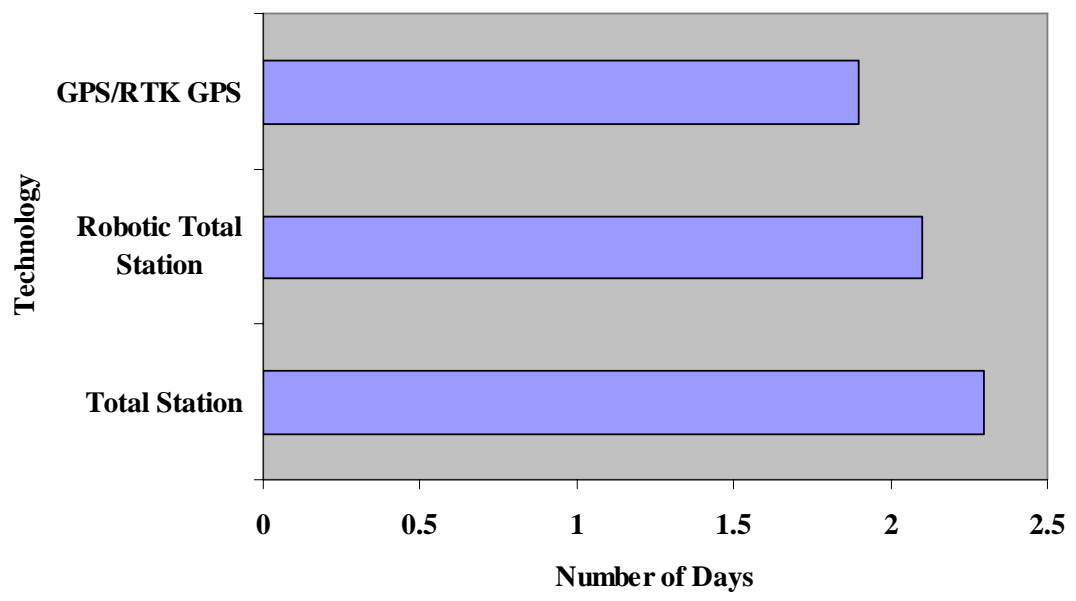

Figure 4.19 Time Required to Collect Data for Irregular Terrain

The average cost of personnel working on the field was around $\$ 45 / \mathrm{hr}$ which was interesting information. The average cost of personnel was $\$ 20 / \mathrm{hr}$ for the DOT personnel while for the private companies it is almost double. It was more or less same for different technologies. The respondents preferred Trimble instruments over Topcon as the second and Leica as the third (Figure 4.20).
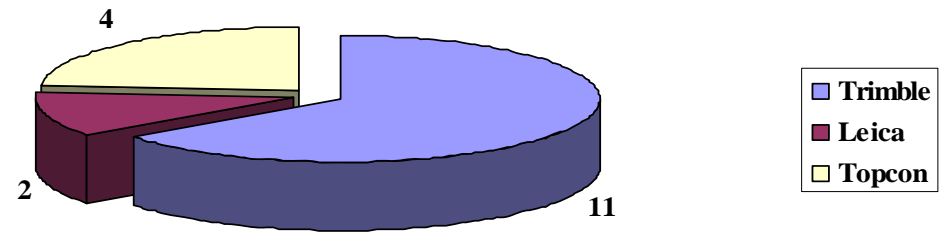

Figure 4.20 Use of Instruments of Different Companies 
The total station was the least costly instrument among all three options. It cost around $\$ 10,000$ on an average while RTS cost approximately \$32,000 and GPS cost around \$42,000 (figure 4.21).

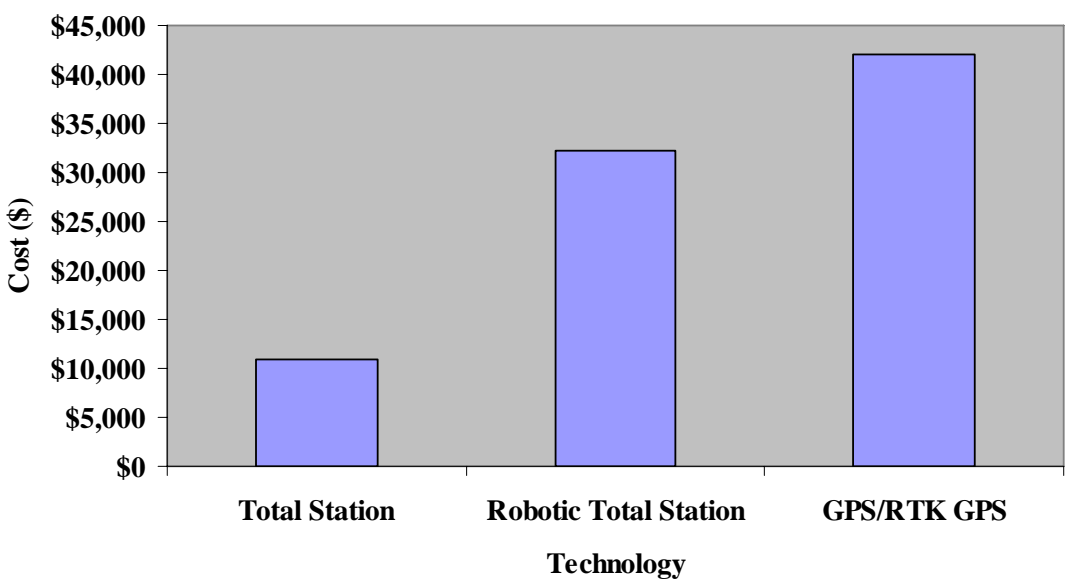

Figure 4.21 Average Cost of Different instruments

All participants responded that all the instruments had almost same life span from 10 to 12 years. The answer obtained from the DOTs was also similar. They said that the instruments had very good service life unless it was broken due to some reason.

In response to the question on the horizontal and vertical accuracy of the technologies used, the answers obtained were similar to the DOT answers. The most accurate technology was total station among all the three technologies, while GPS/RTK GPS was the least accurate method among the three options (figure 4.22). 


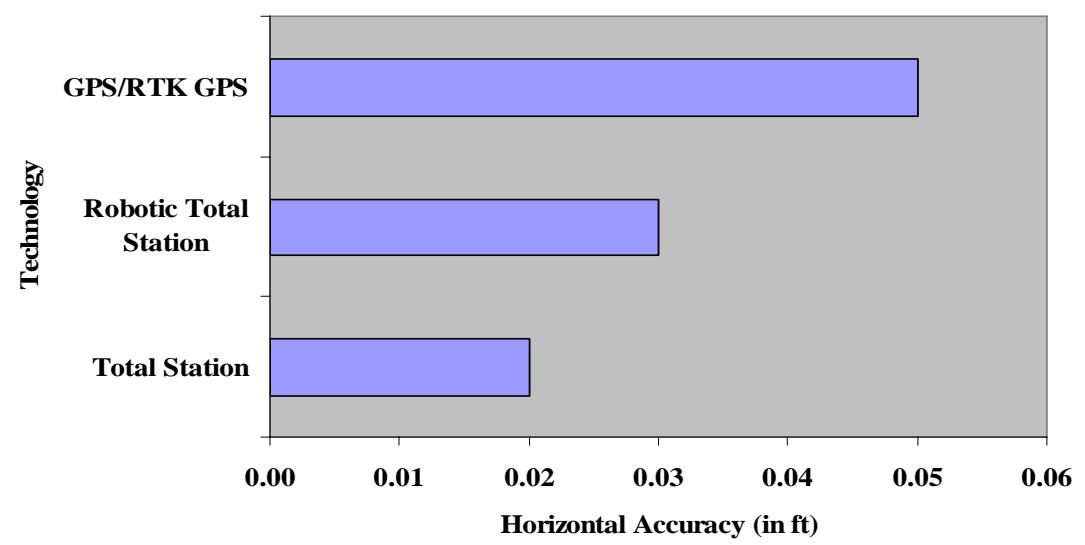

Figure 4.22 Horizontal Accuracy of Different Technologies

In terms of vertical accuracy, total station again topped the chart with the most accurate vertical accuracy. Figure 4.23 shows that the average vertical accuracy of total station was around 0.027 ', while RTS had an accuracy of 0.043'. The vertical accuracy of GPS/RTK GPS was approximately $0.1^{\text {' }}$ which was more than double the accuracy obtained by RTS and almost four times more than the accuracy obtained by total station. The horizontal and vertical accuracy of total station was highest while that for GPS/RTK GPS was the lowest.

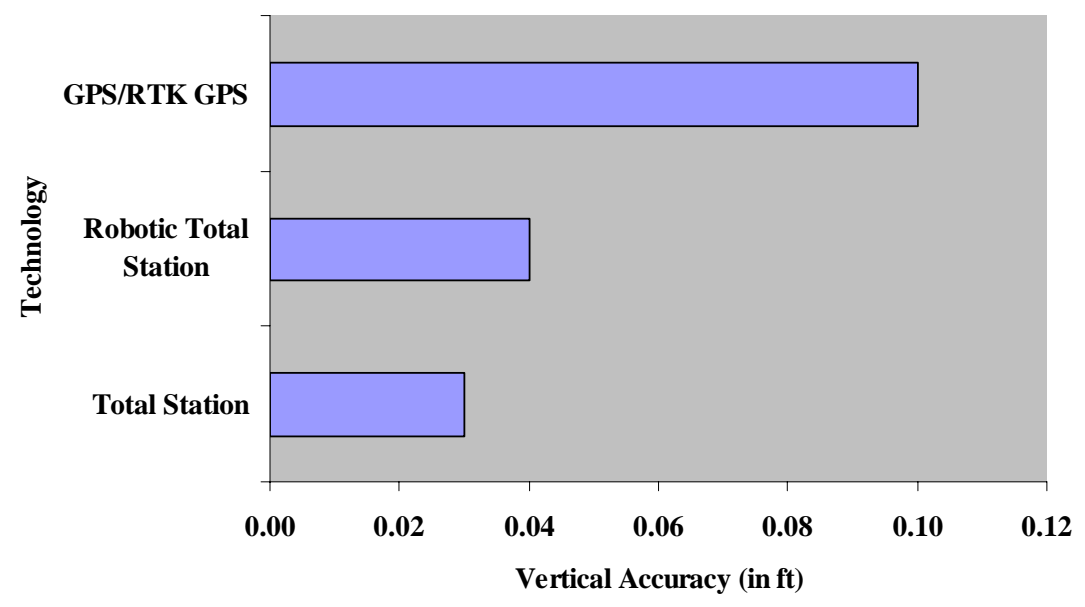

Figure 4.23 Vertical Accuracy of Different Technologies 
The participants were asked to give information on the advantages and limitations of the technologies used by them in earthwork data collection. The advantages and limitations were same as those obtained through the DOT questionnaire survey analysis discussed earlier. All the participants were using the same technology before and after construction (i.e. during the earthwork quantity assessment stage and earthwork pay quantity verification stage). Half of the participants were using tape/theodolite/digital level before using their current method for data collection, but then after noticing the advantages of the new technologies, they started using them. The rest of the participants were using manual total station before switching to either RTS or GPS/RTK GPS. The participants were asked to write their unit price for the earthwork process. However most of the contractors refused to give answer to this question. But some of the contractors said that they charged anywhere between $\$ 3$ to $\$ 15 / C Y$ depending on the various scenario. One contractor said that they charge anywhere between $\$ 3$ to $\$ 6 / \mathrm{CY}$ for the earthwork process.

All participants were using software methods to calculate earthwork quantities. Fifty percent $(50 \%)$ of the participants were using AutoCAD as their main software product to determine the quantity of earthwork. While other participants were using software products like Autodesk Land Development Desktop, Eaglepoint, C\&G survey, etc. It can be concluded here that AutoCAD is the most popular software product among the private players, while it was seen from the DOT questionnaire survey that Microstation and Geopak were the most popular software products. All the participants were satisfied using their respective software products. The only limitation of these software products is that they require certain level of expertise and training. The advantages of these software products were speed and accuracy, quick to get 
quantities of earthwork and good productivity. One of the participants was using Agtek software product before using the current method (i.e. Autodesk land Development Desktop). He changed to the current method because it was more versatile and it could perform more functions. Some participants were using manual average end area method before using their current method. But to keep up with other people and technology, to get more productivity, less human errors they changed to software products.

Participants required 2 engineers in the office to find out the estimated and final quantity of the earthwork. One engineer would perform the work and other would check it as discussed in the state DOTs subchapter. Sometimes, a client requires the use of a particular software product to get seamless data transfer between client and contractor. Seventy percent (70\%) of the participants replied that they had not face this kind of situation, while the other $30 \%$ replied positively saying that the owner asked them to use a particular software to get good compatibility with their software product. In their personal choice question, $90 \%$ of the participants wanted to use RTK GPS for data collection. Some participants wanted to use the combination of RTS and RTK GPS while some wanted to use the combination of total station and GPS. Almost all the participants had the knowledge on the current GPS related technologies i.e. GLONASS and GALILEO. Some of the participants were waiting for the results of the use of these technologies. Some participants didn't have infrastructure to use these technologies. Some participants were not satisfied with the early results of using these technologies.

The last segment of questions was on training related issues. Nine (9) out of 10 participants were giving training to their personnel either "regularly" or "sometimes". The 
average duration of training was from 1 to 2 days but it also depended on the type of training, the expertise level of the personnel, etc. The charge of training varied between $\$ 1,000$ to $\$ 1,500 /$ day as a flat fee or $\$ 400 /$ person. Some participants had their in-house training personnel, so they did not incur any cost from the training sessions. The participants said that training was the most important part as the cost of training is very minor in comparison to the cost of mistakes that could be made by the personnel working on the site or in the office.

\subsection{Analysis of Questionnaire Survey of Equipment and Software Companies}

This subchapter would give an analysis of the questionnaire survey sent to the equipment and software companies. As discussed in the data collection part, very less response was obtained from equipment and software companies. But the required information was found out from each company's website. Following is the analysis of the questionnaire survey for equipment and software companies.

The questionnaire survey was sent to Trimble, Leica, Topcon, Sokkia and TDS/Berger. In addition, lot of information was available on the companies' website and that information was obtained to perform the analysis. Table 4.1 shows the different models and different technologies for each company. All of these models are currently available in the market. 


\begin{tabular}{|c|c|c|c|c|c|c|c|}
\hline Company & Theodolite & Auto Level & Digital Level & Total Station & \begin{tabular}{|c|} 
Robotic Total \\
Station
\end{tabular} & $\begin{array}{c}\text { GPS/RTK } \\
\text { GPS }\end{array}$ & Others \\
\hline Trimble & N/A & N/A & Trimble DiNi & $\begin{array}{c}\text { Trimble M3 } \\
\text { Trimble } 3600\end{array}$ & $\begin{array}{c}\text { Trimble } 5600 \\
\text { Trimble S6 }\end{array}$ & $\begin{array}{c}\text { Trimble R8 } \\
\text { GNSS } \\
\text { Trimble R6 }\end{array}$ & $\begin{array}{c}\text { Trimble VX } \\
\text { Spatial } \\
\text { Station }\end{array}$ \\
\hline Leica & \begin{tabular}{|c} 
Leica Builder T, \\
Leica Builder R, \\
Leica Builder \\
RM
\end{tabular} & $\begin{array}{c}\text { Leica Runner, } \\
\text { Leica NA700, } \\
\text { Leica NA2/NAK2 }\end{array}$ & $\begin{array}{c}\text { Leica } \\
\text { Sprinter, } \\
\text { Leica DNA03 }\end{array}$ & \begin{tabular}{|} 
Leica TPS 700, \\
Leica TPS 800, \\
Leica TPS 1200
\end{tabular} & $\begin{array}{c}\text { Leica } \\
\text { Smartstation }\end{array}$ & $\begin{array}{c}\text { Leica GPS } \\
1200 \text { with } \\
\text { GNSS }\end{array}$ & N/A \\
\hline Topcon & $\begin{array}{l}\text { DT 200, DT } \\
\text { 200L }\end{array}$ & $\begin{array}{c}\text { AT-G series, } \\
\text { AT22A, AT24A }\end{array}$ & $\begin{array}{l}\text { DL101C, } \\
\text { DL102C, } \\
\text { DL103, } \\
\text { DL103AF }\end{array}$ & $\begin{array}{c}\text { GPT7500, } \\
\text { GTS750, } \\
\text { GPT7000I, } \\
\text { GPT7000, } \\
\text { GTS720 }\end{array}$ & $\begin{array}{l}\text { GPT9000A, } \\
\text { GTS900A, } \\
\text { GPT8203M }\end{array}$ & $\begin{array}{l}\text { Milimeter } \\
\text { GPS Plus }\end{array}$ & N/A \\
\hline Sokkia & DT7C, DT20C & N/A & $\begin{array}{l}\text { SDL30, } \\
\text { SDL50 }\end{array}$ & $\begin{array}{c}\text { Series 30R, } \\
\text { Series 30RK, } \\
\text { Series 030K, } \\
\text { Series 130R }\end{array}$ & $\begin{array}{l}\text { SRX Robotic } \\
\text { Total Station }\end{array}$ & $\begin{array}{l}\text { GSR } 2700 \\
\text { ISX }\end{array}$ & N/A \\
\hline
\end{tabular}

Table 4.1 models of Different Technologies in Different Companies (Refer to list of references at the end of the chapter)

The information contained in Table 4.1 was collected from the responses of questionnaire survey and from different companies’ website. All the manufacturers of these instruments claimed that their products were superior to the other products. Trimble had 9 different models that can be used in earthwork data collection process. Some of the advantages of those instruments were their simplicity, highest environmental protection, GPS products' compatibility with GNSS system etc. Their Trimble VX spatial station included Trimble VISION technology which combined total station, 3D scanning and Imaging (video/pictures). Their RTK GPS products were equipped with Trimble R-Track technology for comprehensive GNSS support.

Leica manufactured instruments for each and every technology. Their theodolites had the advantage of being fast with electronic data transfer capability. It also has the capability of 
measuring distance digitally with laser. Leica's auto levels had benefits of being low cost, accurate, less time consuming, good optics and better productivity. The total stations made by Leica have the characteristics of being reflector less measuring devices, long range capabilities, more functions and complex systems. The instruments made by Leica were among the best ones for the surveyors who are trained enough to use the instruments. Sokkia instruments were the cheapest one among all the companies but apart from all the basic features they didn't provide more features. Topcon instruments also had the characteristics of being weather protective, more productive, efficient, affordable and reliable.

In a way, all the manufacturers claimed their instruments to be the best ones in the surveying/construction field. The main lesson learned from this information was that all the instruments were having basic features in them but some might give extra features, some might have better quality, some might have low cost and some might have better functionality. In general, it totally depends on the customer's specifications of which instrument he/she wants to utilize.

The Trimble instruments seemed to be the costliest instruments among all the companies. Their total station cost $\$ 10,000$ on an average, while Sokkia total stations cost from $\$ 7,000$ to $\$ 11,000$. Trimble's robotic total station comes around $\$ 15,000$ to $\$ 30,000$, while Sokkia’s robotic total station costs around $\$ 20,000$ to $\$ 23,000$. Trimble’s RTK GPS costs around $\$ 40,000$ to $\$ 50,000$ which is almost $\$ 2,000$ to $\$ 3,000$ more than the Sokkia and Topcon's instruments. So the analysis shows that Sokkia has the least price for its instruments while Trimble is the costliest brand among all the competitors. But the advantage of Trimble is its simplicity. One can easily 
learn how to use the instrument in comparison to the Leica or Sokkia instruments. Leica instruments are the most complicated instruments and one needs to have training to use it. Leica instruments are also very powerful and it is one of the best options for the surveyors working on the field.

The accuracy levels and service life of all the instruments were more or less same and that should not be a deciding factor on choosing the right instrument. Different companies give different number of batteries and those batteries normally run for 6 to 8 hours depending upon its capacity. One has to charge it before using it; normally lithium iron batteries are being use in the surveying instruments. All the companies had their recommended instruments for earthwork data collection. According to Trimble, their VX Spatial Station could capture information on volumes and shapes. When not used for volume calculation, the Trimble VX could be used for standard survey applications, providing added-value on construction site. If highly detailed volume computation is required, Trimble GX 3D scanner could provide a fully comprehensive set of 3D details. However Trimble also said that Trimble R6 and R8 GNSS are recommended for working in open or long range environment. Leica recommended its smart station (combination of RTS and GPS) and its Leica GPS 1200 with GNSS system for the earthwork data collection. Topcon advised to use its GPS millimeter device or any of its robotic total station for long range projects. They said that these instruments would give better productivity and accurate results if used correctly, while Sokkia recommended its SRX robotic Total Station for collecting earthwork data. 
Five companies were approached to gather information about software products available. The questionnaire survey for state DOTs and Professional companies gave information on the most popular software among the participants. Bentley was the most popular software company among the state DOTs. Lots of DOTs were using Geopak, InRoads and Microstation in their quantity calculation process. However Autodesk was the most popular software company among the private players. Lots of players were using AutoCAD and Autodesk Land Development Desktop for their earthwork quantity calculations. So the companies to which the questionnaire survey was sent were Microsurvey, Bentley, Autodesk, Carlson and Traverse PC. Trimble was the other company from which software information was collected. Table 4.2 shows the different software products provided by different software companies.

\begin{tabular}{|c|c|}
\hline Company & Software Products Provided By the Company \\
\hline \hline Autodesk & AutoCAD 2008, AutoCAd Land Desktop 2008, AutoCAD Civil 3D 2008 \\
\hline Bentley & Microstation, Geopak, InRoads, MXRoad \\
\hline Carlson & Carlosn Survey 2008, Carlson Civil Suite 2008, Carlson Roads 2007 \\
\hline Microsurvey & MS CAD - earth, Field Genius \\
\hline Trimble & Terramodel, Paydirt, Trimble Geomatics Office, Trimble Business Center \\
\hline
\end{tabular}

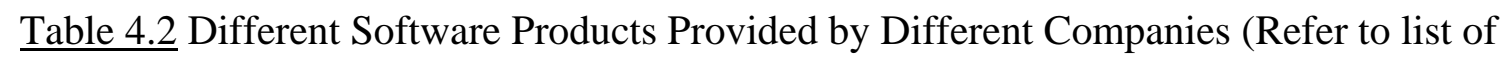
references at the end of the chapter)

The AutoCAD and Microstation are the two basic software products, which are used with other software products to come up with the final earthwork quantities. Generally various combinations of these software products are Microstation+Geopak, Microstation+InRoads, AutoCAD+Geopak or InRoads etc. Software products like Terramodel and Paydirt provided by Trimble can work with any of the software product (i.e. AutoCAD or Microstation). One 
limitation about the Trimble equipment is that it requires another Trimble product to transfer the data from the instrument to the computer. Various Trimble software products are listed in Table 4.2. Terramodel and Trimble Geomatics Office are some of the most powerful software products manufactured by Trimble. They can be used to calculate the quantities of earthwork as well as perform design work.

Carlson software products range from $\$ 1,500$ to $\$ 3,500$. The software products developed by Carlson are one of the most versatile products and they can perform lot more than just performing quantity calculations. These software products are also good for the design work. These software products can be used with AutoCAD to get the final quantities. Bentley products range from $\$ 5,000$ to $\$ 7,500$ which is more costly than the Carlson products. While Trimble products are the most costly software products. These software products range anywhere from $\$ 7,000$ to $\$ 9,000$.

All the companies advised to have training before using their products. Generally training duration ranged from 1 to 2 days with the flat fee of $\$ 1,000$ to $\$ 1,200$ per day. They also charge from $\$ 200$ to $\$ 1,000$ upgrade of the software products. Normally the selection of software products would depend on the selected instrument for the earthwork data collection. For example, Trimble product would require the use of Trimble software with either AutoCAD or Microstation. The selection of a software product also depends on personal choice. If the engineers are experienced with a specific software product, then that product could get more productivity and efficiency from the engineers. 


\subsection{Analysis of Case Study with Owner and Contractor}

Two case studies were performed as discussed earlier in the data collection stage in order to get some insights into problems faced by contractors in working with INDOT and problems faced by personnel working for INDOT on different construction projects. Several problems were found out from two case studies, one with contractor and one with owner. Following sub chapters will give a description on the problems found and some probable solutions suggested by owner personnel and contractor personnel. The solution will also include some suggestions made by research team in order to solve the problem.

\subsubsection{Analysis of SR 48 Reconstruction Project}

INDOT gives hard copies of drawings to each and every bidder when they are bidding on any construction project. The contractor either has to transfer these files to their computer and calculate the quantities of different material or they have to apply some manual method to come up with the quantities of different material for bidding. The contractor said that this procedure was really time consuming and tedious. The contractor suggested that if INDOT starts giving out digital plans, it would be easier for contractors to come up with the estimate in very less time and the winning contractor can use these files in the construction stage to put into their earthmoving equipment for stakeless construction. In this case, the owner and contractor would be using the same files, so the chances of claims would be very less. 
An innovative option was proposed by the contractor to make their work easy in the construction stage as well as to make life easy for the owners. Today, most of the contractors have on-board GPS on their earth moving equipment like bulldozers, scrapers, back hoes, etc. The owner (i.e. INDOT) can put their design drawings into a Personal Computer Memory (PCM) card and give it to the contractor. Owners just have to put one condition saying that contractors have to work according to this data. That PCM card will go into the on-board GPS and cutting and filling will be done according to that data. There will be very less claims from contractor as they are using the owner given data in the construction. The only disadvantage with this technology is that in case of lot of change orders, owner has to make changes into PCM card each time a change order is made. So it might take more time in doing this process each time a change order is made.

Contractor made a lot of emphasis on training. They give training to their personnel regularly, and training sessions run from 1 day to 2 days depending upon the type of training. Generally, on purchasing any instrument or software product, the vendor gives one day training to show how to use the instrument. The contractor said that the importance of training cannot be emphasized more heavily.

\subsubsection{Analysis of SR 129 Reconstruction Project}

The owner personnel provided some insights into SR 129 reconstruction project's problems and they also gave some suggestions on how to eliminate those problems. Firstly, there 
were lot of change orders due to inaccurate plans in SR 129 project and that was one of the reasons for delay in the project. Engineers working on that site said that owner's consultant did not perform a good job in making the plans and INDOT might not have checked the plans thoroughly before giving out to the contractors. Because of this error, lot of change orders took place and cost of the project increased. To counteract this problem, engineers suggested that owner should work closely with the consultant in the beginning stage of the project to come up with the correct plans. If the plans are not accurate, then there could be a lot of problems in the later stage of the project.

In SR 129 project, the owner had very less personnel on work. There were only 4 persons working on this project from the owner side and they were responsible for each and every activity happening on the 12 mile SR 129 reconstruction site. The work ranged from inspection, testing of soil and paving materials, stake out check, final elevations check, billing, final cross sections check and making of the same etc. The amount of work on this project required more number of personnel from the owner side. The engineers working on that project mentioned that 1 or 2 more engineers could have increased the productivity of the project and it could have helped in decreasing the delay on the project.

At the start of the project, owner did not have modern surveying instruments (i.e. GPS) for their use. They were relying on the contractor's data. They had to rent the equipment in the middle of the project from the contractor to work more productively and accurately. If they had this equipment from the start of the project the work could have progressed at a better speed and they would have been in a totally different situation. The reliance on contractor also made them 
handicapped for some period of time. Moreover, the owner didn't have the software (i.e. Terramodel) required for transferring the data from GPS instrument to the computer. They only had trial version of the software which had limited functions on it. But they came to know that Seymour district was using this software product which might be of use for them. The INDOT should coordinate with all the districts and try to purchase all the equipment and software products centrally from the main office.

As discussed before, the owner personnel had rented GPS equipment from the contractor. The owner personnel were given one day training on how to use this equipment. A person from USI consultant (a professional company) came on site to give training on some of the functions of GPS instrument. They were not given any professional training from any GPS equipment company. They were using this equipment by trial and error method. They also had to use Terramodel software for transferring the data from GPS instrument to the computer. However, they also didn't have expertise on this software and they were not given training on how to use this software. INDOT personnel said that their department should give them a proper training in order to use these modern instruments and software products efficiently and productively. They agreed that training would have made the work much easier and faster for them.

\subsection{Recommendations to INDOT based on Data Analysis}

This section includes the recommendations from the research team based on the data collection and data analysis of the INDOT telephone interviews, state DOT questionnaire 
surveys, equipment and software vendor interviews, professional companies' questionnaire surveys, case studies with owner and contractor and questionnaire surveys with equipment and software companies. The recommendations given in next few sub sections are based on the data analysis, researchers' point of view and according to the objectives mentioned in the beginning of the chapter.

\subsubsection{Selection of a Technology for Earthwork Data Collection}

The analysis of the data indicated that the INDOT engineers were mainly using total station and GPS in their process, while DOTs were mainly using total station, RTS, GPS/RTK GPS and aerial photogrammetry depending upon various conditions prevailing on the site as well as monetary and expertise issues. However, professional companies were mainly using GPS/RTK GPS, RTS and total station in their earthwork data collection process. When asked to give recommendations on their personal choice, participants recommended the combinations of RTK GPS, RTS and aerial photogrammetry depending on site conditions, timeline, accuracy required, environmental conditions, etc. Participants said that one should not choose only one technology to work with but a combination of various technologies would give the optimum solution.

The equipment companies and vendors of different equipment companies also suggested using combination of RTS and RTK GPS depending upon atmospheric, topographical, timeline, accuracy, etc. based on the suggestions and literature review done by researchers, a combination 
of RTS, RTK GPS and aerial photogrammetry for earthwork data collection could be recommended. GPS/RTK GPS and aerial photogrammetry options are one of the best options for large construction projects as they are the fastest and productive methods. The personnel requirement is also less in these methods and the accuracy levels are also competitive.

However RTK GPS, RTS and aerial photogrammetry are some of the costliest options available today. In comparison to the selected technologies, total station and digital levels are cheaper and they give the best accuracy. However, total station and digital level requires minimum 2 men on the field and it takes a lot of time to collect the data on the field in comparison to the chosen techniques. Some of the advantages like the electronic data transfer, software compatibility, etc., are also not available with these technologies. In a way, there is always a trade-off associated with selecting any technology. However, combination of RTS, RTK GPS and aerial photogrammetry seems to be the best option for INDOT projects.

\subsubsection{Equipment Company Selection}

After doing the data analysis, it was found out that Trimble was the most popular company among the INDOT participants, DOTs and professional companies. Trimble had the highest amount of share among all the manufacturing companies in all three parties. While Leica and Topcon were the second most popular companies within these three parties. As said in the analysis part, Trimble had the most costly equipment among all the companies. But the main advantage of Trimble was its simplicity. One would not require lot of time to learn Trimble 
instruments before using them. On the other hand, Leica and Topcon were cheaper than Trimble but one would want to have a proper training before using those instruments. Leica instruments were powerful but they were also complex, those instruments were perfect for the surveyors. After looking at all the companies, researchers found that Leica was one of the most efficient instrument for the surveying compared to other companies' instruments.

\subsubsection{Software Product Selection}

It was seen in the data analysis section that Bentley products were the most used products within different DOTs throughout the US. On the other hand, Autodesk products were the most used products in the private companies section. The companies like Carlson, Microsurvey, etc., were having a small share of market but they were more popular among the small private players. One more advantage of these companies is their low cost. Because of their low cost, small players could afford them in comparison to the high cost of Autodesk and Bentley products. Autodesk and Bentley, both companies had competitive software products that were giving satisfactory performance to the DOT participants and private companies' participants. However, it is important that all the offices of INDOT should use the same software product so that the data transfer is seamless and all are connected with each other. 


\subsubsection{Training Needs}

After getting response from INDOT engineers, state DOTs, professional companies, vendors and case study participants regarding various training related statistics and issues, it was determined that training should be given to INDOT personnel either at regular interval of time or at the time when any new technology is introduced in the market or in the organization.

Some of the INDOT engineers did not receive training from INDOT for the new technologies that they were using, so they had to self-train themselves. The efficiency and productivity of those engineers decreased because they did not know the correct way to use those technologies. They said that it would be useful if INDOT would start giving them training for the new techniques and methods. They said that it would be a win-win situation for both INDOT and the personnel who are taking that training. With the training, the productivity of personnel will be increased and he/she can work faster towards completing the project on time. The state DOT participants also mentioned the importance of training. They suggested giving training to the whole survey or design group when a technology or a software product is introduced in the organization. A number of participants were having in-house training personnel who give training to the employees in keeping them up to date with the technology. Those DOTs even didn’t have to pay for every individual training session as they had training personnel inside the organization. The private companies also gave training to their personnel on a regular basis. They also mentioned that the cost of training is very less compared to the cost of a mistake made by the personnel. 
So the preferred recommendation to the INDOT would be to have training personnel inside the organization who provide training to all the employees whenever training is required. It was observed in the INDOT that some districts were getting training at regular time while the other districts were not getting training. Training sessions given by the dealers could be coordinated for a particular technology at the time of buying it. The cost of such training is around $\$ 1,000 /$ day as a flat fee for up to 10 people. INDOT can coordinate with the surveyors working for them and try to arrange training session for them whenever a new technology is being introduced in the INDOT.

\subsubsection{Other Recommendations}

The researchers received some suggestions from the vendors of different equipment for earthwork data collection and the participants of the case studies done in Indiana. Some recommendations made by them and researchers are discussed below:

INDOT and the consultancy firm working with INDOT for preparing the drawings before bidding should work together and come up with the correct plans to give out to the bidders. Any mistake in these plans would be one of the main roots of the claims and discrepancy between owner and contractor. It was seen in one of the case studies that lot of change orders were one of the main reasons of the project delay and moreover more claims from contractor. The engineers working on that project informed that the plans were not up to the mark and that was one of the 
reasons for the delay. So, if owner and consultants work together in the early part of the stage and come up with the correct plans, then this problem can be solved.

INDOT should consider purchasing all the equipment and software products centrally for all the offices in Indiana and try to use the same products all over the state. From the case studies and talking with engineers, it seemed that all the districts were disconnected from each other and very less information was available with personnel on which software or instrument is being used by the other district. If the purchases are made centrally and all the offices are connected, then one can easily transfer the data from one office to other office and personnel can be transferred from one place to other depending upon the requirement. The personnel working in one office will not feel less comfort working on the same software in the other office. The coordination among all the offices can bring synergies and as a result of which the productivity of the offices can get increased.

One of the contractor also mentioned that if INDOT could give them the drawings digitally before the bidding it would be easier for them. The contractor also mentioned that presently almost all the earthwork contractors would have GPS on their earthmoving equipment, so INDOT could insert their drawing files in contractor's PCM card and give it to the contractor to put in their GPS equipment and use that data to do the earthwork during the construction. This way the contractor would be using the owner's data and there would be fewer chances of claims from contractor. One of the vendors mentioned about including a clause in the bid/specifications asking to use a particular software product, so that both owner and contractors are on the same plane and working together to achieve the goal. 


\subsection{Conclusions}

The data analysis was done on the data collected through telephone interviews with INDOT engineers, questionnaire surveys of state DOTs, professional companies, equipment and software companies, case studies with owner and contractor and personal interviews with equipment vendors.

The data provided an insight into the current state of practice within different DOTs and their views on different earthwork data collection and quantity calculation techniques. The case studies gave an insight into how things are actually working on site and what other problems could make an impact other than the methods for earthwork data collection and quantity calculation in the delay of the project. A good set of information about different equipment and software for earthwork data collection and quantity calculation was received from the vendor interviews; moreover the information and suggestions obtained from vendors were totally unbiased as they sell equipment and software products for more than one company and they knew the comparison between those companies and products.

Also data was analyzed with respect to the training needs for personnel working for earthwork data collection and quantity calculation. Some recommendations other than problems for earthwork data collection and quantity calculation techniques were identified including the organization structure of INDOT and training coordination among all the parties working under INDOT. 


\subsection{References}

Autodesk Inc., <www.autodesk.com> (Last Visited - 9/23/07)

Bentley Systems, Inc., <www.bentley.com> (Last Visited - 9/12/07)

Carlson Software, <www.carlsonsw.com> (Last Visited - 9/27/07)

Leica Geosystems, <www.leicaus.com> (Last Visited - 9/20/07)

Microsurvey, <www.microsurvey.com> (Last Visited - 9/27/07)

Sokkia Co., <www.sokkia.com> (Last Visited - 9/23/07)

Topcon Positioning Systems, Inc., <www.topconpositioning.com> (Last Visited - 9/18/07)

Trimble, Inc., <www.trimble.com> (Last Visited - 9/25/07) 


\section{CHAPTER 5. SUMMARY AND CONCLUSION}

\subsection{Overall Summary and Conclusion}

Unlike slowly growing construction industry, surveying industry has come a long way as far as the technology revolution is concerned. The amount of transformation in this sub industry is quite noticeable. This transformation has given efficiency and better productivity in the earthwork process. It has made the earthwork data collection and quantity calculation less time consuming, more efficient, more productive with less manpower and in the end more profitable. It is now high time for the organizations/private companies/surveyors and consultants to apply these modern methods of surveying for earthwork data collection and quantity calculation in their construction and infrastructure projects (if they still haven’t applied these techniques)

While reviewing different literature and talking to different vendors for earthwork data collection and quantity calculation, it was found out that different modern technologies have their own unique advantages and disadvantages when it came to efficiency, manpower requirement, cost, geographic flexibility, etc. Different techniques were advantageous in different scenario and one couldn't simply give priority to any of the techniques without any background on different constraints, characteristics and requirements of a particular project on which the technology would be applied. Main goals/objectives of this project were to find out such techniques for earthwork data collection and quantity calculation which can be used by INDOT on their large construction projects such that productivity and accuracy of earthwork 
data collection and quantity calculation could be improved, and to determine the training needs for the surveyors/engineers for using these new techniques and methods.

To achieve these goals, different properties like initial cost, personnel requirement on the field, maintenance requirement, advantages, disadvantages, etc., of those modern/current techniques for earthwork data collection and quantity calculation had to be determined. In order to find these properties, several parties were contacted by phone or email. The parties were Indiana DOT, different state DOTs throughout the US, equipment and software manufacturers, professional/surveying companies from Indiana and vendors of different equipment and software products for earthwork data collection and quantity calculation. These parties were either sent a questionnaire survey or they were asked questions over the phone or via personnel interviews. Case studies were also done with the owner and a contractor on two Indiana highway reconstruction projects.

From all these tasks, current state of practice for different participants, the problems in using these techniques, current state of training, and their opinion on new and modern technologies, etc., were determined. The main task was to analyze the subjective data derived from all these participants and to determine the state of the art and state of practice for earthwork data collection and quantity calculation. In terms of the technologies for earthwork data collection, the most popular technologies were RTK GPS, robotic total station and aerial photogrammetry. The combination of all three technologies with respect to different constraints, characteristics and requirements of a particular project would be most suitable as analyzed by the researchers from the collected data. The other recommendation derived from this research is to 
adopt a centralized purchasing system for different earthwork data collection instruments and quantity calculation software products. This would allow INDOT to know which district has which instrument and software and they can use those products among different districts when they need it. One more associated benefit with this initiative would be to have a central training for all the surveyors when INDOT buys a new instrument/software. By this way, all the personnel would be up to date with the use of these modern and efficient products.

The participants used different software products for earthwork quantity calculation. The data was transferred from instrument to computer and then the quantity was derived with the use of different software products. The most popular software product among all the DOTs was Bentley products. The data showed that almost $80 \%$ of the participants were using Bentley products for their earthwork quantity calculation, while Autodesk was the most popular software in the private sector. The researchers concluded that Bentley products would give INDOT an advantage because of experience of some of the INDOT personnel in using these products All the participants in this project put a heavy weight on the importance of training for organization's personnel. The training cost for any new technology of earthwork data collection and quantity calculation was approximately $\$ 1000 /$ day. It was suggested by the research team that whenever INDOT buys any instrument or software product from its centralized system, it should give a thorough 1 to 2 days of training on that particular new product to their related personnel and whenever those software products or instruments get updated; a quick update should be provided. By this way, the personnel will remain updated with the technology that they are using and their efficiency and productivity would go higher. 
Apart from these technical aspects of earthwork data collection and quantity calculation, the research team found out some other points of concern while talking to all the related participants. The participants recommended that INDOT should work closely with their consultants while preparing the drawings for the project to eliminate mistakes and the potential claims. In case of change orders, INDOT should give the revised copy of drawings to the contractor as soon as possible, so that it would be easy for the contractor to work according to the revised plans. As mentioned earlier, a centralized purchasing system for equipment and software products would benefit the working and coordination within INDOT.

\subsection{Limitations of This Research}

The project faced some limitations due to some of the constraints during the course of research. The limitations of this research are as follows:

- The timeline of this project did not allow the research team to do any experiment/test with the different instruments and software products. The researchers had to rely on questionnaire surveys, telephone/personal interviews and case studies to get the data in a short time. Moreover the data obtained was mostly subjective.

- The analysis of the data obtained from different parties involved in the project also depends on the number of responses obtained by the research team. The response obtained from professional companies in Indiana and equipment/software companies was very poor, which might have affected the results of the study. 
- The monetary constraints did not permit researchers to go out of the state and perform case studies throughout the U.S. Live demonstrations of different data collection and quantity calculation techniques on different projects would have provided additional insight into those techniques.

- The technologies used for earthwork data collection and quantity calculation are generally used for many other purposes (e.g., earthwork data collection technologies are also used in construction stage to measure elevation of final surface, in mapping, in bridge structures, for erosion control, in drainage construction, staking, etc., and quantity calculation software are also used in design of the project, land development, data management, stake out, etc.). So it may not be appropriate to choose a technology simply based on earthwork data collection and quantity calculation requirements. It may happen that a software product is powerful in calculating earthwork quantities but it may not be powerful in other required functions. So it was recommended by the researchers that before choosing any technology for earthwork data collection and quantity calculation, other uses of that technology should be identified and studied.

\subsection{Contributions of this Research}

This research provides significant benefits to INDOT and the construction/surveying industry as a whole. First off all, the literature review gives an overall idea on different past and current techniques of earthwork data collection and earthwork quantity calculation. It also gives an idea on some new techniques like stakeless construction and vangarde method. This 
information provides a good overview of the earthwork data collection/quantity calculation techniques.

A detailed view on the current techniques/methods on earthwork data collection and quantity calculation used by different DOTs throughout the United States and by different professional companies in Indiana was determined in this research. This data also included benefits and drawbacks of the current methods used by the DOTs/professional companies. This research also provides an insight into the different problems faced by the surveyors/engineers in using these instruments on site and the use of software products in the offices.

Through literature review, questionnaire surveys, case studies and personal interviews with vendors, this research gives an unbiased opinion on the advantages and disadvantages of different instruments and software products available in the market for earthwork data collection and quantity calculation. The case studies and vendor interviews provided some other issues on which INDOT can improve to make things smoother between contractor and owner. All the participants emphasized the importance of training for more efficient and productive work. The research provides data regarding normal duration and cost of training. Normal duration of training for survey equipment and related software products varies between 1 to 2 days individually and the cost of training is normally a flat fee of $\$ 1,000 /$ day up to a certain number of participants. The training cost increases if participant number goes beyond certain limit which could be in the range of $\$ 150$ to $\$ 300$ per person. It is recommended that INDOT give training to their personnel on whatever new instruments/software products they buy for earthwork data collection or quantity calculation. 


\subsection{Recommended Future Research}

This research provides foundation for selecting the appropriate methods for earthwork data collection and quantity calculation. While doing this research, several new things were found out which were connected to this research but because of time constraints and scope of this research they were eliminated from being researched further.

As discussed in the limitations of this research, because of monetary and time constraints the tasks performed in this research were dependent on other parties. It would be useful to conduct experimental tests/pilot studies on these potential new instruments and software products to better determine their pros and cons. A research study can be done on evaluating these technologies while they are being implemented in pilot/actual projects.

The stakeless construction is one of the upcoming technologies which is being used by some of the private contractors in United States in earthwork construction. The main objective of this technology is to reduce time of construction by increasing efficiency and productivity of the personnel working on the site. In this method, the drawings are downloaded onto the onboard GPS systems of excavators/bulldozers working on the site for excavation, and the equipment works according to the elevations given in the plans. Contractors have determined that this technology saves a lot of time and it reduces the claims from the contractors as contractors and owners are using the same set of plans. A thorough research can be done in extension to this research in understanding the mechanism of the onboard GPS system on the excavating equipment and the advantages/applicability of this equipment on large construction projects. 
Some states in the US have already specified the use of this technology as a step forward in trying to make the functions more efficient and productive.

As said earlier, it is not advisable to choose a technology simply on the basis of one application; but one should look into different uses of all the technologies and make decision on the product with multiple usages if possible. This research was specifically focused on choosing a technology for earthwork data collection and quantity calculation requirements. A research can be performed to find out other uses of different technologies available for earthwork data collection or quantity calculation and find out which technologies are best suitable for INDOT according to different uses of these technologies. 
BIBLIOGRAPHY 
Ackermann, Friedrich, "Airborne Laser Scanning - Present Status and Future Expectations”, ISPRS Journal of Photogrammetry \& Remote Sensing, Stuttgart, Germany.

Autodesk Inc., <www.autodesk.com> (Last Visited - 9/23/07)

Bentley Systems, Inc., <www.bentley.com> (Last Visited - 9/12/07)

Brenner, Claus (2006). "Digital Recording and 3D Modeling”, International Summer School, Greece, 24-29 April, 2006.

“CALTRANS", <http://www.dot.ca.gov/hq/esc/geometronics/vangarde.html>, (Last visited 9/2/2007)

Carlson Software, <www.carlsonsw.com> (Last Visited - 9/27/07)

Cole, George M., Harbin, Andrew L. (2006). Surveyor Reference Manual, Professional Publications, Inc., Belmont, CA.

Dagostino, Frank R., Feigenbaum, Leslie. (2003). Estimating in Building Construction, Prentice Hall, Inc., Upper Saddle River, N.J.

Duffell, C. G., Rudrum, D. M., "Remote Sensing Techniques for Highway Earthwork Assessment”, Manchester, United Kingdom.

Easa, Said M., “Eastimating Earthwork Volumes for Curved Roadways”, Ryerson University, Toronto, Canada.

Fotopoulos, Georgia, Kotsakis, Christopher, Sideris, Michael G., "How Accurately Can We Determine Orthometric Height Differences from GPS and Geoid Data”, University of Calgary, Calgary, Canada.

Highway Surveying Manual, (2005). Washington State Department of Transportation, USA.

$<$ http://www.cenews.com/article.asp?id=618 >, (Last Visited - 8/2/2007)

$<$ http://cms.transportation.org/sites/construction/docs/Gower\%20\%20Stakeless\%20Construction. pdf $>$, (Last Visited - 9/3/2007)

“Industrializing the Residential Construction Site” (2000). Center for Housing Research (2000), Virginia Polytechnic Institute, Department of Housing and Urban Development (HUD) (2000).

Habib, A. F., Ghanma, M. S., Tait, M. "Integration of LiDAR and Photogrammetry for Close Range Application”, Department of Geomatics Engineering, University of Calgary, Canada.

Kavanagh, Barry F. (2001). Surveying: with construction applications, Prentice Hall, Upper Saddle River, NJ. 
Leick, Alfred (2004). GPS satellite surveying, Wiley, New York, NY.

Leica Geosystems, <www.leicaus.com> (Last Visited - 9/20/07)

Leica TPS 1200, <http://www.advancedlasers.com/images/tps1200.jpg>, (Last Visited 8/29/2007)

Microsurvey, <www.microsurvey.com> (Last Visited - 9/27/07)

"New LiDAR Technology Helps U.S. Army Corps of Engineers Deal With Ages-Old Erosion Problem in Great Lakes Region”, $<$ http://www.woolpert.com/asp/articles/New_LiDAR_Technology.asp>, (Last Visited $8 / 29 / 2007)$

Norse, Edmund, "Defining the Future of Satellite Surveying with Trimble R-Track Technology”, Trimble Survey Division, Westminster, CO, USA.

“NYSDOT Continuously Operating Reference Station (CORS) Network”, Design Service Bureau, Land Surveying Section, NYSDOT, NY.

“ODOT’s State-Wide RTK GPS Network”, Ohio Department of Transportation, 28 October, 2005.

“Ohio Department of Transportation”, <http://www.dot.state.oh.us/>, (Last visited - 9/1/2007)

Petzold, Bettina, Reiss, Peter, Stossel, Wolfgag. "Laser Scanning-Surveying and Mapping Agencies are using a New Technique for the Derivation of Digital Terrain Models”, ISPRS Journal of Photogrammetry and Remote Sensing, Bonn, Germany.

Robotic Total Station, <http://www.teamelmers.com/surveying.htm>, (Last Visited - 8/22/2007)

Sokkia Co., <www.sokkia.com> (Last Visited - 9/23/07)

Sokkia Robotic Total Station, <http://www.jobsitesurvey.com/23choosets.htm>, (Last Visited 8/19/2007)

“Surveying and Mapping: History, Current Status, and Future Projections", $<$ http://scitation.aip.org/getabs/servlet/GetabsServlet?prog=normal\&id=JSUED20001280000 03000079000001\&idtype=cvips\&gifs=yes $>$, (Last Visited $-8 / 2 / 2007$ )

Txdot GPS User Manual, (2005). Texas Department of Transportation, TX, USA.

Topcon Positioning Systems, Inc., <www.topconpositioning.com> (Last Visited - 9/18/07)

Total Station Data Sheet, <www.trimble.com> (Last Visited -11/10/07) 
Trimble DiNi Digital level, <http://www.trimble.com/graphics/dini.jpg>, (Last Visited 8/28/2007)

Wolf, Paul R., Ghilani, Charles D. (2002). Elementary Surveying: An Introduction to Geomatics, Prentice Hall, Inc., Upper Saddle River, N.J.

Yanalak, M. (2005). “Computing Pit Excavation Volume”, Journal of Surveying Engineering, ASCE, February, Vol. 131, No. 1, pp. 15-19. 


\section{$\underline{\text { APPENDICES }}$}


Appendix 1: Questions for INDOT Engineers/Surveyors 


\section{$\underline{\text { Sample List of Questions for INDOT Engineers/Surveyors }}$}

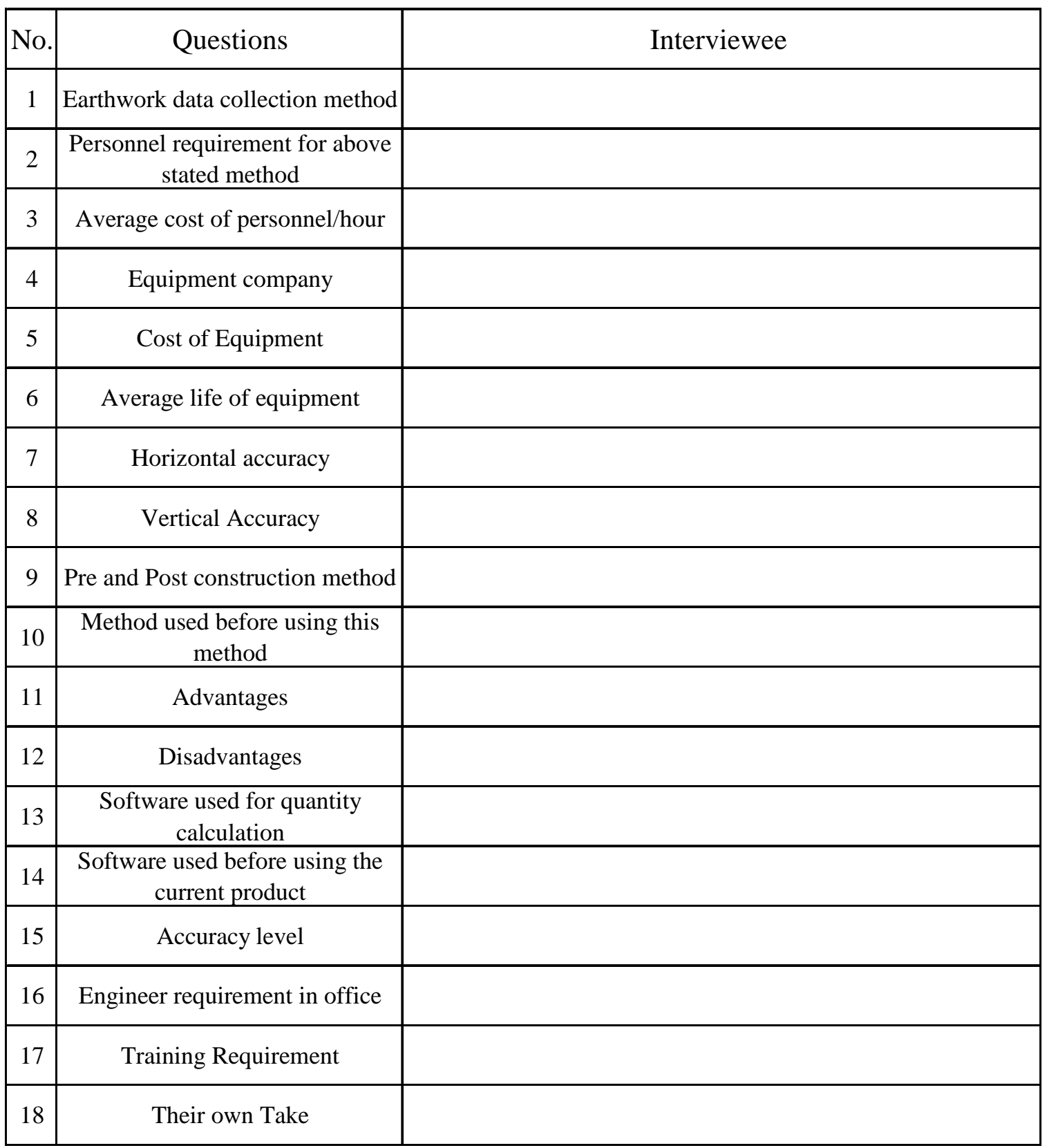


Appendix 2: Questionnaire Survey for State DOTs 


\section{Joint Transportation Research Program (JTRP)}

in Cooperation with the Indiana Department of Transportation and the Federal Highway Administration

\section{ACQUISITION AND ANALYSIS OF EARTHWORK PAY QUANTITY VERIFICATION DATA}

\section{Questionnaire}
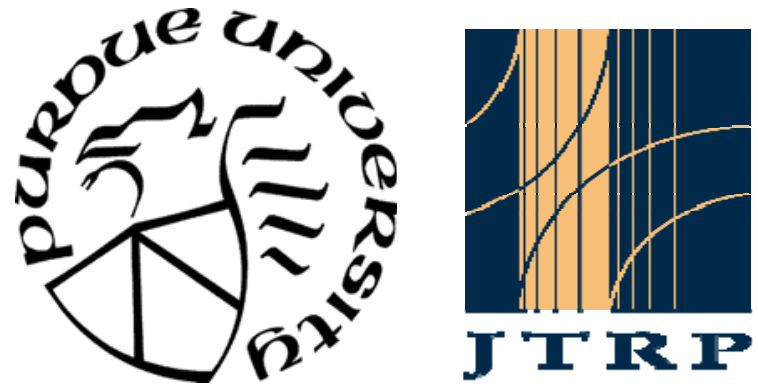

Conducted by:

$\underline{\text { Purdue University/Joint Transportation Research Program }}$

\begin{tabular}{|c|c|}
\hline \multicolumn{2}{|c|}{ Project Team } \\
\hline \multicolumn{2}{|c|}{$\begin{array}{c}\text { Dr. Makarand (Mark) Hastak } \\
\text { Professor of Civil Engineering } \\
\text { (Head, Div. of Constr. Engr. \& Mgmt., Purdue University) } \\
\text { email: hastak@ecn.purdue.edu } \\
\text { Phone: 765-494-0641 } \\
\text { Fax: (765) 494-0644 }\end{array}$} \\
\hline Research Assistant & $\begin{array}{c}\text { Sharvil Shah, MS student } \\
\text { (Div. of Constr. Engr. \& Mgmt. Purdue University) } \\
\text { email: shahss@purdue.edu }\end{array}$ \\
\hline Purdue University, School of $\mathrm{c}$ & $\begin{array}{l}\text { g, } 550 \text { Stadium Mall Drive, West Lafayette, } \\
907-2051\end{array}$ \\
\hline
\end{tabular}




\section{Purpose of Questionnaire}

This research is sponsored by the Joint Transportation Research Program in cooperation with the Indiana Department of Transportation and the Federal Highway Administration. This research is being conducted by Prof. Makarand (Mark) Hastak, Ph.D., CCE, School of Civil Engineering, Purdue University.

Earthwork is one of the main activities in any large construction project. Modern techniques and tools in data collection and quantity calculation of earthwork have created scope for decreasing the duration and personnel requirements, particularly for large and fast track projects. The main objective of this project is to find out different methods and tools that can be used in any large construction project for data acquisition and quantity calculations while saving time, personnel and money.

The purpose of this survey is to collect objective and subjective data with regard to various methods and tools used by different DOTs throughout the US for acquisition and analysis of earthwork pay quantity verification data for a construction project.

Your input will assist in the development of a detailed report and research summary that will compile the research findings. The final report will address current state of practice of various DOTs in the US, difficulties in using these techniques, efficiency, productivity, cost, man-hour requirements of different methods. The research will also recommend tools and methods that are best suitable for acquisition and analysis of earthwork pay quantity verification data and the required training needs. Please take a few minutes to complete the survey. Where numerical data is requested, reasonable estimates and/or ranges are acceptable. Please return the survey by e-mail or regular mail at the address provided on the last page.

\section{Some Important Terms:}

\section{AS-IS EARTHWORK QUANTITY ASSESSMENT STAGE}

Earthwork data acquisition and quantity calculations prior to construction to establish the approximate quantity of earthwork required.

\section{EARTHWORK PAY QUANTITY VERIFICATION STAGE}

Earthwork data acquisition and quantity calculations post construction to establish the actual quantity of earthwork and pay quantity verification.

\section{General Information}

Organization:

Respondent's name:

Position/Title:

Address:

Tel: Fax: E-mail: 
NOTE: Please answer the following questions with respect to your state of practice.

1. AS-IS EARTHWORK QUANTITY ASSESSMENT STAGE: PART-1

\begin{tabular}{|c|c|c|c|c|c|c|c|}
\hline Technology & $\begin{array}{c}\text { Method Used } \\
\text { (Upto } 3 \text { Miles } \\
\text { Length) }\end{array}$ & $\begin{array}{c}\text { Method Used } \\
\text { (More Than } \\
3 \text { Miles } \\
\text { Length) }\end{array}$ & $\begin{array}{c}\text { List } \\
\text { Personnel } \\
\text { Requirement }\end{array}$ & $\begin{array}{l}\text { Time Required } \\
\text { to take data for a } \\
\text { Length of } 1 \text { mile } \\
\text { (Regular } \\
\text { Terrain) }\end{array}$ & $\begin{array}{l}\text { Time Required } \\
\text { to take data for } \\
\text { a Length of } 1 \\
\text { mile (Irregular } \\
\text { Terrain) }\end{array}$ & $\begin{array}{l}\text { Average } \\
\text { Cost of } \\
\text { Personnel/ } \\
\text { Hour }\end{array}$ & $\begin{array}{l}\text { Equipment Used } \\
\text { (Manufacturer) }\end{array}$ \\
\hline \multicolumn{8}{|l|}{ Theodolite/Tape } \\
\hline \multicolumn{8}{|l|}{ Total Station } \\
\hline \multicolumn{8}{|c|}{$\begin{array}{c}\text { Robotic/Semi } \\
\text { Robotic Total Station }\end{array}$} \\
\hline \multicolumn{8}{|l|}{ GPS/RTK GPS } \\
\hline \multicolumn{8}{|l|}{$\begin{array}{c}\text { RTK GPS } \\
\text { (with CORS) }\end{array}$} \\
\hline \multicolumn{8}{|l|}{ LiDAR } \\
\hline \multicolumn{8}{|l|}{$\begin{array}{c}\text { Aerial } \\
\text { Photogrammetry }\end{array}$} \\
\hline $\begin{array}{l}\text { Other (Please } \\
\text { explain) }\end{array}$ & & & & & & & \\
\hline
\end{tabular}




\section{AS-IS EARTHWORK QUANTITY ASSESSMENT STAGE: PART-2}

\begin{tabular}{|c|c|c|c|c|c|c|}
\hline Technology & $\begin{array}{c}\text { Cost of } \\
\text { Equipment }\end{array}$ & $\begin{array}{c}\text { Average Life } \\
\text { of } \\
\text { Equipment } \\
\end{array}$ & $\begin{array}{c}\text { Horizontal } \\
\text { Accuracy }\end{array}$ & $\begin{array}{l}\text { Vertical } \\
\text { Accuracy }\end{array}$ & Advantages & Difficulties/ Limitations \\
\hline \multicolumn{7}{|l|}{ Theodolite/Tape } \\
\hline \multicolumn{7}{|l|}{ Total Station } \\
\hline \multicolumn{7}{|c|}{$\begin{array}{c}\text { Robotic/Semi } \\
\text { Robotic Total Station }\end{array}$} \\
\hline \multicolumn{7}{|l|}{ GPS/RTK GPS } \\
\hline \multicolumn{7}{|l|}{$\begin{array}{c}\text { RTK GPS } \\
\text { (with CORS) }\end{array}$} \\
\hline \multicolumn{7}{|l|}{ LiDAR } \\
\hline \multicolumn{7}{|l|}{$\begin{array}{c}\text { Aerial } \\
\text { Photogrammetry }\end{array}$} \\
\hline $\begin{array}{l}\text { Other (Please } \\
\text { explain) }\end{array}$ & & & & & & \\
\hline
\end{tabular}




\section{EARTHWORK PAY QUANTITY VERIFICATION STAGE: PART 1}

Please check here if the technologies used in this stage are the same as in the as-is earthwork quantity assessment stage:

\begin{tabular}{|c|c|c|c|c|c|c|c|}
\hline Technology & $\begin{array}{c}\text { Method Used } \\
\text { (Upto } 3 \text { Miles } \\
\text { Length) }\end{array}$ & $\begin{array}{c}\text { Method Used } \\
\text { (More Than } \\
3 \text { Miles } \\
\text { Length) }\end{array}$ & $\begin{array}{c}\text { List } \\
\text { Personnel } \\
\text { Requirement }\end{array}$ & $\begin{array}{c}\text { Time Required } \\
\text { to take data for a } \\
\text { Length of } 1 \text { mile } \\
\text { (Regular } \\
\text { Terrain) } \\
\end{array}$ & $\begin{array}{c}\text { Time Required } \\
\text { to take data for } \\
\text { a Length of } 1 \\
\text { mile (Irregular } \\
\text { Terrain) } \\
\end{array}$ & $\begin{array}{l}\text { Average } \\
\text { Cost of } \\
\text { Personnel/ } \\
\text { Hour }\end{array}$ & $\begin{array}{l}\text { Equipment Used } \\
\text { (Manufacturer) }\end{array}$ \\
\hline \multicolumn{8}{|l|}{ Theodolite/Tape } \\
\hline \multicolumn{8}{|l|}{ Total Station } \\
\hline \multicolumn{8}{|c|}{$\begin{array}{c}\text { Robotic/Semi } \\
\text { Robotic Total Station }\end{array}$} \\
\hline \multicolumn{8}{|l|}{ GPS/RTK GPS } \\
\hline \multicolumn{8}{|l|}{$\begin{array}{c}\text { RTK GPS } \\
\text { (with CORS) }\end{array}$} \\
\hline \multicolumn{8}{|l|}{ LiDAR } \\
\hline \multicolumn{8}{|l|}{$\begin{array}{c}\text { Aerial } \\
\text { Photogrammetry }\end{array}$} \\
\hline $\begin{array}{l}\text { Other (Please } \\
\text { explain) }\end{array}$ & & & & & & & \\
\hline
\end{tabular}


EARTHWORK PAY QUANTITY VERIFICATION STAGE: PART 2

\begin{tabular}{|c|c|c|c|c|c|c|}
\hline Technology & $\begin{array}{c}\text { Cost of } \\
\text { Equipment }\end{array}$ & $\begin{array}{c}\text { Average Life } \\
\text { of } \\
\text { Equipment } \\
\end{array}$ & $\begin{array}{c}\text { Horizontal } \\
\text { Accuracy }\end{array}$ & $\begin{array}{l}\text { Vertical } \\
\text { Accuracy }\end{array}$ & Advantages & Difficulties/ Limitations \\
\hline \multicolumn{7}{|l|}{ Theodolite/Tape } \\
\hline \multicolumn{7}{|l|}{ Total Station } \\
\hline \multicolumn{7}{|c|}{$\begin{array}{c}\text { Robotic/Semi } \\
\text { Robotic Total Station }\end{array}$} \\
\hline \multicolumn{7}{|l|}{ GPS/RTK GPS } \\
\hline \multicolumn{7}{|l|}{$\begin{array}{c}\text { RTK GPS } \\
\text { (with CORS) }\end{array}$} \\
\hline \multicolumn{7}{|l|}{ LiDAR } \\
\hline \multicolumn{7}{|l|}{$\begin{array}{c}\text { Aerial } \\
\text { Photogrammetry }\end{array}$} \\
\hline $\begin{array}{l}\text { Other (Please } \\
\text { explain) }\end{array}$ & & & & & & \\
\hline
\end{tabular}


2. Please answer the questions given in the following table, If Applicable.

\section{AS-IS EARTHWORK QUANTITY ASSESSMENT STAGE}

\begin{tabular}{|c|c|c|c|c|c|c||}
\hline Technology & $\begin{array}{c}\text { Own/ } \\
\text { Subcontract }\end{array}$ & $\begin{array}{c}\text { Type of } \\
\text { Aircraft Used }\end{array}$ & $\begin{array}{c}\text { Rate of } \\
\text { Aircraft/ Hour }\end{array}$ & $\begin{array}{c}\text { Technology } \\
\text { Maintenance } \\
\text { Cost/Year }\end{array}$ & $\begin{array}{c}\text { Fuel Cost/ } \\
\text { Hour }\end{array}$ & $\begin{array}{c}\text { Charge (If } \\
\text { Subcontracted) }\end{array}$ \\
\hline LiDAR & & & & & & \\
\hline $\begin{array}{c}\text { Aerial } \\
\text { Photogrammetry }\end{array}$ & & & & & & \\
\hline
\end{tabular}

\section{EARTHWORK PAY QUANTITY VERIFICATION STAGE}

\begin{tabular}{|c|c|c|c|c|c|c|}
\hline Technology & $\begin{array}{c}\text { Own/ } \\
\text { Subcontract }\end{array}$ & $\begin{array}{c}\text { Type of } \\
\text { Aircraft Used }\end{array}$ & $\begin{array}{c}\text { Rate of } \\
\text { Aircraft/ Hour }\end{array}$ & $\begin{array}{c}\text { Technology } \\
\text { Maintenance } \\
\text { Cost/Year }\end{array}$ & $\begin{array}{c}\text { Fuel Cost/ } \\
\text { Hour }\end{array}$ & $\begin{array}{c}\text { Charge (If } \\
\text { Subcontracted) }\end{array}$ \\
\hline LiDAR & & & & & & \\
\hline $\begin{array}{c}\text { Aerial } \\
\text { Photogrammetry }\end{array}$ & & & & & & \\
\hline
\end{tabular}


3. Which methods were being used by your department before using this method of surveying?

As is earthwork quantity assessment stage

Earthwork pay quantity verification stage

4. If you have changed your method, when and why did you change it?

As is earthwork quantity assessment stage

Earthwork pay quantity verification stage 


\section{Quantity Calculation stage}

1. Which method do you use for calculating earthwork quantities?

$\square$ Manual

$\square$ Software

2. If you use a manual method, which manual method do you generally use?

$\square$ Average end area method

$\square$ Cross section method

$\square$ Other:

3. If you use software for quantity calculation, which software do you use?
$\square$ InRoads
$\square$ AutoCad
$\square$ Microstation
$\square$ Geopak
$\square$ Other:

4. What level of accuracy do you get for earthwork quantity calculations using your current method(s)?

5. Do you find any difficulty in using your current method(s)?

6. What are the advantages of the current method(s) of quantity calculation that you use in your department?

7. How many engineers are required to process the data in the office? (approximately) 
8. How much time is generally required to process the data and get the final quantity in the office? (approximately)

9. Which method of quantity calculation were you using before using this method?

10. If you have changed your method from an old one, what is the reason behind changing the method?

11. If you are given the opportunity to choose any of the following methods for earthwork quantity calculation, which method(s) would you choose?

$\square$ Theodolite/Tape

Total Station

$\square$ Semi Robotic/Robotic Total Station

$\square$ GPS/RTK GPS

$\square$ LiDAR

Aerial Photogrammetry

WHY?

12. Do you know about GLONASS and GALILEO technologies?

$\square$ Yes

$\square$ No

If yes, what is your opinion about these technologies? Are you planning to adapt these technologies in the near future? 
13. Does your department provide training to your employees at regular interval to familiarize with the new technology?

$\square$ Yes

$\square$ No

14. What is the duration of the training session?

15. What is the approximate cost of training per person?

\section{Thank you for your input}

Please return the finished questionnaire by July 31, 2007 to:

\begin{tabular}{|c|c|}
\hline E-mail & shahss@purdue.edu, hastak@ecn.purdue.edu \\
\hline & Dr. Makarand (Mark) Hastak, \\
Professor of Civil Engineering \\
Address & (Head, Div. of Constr. Engr. \& Mgmt. Purdue University) \\
School of Civil Engineering, \\
\\
550 Stadium Mall Drive, West Lafayette, \\
Indiana, 47907-2051 \\
Phone: 765-494-0641 \\
Fax: (765) 494-0644
\end{tabular}


Appendix 3: Questions for Equipment/Software Vendors 


\section{Sample List of Questions for Equipment/Software Vendors}

1. Company Name

2. Which company's equipment they sell?

3. Name/model number of the equipment in each company.

4. All the characteristics of the equipment (no of models, name of model, cost, accuracy, advantages, built in collection memory, service life, personnel requirement, maintenance requirement, battery requirement, measuring range etc.)

5. How does vendor think about each and every company?

6. Selling data/statistics of each company's equipment

7. Do any of these companies have any time saving features?

8. Which company's equipment is better for earthwork data collection? Why?

9. Any special characteristics of these equipment?

10. Training requirement for these equipment?

11. Cost of training?

12. Duration of training?

13. Have they ever given training to INDOT?

14. Any compatible Software with these equipment?

15. Licensing cost, upgrade requirements, training requirements and duration, accuracy, special features of this product with respect to earthwork data collection etc

16. Are any of the companies developing any new technology that would facilitate this work?

17. Best combination of software and equipment? (for earthwork process)

18. What would be your recommended equipment under different circumstances of data collection for earthwork? Why? 
Appendix 4: Questionnaire Survey for Equipment Companies 


\section{Joint Transportation Research Program (JTRP)}

in Cooperation with the Indiana Department of Transportation and the Federal Highway Administration

\section{ACQUISITION AND ANALYSIS OF EARTHWORK PAY QUANTITY VERIFICATION DATA}

\section{Questionnaire}
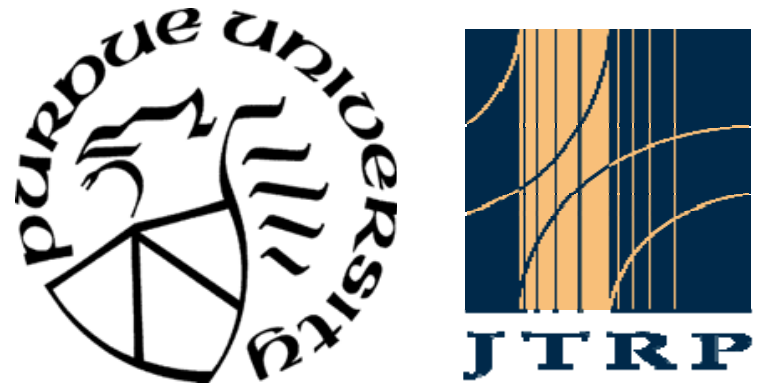

Conducted by:

$\underline{\text { Purdue University/Joint Transportation Research Program }}$

\begin{tabular}{|c|c|}
\hline \multicolumn{2}{|c|}{ Project Team } \\
\hline \multicolumn{2}{|c|}{$\begin{array}{c}\text { Dr. Makarand (Mark) Hastak } \\
\text { Professor of Civil Engineering } \\
\text { (Head, Div. of Constr. Engr. \& Mgmt., Purdue University) } \\
\text { email: hastak@ecn.purdue.edu } \\
\text { Phone: 765-494-0641 } \\
\text { Fax: (765) 494-0644 }\end{array}$} \\
\hline Research Assistant & $\begin{array}{c}\text { Sharvil Shah, MS student } \\
\text { (Div. of Construction Engineering \& Management) } \\
\text { email: shahss@purdue.edu }\end{array}$ \\
\hline Purdue University, School of $\mathrm{c}$ & $\begin{array}{l}\text {, } 550 \text { Stadium Mall Drive, West Lafayette, } \\
7-2051\end{array}$ \\
\hline
\end{tabular}




\section{Purpose of Questionnaire}

This research is sponsored by the Joint Transportation Research Program in cooperation with the Indiana Department of Transportation and the Federal Highway Administration. This research is being conducted by Prof. Makarand (Mark) Hastak, Ph.D., CCE, School of Civil Engineering, Purdue University.

Earthwork is one of the main activities in any large construction project. Modern techniques and tools in data collection and quantity calculation of earthwork have created scope for decreasing the duration and personnel requirements, particularly for large and fast track projects. The main objective of this project is to find out different methods and tools that can be used in any large construction project for data acquisition and quantity calculations while saving time, personnel and money.

The specific purpose of this survey is to collect objective and subjective data with regard to various equipment and software produced by different companies throughout the US for acquisition and analysis of earthwork pay quantity verification data for a construction project. For example, Total Station, GPS, LiDAR etc. and the associated software.

Your input will assist in the development of a detailed report and research summary that will compile the research findings. The final report will address current state of practice of various DOTs in the US, efficiency, productivity, cost, man-hour requirements of different methods as well as difficulties in using these techniques. The research will also recommend tools and methods that are best suitable for acquisition and analysis of earthwork pay quantity verification data and the required training needs. Please take a few minutes to complete the survey. Where numerical data is requested, reasonable estimates and/or ranges are acceptable. Please return the survey by e-mail or regular mail at the address provided on the last page.

\section{General Information}

Organization:

Respondent's name:

Position/Title:

Address:

Tel: Fax: E-mail: 
NOTE: Please complete the following two tables for each and every equipment model available from your company.

5. EQUIPMENT FOR EARTHWORK DATA COLLECTION

\begin{tabular}{|c|c|c|c|c|c|c|c|}
\hline Technology & $\begin{array}{l}\text { No. of } \\
\text { Models }\end{array}$ & Name of Models & $\begin{array}{c}\text { Average } \\
\text { Cost or } \\
\text { Cost } \\
\text { Range }\end{array}$ & $\begin{array}{c}\text { Time required } \\
\text { to collect data } \\
\text { for a length of } \\
1 \text { mile (regular } \\
\text { terrain) } \\
\end{array}$ & $\begin{array}{l}\text { Time required } \\
\text { to collect data } \\
\text { for a length of } 1 \\
\text { mile (Irregular } \\
\text { terrain) } \\
\end{array}$ & $\begin{array}{c}\text { Accuracy } \\
\text { (Specify } \\
\text { Unit) }\end{array}$ & $\begin{array}{c}\text { Please } \\
\text { elaborate } \\
\text { your } \\
\text { response on } \\
\text { Accuracy } \\
\end{array}$ \\
\hline \multicolumn{8}{|c|}{$\begin{array}{c}\text { Theodolite/Digital } \\
\text { Level }\end{array}$} \\
\hline \multicolumn{8}{|l|}{ Total Station } \\
\hline \multicolumn{8}{|l|}{$\begin{array}{l}\text { Semi Robotic } \\
\text { Total Station }\end{array}$} \\
\hline \multicolumn{8}{|l|}{$\begin{array}{l}\text { Robotic Total } \\
\text { Station }\end{array}$} \\
\hline \multicolumn{8}{|l|}{ GPS } \\
\hline \multicolumn{8}{|l|}{ RTK GPS } \\
\hline \multicolumn{8}{|l|}{$\begin{array}{c}\text { Aerial } \\
\text { Photogrammetry }\end{array}$} \\
\hline $\begin{array}{l}\text { Other (Please } \\
\text { explain) }\end{array}$ & & & & & & & \\
\hline
\end{tabular}




\begin{tabular}{|c|c|c|c|c|c|}
\hline Technology & $\begin{array}{c}\text { Advantages with respect to } \\
\text { your Competitor(s) }\end{array}$ & $\begin{array}{c}\text { In-built Data } \\
\text { Collection } \\
\text { Memory } \\
\end{array}$ & $\begin{array}{l}\text { Measuring } \\
\text { Range }\end{array}$ & $\begin{array}{c}\text { Service Life } \\
\text { (Normal } \\
\text { Conditions) } \\
\end{array}$ & $\begin{array}{c}\text { Personnel } \\
\text { Requirement on } \\
\text { the field }\end{array}$ \\
\hline \multicolumn{6}{|l|}{$\begin{array}{l}\text { Theodolite/Digital } \\
\text { Level }\end{array}$} \\
\hline \multicolumn{6}{|l|}{ Total Station } \\
\hline \multicolumn{6}{|l|}{$\begin{array}{l}\text { Semi Robotic } \\
\text { Total Station }\end{array}$} \\
\hline \multicolumn{6}{|l|}{$\begin{array}{l}\text { Robotic Total } \\
\text { Station }\end{array}$} \\
\hline \multicolumn{6}{|l|}{ RTK GPS } \\
\hline \multicolumn{6}{|l|}{$\begin{array}{c}\text { Aerial } \\
\text { Photogrammetry }\end{array}$} \\
\hline $\begin{array}{l}\text { Other (Please } \\
\text { explain) }\end{array}$ & & & & & \\
\hline
\end{tabular}




\begin{tabular}{|c|l|l|l|l|l|l|}
\hline Technology & Maintenance Requirement & $\begin{array}{c}\text { Battery } \\
\text { Required and } \\
\text { cost }\end{array}$ & $\begin{array}{c}\text { Life of } \\
\text { Battery }\end{array}$ & $\begin{array}{c}\text { Additional } \\
\text { Hardware } \\
\text { Requirement } \\
\text { (If Any) }\end{array}$ & $\begin{array}{c}\text { Duration } \\
\text { of } \\
\text { Training }\end{array}$ & $\begin{array}{c}\text { Cost of } \\
\text { Training } \\
\text { (Specify } \\
\text { Unit) }\end{array}$ \\
\hline $\begin{array}{c}\text { Theodolite/Digital } \\
\text { Level }\end{array}$ & & & & & & \\
\hline $\begin{array}{c}\text { Total Station } \\
\text { Semi Robotic } \\
\text { Total Station }\end{array}$ & & & & & & \\
\hline $\begin{array}{c}\text { Robotic Total } \\
\text { Station }\end{array}$ & & & & & & \\
\hline $\begin{array}{c}\text { GPS } \\
\text { RTK GPS }\end{array}$ & & & & & & \\
\hline $\begin{array}{c}\text { Aerial } \\
\text { Photogrammetry }\end{array}$ & & & & & & \\
\hline $\begin{array}{c}\text { Other (Please } \\
\text { explain) }\end{array}$ & & & & & & \\
\hline
\end{tabular}


SOFTWARE FOR EARTHWORK QUANTITY CALCULATION

\begin{tabular}{|c|c|c|c|c|c|c|c|c|}
\hline Technology & $\begin{array}{l}\text { Specified } \\
\text { Software }\end{array}$ & $\begin{array}{l}\text { Cost of } \\
\text { Licensing } \\
\text { (software) }\end{array}$ & $\begin{array}{l}\text { Any Other } \\
\text { Compatible } \\
\text { Software }\end{array}$ & $\begin{array}{l}\text { Training } \\
\text { Requirement } \\
\text { to use this } \\
\text { software }\end{array}$ & $\begin{array}{c}\text { Duration } \\
\text { of } \\
\text { Software } \\
\text { Training }\end{array}$ & $\begin{array}{c}\text { Cost of } \\
\text { Software } \\
\text { Training } \\
\text { (Specify Unit) }\end{array}$ & $\begin{array}{c}\text { Accuracy } \\
\text { of } \\
\text { Software } \\
\text { (Specify } \\
\text { Unit) } \\
\end{array}$ & $\begin{array}{c}\text { Please } \\
\text { elaborate } \\
\text { your } \\
\text { response on } \\
\text { Accuracy } \\
\end{array}$ \\
\hline \multicolumn{9}{|l|}{$\begin{array}{c}\text { Theodolite/Digital } \\
\text { Level }\end{array}$} \\
\hline \multicolumn{9}{|l|}{ Total Station } \\
\hline \multicolumn{9}{|l|}{$\begin{array}{l}\text { Semi Robotic } \\
\text { Total Station }\end{array}$} \\
\hline \multicolumn{9}{|l|}{$\begin{array}{l}\text { Robotic Total } \\
\text { Station }\end{array}$} \\
\hline \multicolumn{9}{|l|}{ GPS } \\
\hline \multicolumn{9}{|l|}{ RTK GPS } \\
\hline \multicolumn{9}{|l|}{$\begin{array}{c}\text { Aerial } \\
\text { Photogrammetry }\end{array}$} \\
\hline $\begin{array}{l}\text { Other (Please } \\
\text { explain) }\end{array}$ & & & & & & & & \\
\hline
\end{tabular}


1. What would be your recommended equipment under different circumstances of data collection for earthwork? Why?

2. What would be your recommended software product under different circumstances of quantity calculation for earthwork? Why?

3. Would you please send us the brochure for all of the above mentioned survey equipments by email or by post to the address given below?

\section{Thank you for your input}

Please return the finished questionnaire by Jull 22, 2007 to:

\begin{tabular}{|c|c|}
\hline E-mail & shahss@purdue.edu, hastak@ecn.purdue.edu \\
\hline & Dr. Makarand (Mark) Hastak, \\
Professor of Civil Engineering \\
Address & (Head, Div. of Constr. Engr. \& Mgmt. Purdue University) \\
& School of Civil Engineering, \\
& 550 Stadium Mall Drive, West Lafayette, \\
& Indiana, 47907-2051 \\
& Phone: 765-494-0641 \\
Fax: (765) 494-0644
\end{tabular}


Appendix 5: Questionnaire Survey for Software Companies 


\section{Joint Transportation Research Program (JTRP)}

in Cooperation with the Indiana Department of Transportation and the Federal Highway Administration

\section{ACQUISITION AND ANALYSIS OF EARTHWORK PAY QUANTITY VERIFICATION DATA}

\section{Questionnaire}
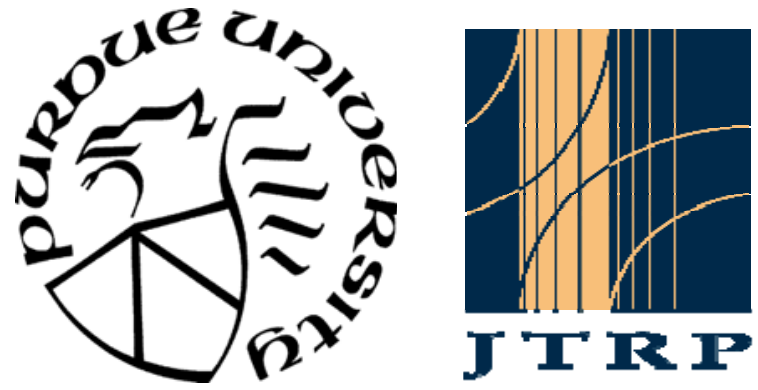

Conducted by:

$\underline{\text { Purdue University/Joint Transportation Research Program }}$

\begin{tabular}{|c|c|}
\hline \multicolumn{2}{|c|}{ Project Team } \\
\hline \multicolumn{2}{|c|}{$\begin{array}{c}\text { Dr. Makarand (Mark) Hastak } \\
\text { Professor of Civil Engineering } \\
\text { (Head, Div. of Constr. Engr. \& Mgmt., Purdue University) } \\
\text { email: hastak@ecn.purdue.edu } \\
\text { Phone: 765-494-0641 } \\
\text { Fax: (765) 494-0644 }\end{array}$} \\
\hline Research Assistant & $\begin{array}{c}\text { Sharvil Shah, MS student } \\
\text { (Div. of Construction Engineering \& Management) } \\
\text { email: shahss@purdue.edu }\end{array}$ \\
\hline Purdue University, School of $\mathrm{c}$ & $\begin{array}{l}\text {, } 550 \text { Stadium Mall Drive, West Lafayette, } \\
7-2051\end{array}$ \\
\hline
\end{tabular}




\section{Purpose of Questionnaire}

This research is sponsored by the Joint Transportation Research Program in cooperation with the Indiana Department of Transportation and the Federal Highway Administration. This research is being conducted by Prof. Makarand (Mark) Hastak, Ph.D., CCE, School of Civil Engineering, Purdue University.

Earthwork is one of the main activities in any large construction project. Modern techniques and tools in data collection and quantity calculation of earthwork have created scope for decreasing the duration and personnel requirements, particularly for large and fast track projects. The main objective of this project is to find out different methods and tools that can be used in any large construction project for data acquisition and quantity calculations while saving time, personnel and money.

The purpose of this survey is to collect objective and subjective data with regard to various software products used for acquisition and analysis of earthwork pay quantity verification data for a construction project. (For example, software products related to roadway design, volume calculation, designing etc.)

Your input will assist in the development of a detailed report and research summary that will compile the research findings. The final report will address current state of practice of various DOTs in the US, efficiency, productivity, cost, man-hour requirements of different methods as well as difficulties in using these techniques. The research will also recommend tools and methods that are best suitable for acquisition and analysis of earthwork pay quantity verification data and the required training needs. Please take a few minutes to complete the survey. Where numerical data is requested, reasonable estimates and/or ranges are acceptable. Please return the survey by e-mail or regular mail at the address provided on the last page.

\section{General Information}

Organization:

Respondent's name:

Position/Title:

Address:

Tel: Fax: E-mail: 


\section{JTRP PROJECT: SPR-3082}

\section{Please answer the following questions:}

1. Different software products manufactured by your company that can be used in earthwork data collection and earthwork quantity calculation.

2. Number of years since product is introduced in the market

3. Version of each software product mentioned above.

4. The cost of licensing for the above mentioned software products. (Please specify unit)

5. System requirements for the above mentioned software products.

6. The upgrade/maintenance requirements for these software products 


\section{JTRP PROJECT: SPR-3082}

7. The upgrade/maintenance cost for these software products

8. Training requirements for these software products

9. The approximate training duration for these software products

10. The training cost for these software products (approximately)

11. The accuracy of these software products for earthwork quantity (volume) calculation with respect to methodology (e.g. average end area method, cross section method etc.) used for that. (Please provide the method and the associated accuracy)

12. Special features of these software products (if any) with respect to earthwork data collection and quantity calculation process 


\section{JTRP PROJECT: SPR-3082}

13. Domestic and international market sales for past five years (with respect to number of units sold or \$ volume)

14. Do you suggest any compatible equipment with this software?

15. What would be your recommended software product under different circumstances of acquisition and analysis of earthwork pay quantity verification data? Why?

16. Would you please send us the brochure for all of the above mentioned software products by email or by post to the address given below?

\section{Thank you for your input}

Please return the finished questionnaire by July 22, 2007 to:

\begin{tabular}{|c|c|}
\hline E-mail & shahss@purdue.edu, hastak@ecn.purdue.edu \\
\hline & Dr. Makarand (Mark) Hastak, \\
& Professor of Civil Engineering \\
Address & (Head, Div. of Constr. Engr. \& Mgmt. Purdue University) \\
& School of Civil Engineering, \\
& 550 Stadium Mall Drive, West Lafayette, \\
& Indiana, 47907-2051 \\
& Phone: 765-494-0641 \\
Fax: (765) 494-0644
\end{tabular}


Appendix 6: Questions for Case Study Participants 


\section{$\underline{\text { Sample List of Questions for Case Study Participants }}$}

1. General Description
a. Project Name
b. Size of the project
c. Cost
d. Contractors involved
e. Duration
f. Location
g. Start and Completion date
h. Volume of earthwork quantity in project
i. Consultants for quantity calculation (if any)
j. Any subcontractors for earthwork data collection and quantity calculation
k. Type of contract for earthwork (lump sum, unit price etc.)

2. General procedure of earthwork process for owner/contractor (how they start the work- any exact steps that they follow)

3. Pre-Earthwork Procedure
a. What method and tools used for earthwork data collection
b. How many surveyors and support staff were working to get the data?
c. In house capabilities or outsourced? Do you do any checks on the outsourced work?
d. What company's equipment used?
e. Cost of personnel, Time required taking the data.
f. Accuracy of the equipment (horizontal \& Vertical)
g. Life of the equipment
h. Equipment on rent or they have bought it?

4. Post Construction
a. Same technology used as used in pre-earthwork procedure?
b. Any difference between pre and post construction procedure?
c. Same number of personnel used as used in pre-earthwork procedure?
d. Is level of detail same? 
e. With same accuracy?

5. Do you give training to your surveyors regularly?

6. Does vendor give training to you when you buy any equipment?

7. Cost, duration and importance of training.

8. What are the benefits of that technology?

9. Limitations of used technology?

10. How do you decide that we are going to use this technology in this project?

11. Which software do you use to calculate the earthwork quantities?

12. Accuracy of that software, Company?

13. Advantages and limitation of current software product?

14. How many engineers required to process the data and get the quantity

15. Other than this project, which other technology is used by your company?

16. How important is to know the topography and environment conditions to select any technology?

17. Any other software used by their company? 
LFET INTENTIONALLY BLANK 